\title{
Role of cellular prion protein
}

\section{in synucleinopathies}

\author{
Dissertation \\ for the award of the degree \\ "Doctor rerum naturalium" \\ at the Georg-August-Universität Göttingen
}

within the doctoral programme "Molecular Medicine"
of the Georg-August University School of Science (GAUSS)

Submitted by

Tobias Thom

from Berlin, Germany

Göttingen, 2020 


\section{Thesis advisory committee}

\section{Prof. Dr. Inga Zerr}

University Medical School Göttingen,

Dept. Neurology

Prof. Dr. Andre Fischer

University Medical Center Göttingen,

German Center for Neurodegenerative Diseases (DZNE)

Prof. Dr. Wolfgang Brück

University Medical School Göttingen,

Dept. of Neuropathology

\section{Members of the examination board:}

\section{Prof. Dr. Alexander Flügel}

University Medical Center Göttingen,

Institute for Neuroimmunology and Multiple Sclerosis Research

Prof. Dr. E. A. Wimmer

Georg-August-University Göttingen,

Dept. of Developmental Biology

Prof. Dr. Jürgen Wienands

University Medical Center Göttingen,

Institute for Cellular and Molecular Immunology 


\section{Table of content}

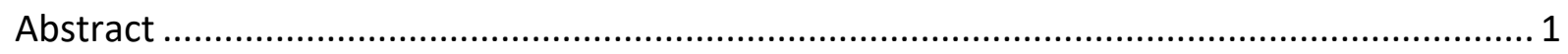

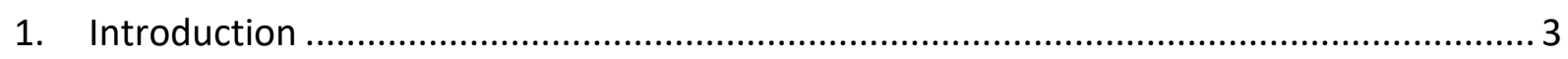

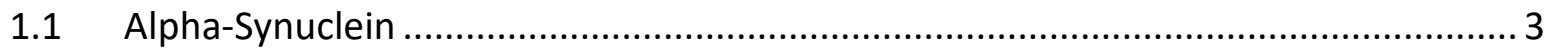

1.1.1 Pathogenic alpha-synuclein in synucleinopathies ......................................... 3

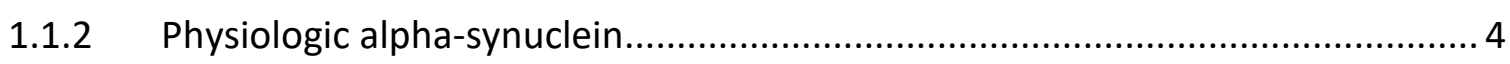

1.2 Role of $\mathrm{PrPC}^{\mathrm{C}}$ in neurodegenerative diseases ....................................................... 7

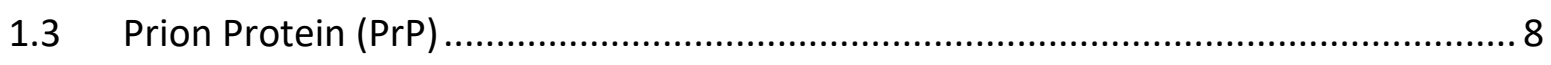

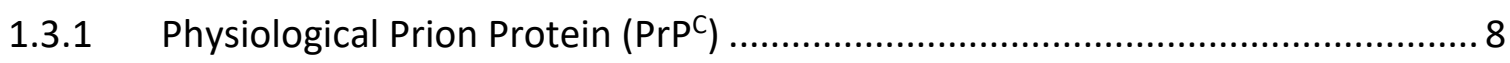

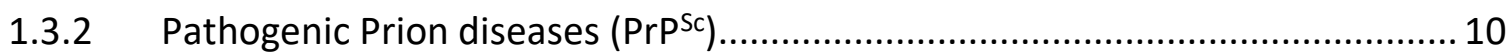

1.4 Misfolding of proteins based on the prion hypothesis ......................................... 10

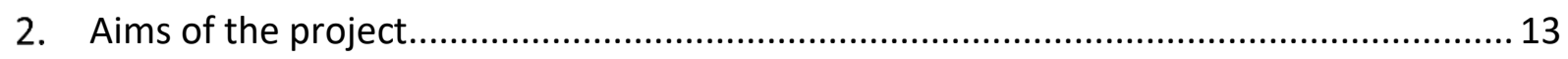

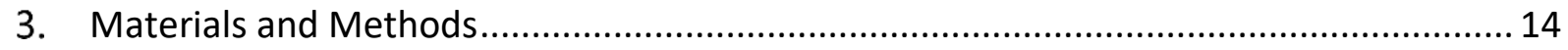

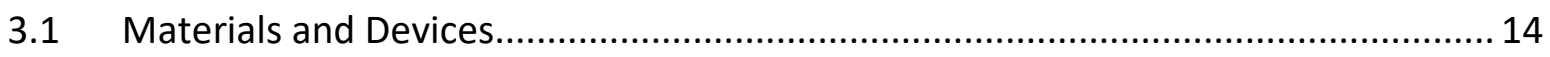

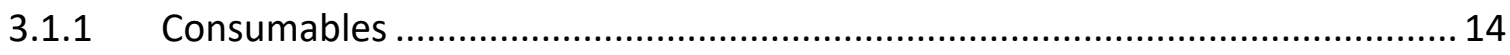

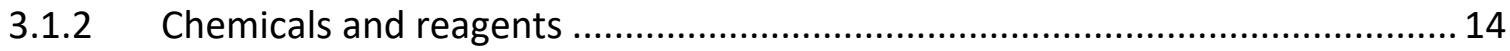

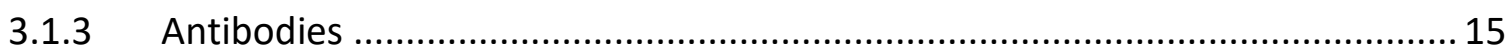

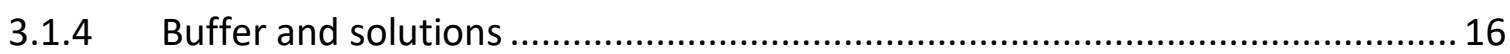

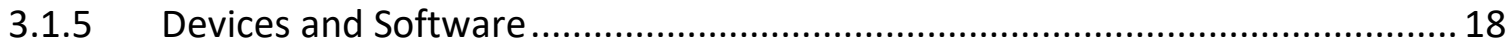

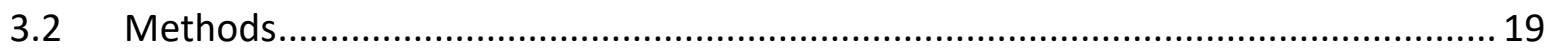

3.2.1 SDS-polyacrylamide gel electrophoresis (SDS PAGE) ................................... 19

3.2.2 Electro transfer of proteins (Western Blot) …............................................... 19

3.2.3 Immunological detection of protein on the membrane ................................. 19

3.2.4 ELISA measurement of total and oligomeric alpha-synuclein .......................... 20

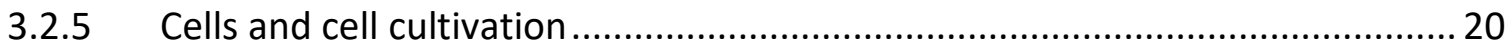

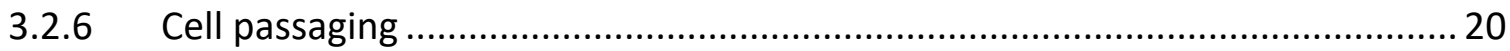

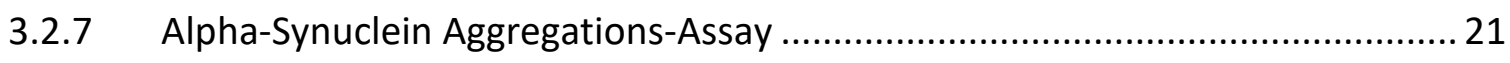

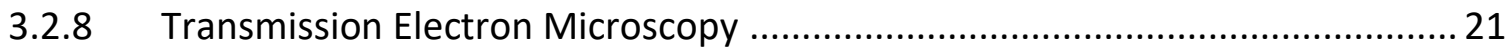

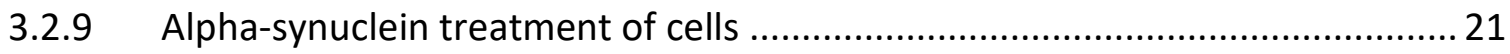

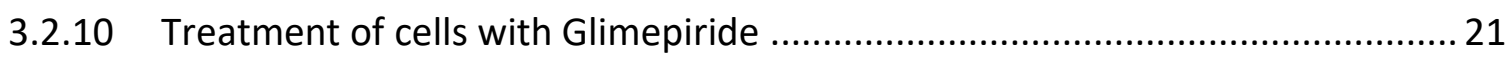

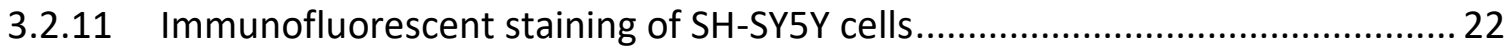




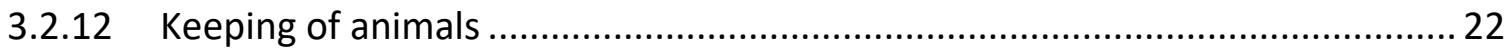

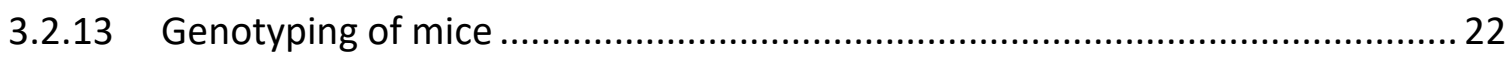

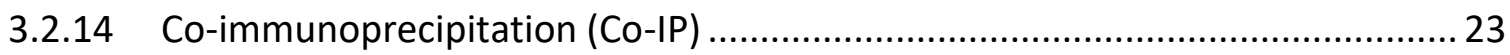

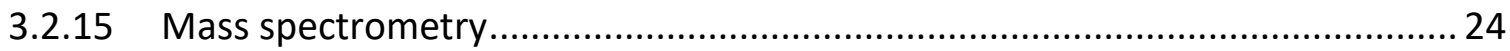

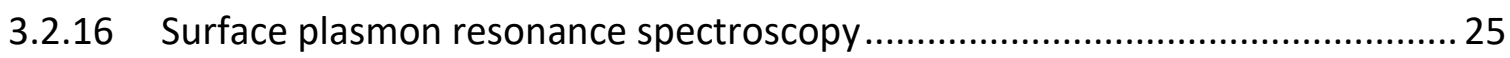

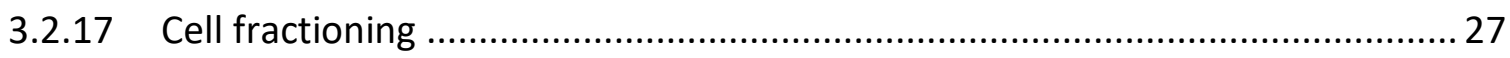

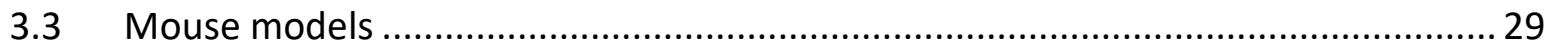

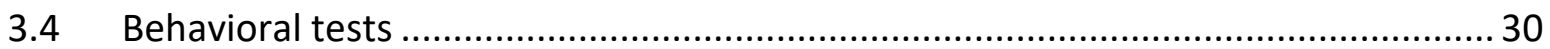

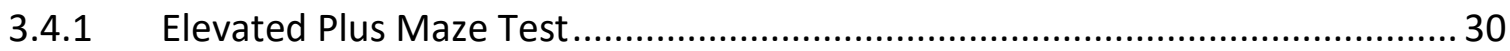

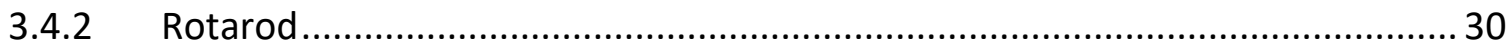

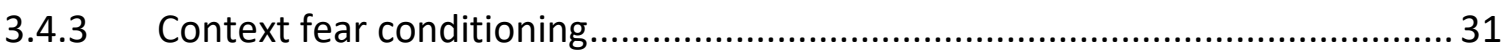

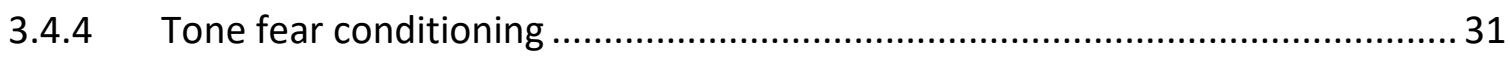

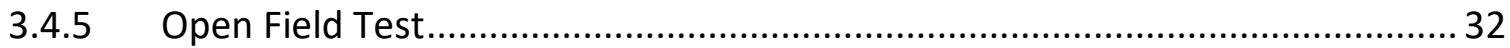

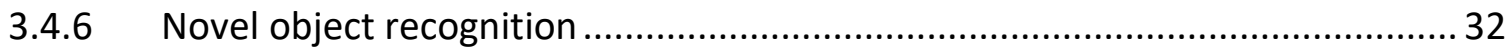

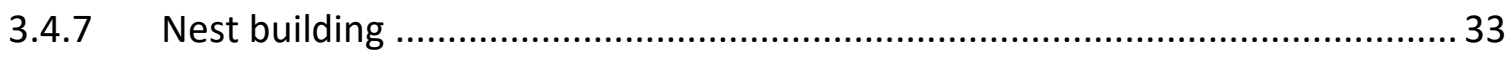

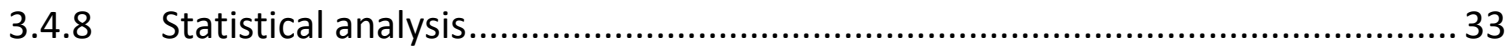

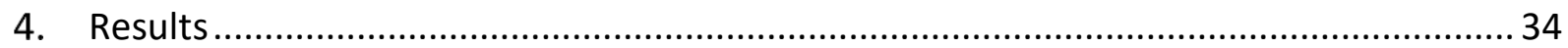

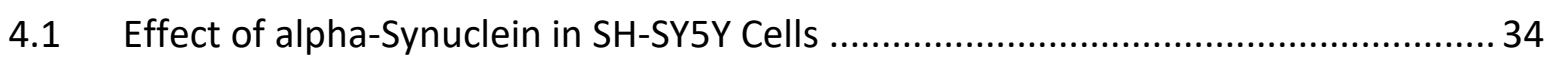

4.1.1 Quantification of PrPC expression in SH-SY5Y and SH-SY5Y-PrP cells ................. 34

4.1.2 Characterization of monomeric and oligomeric alpha-synuclein ...................... 34

4.1.3 Treatment of SH-SY5Y cells with recombinant alpha-synuclein ....................... 35

4.1.4 Phosphorylation of alpha-synuclein after uptake in SH-SY5Y cell lines............. 36

4.1.5 Removal of membrane-bound PrPC by glimepiride ....................................... 37

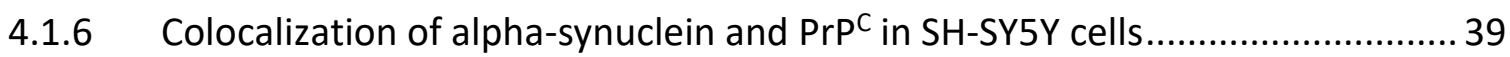

4.1.7 Localization of $\mathrm{PrP}^{\mathrm{C}}$ and alpha-synuclein in common cell compartments after subcellular fractioning

4.2 Direct interaction of alpha-Synuclein and $\operatorname{Pr} \mathrm{P}^{\mathrm{C}}$

4.1 In vivo studies of $\mathrm{PrP}^{\mathrm{C}}$-mediated toxicity indicated by altered biochemical properties and behavioral deficits

4.1.1 Comparison of the expression level of alpha-synuclein in Tgm83 mice in dependence from $\operatorname{PrPC}$

4.1.2 Analysis of total and oligomeric aSyn in Tgm83 and TgmPrP00 brains via ELISA.. 
4.1.3 Analysis of phosphorylated alpha-synuclein levels in connection with $\operatorname{PrPC}$ expression

4.1.4 Analysis of alpha-synuclein characteristics in ThySyn and ThySynPrP00 mice.. 49

4.1.5 ELISA of total and oligomeric alpha-Synuclein in ThySyn and ThySynPrP00 ..... 50

4.2 Subcellular fractioning of aSyn and PrPC in ThySyn and ThySynPrP00.................... 51

4.3 Co-immunoprecipitation of $\mathrm{PrP}^{\mathrm{C}}$ and alpha-synuclein in ThySyn mice .....................53

4.3.1.1 Characterization of common interaction partners of $\operatorname{PrP}^{C}$ and aSyn by mass spectrometric analysis of Co-IP lysates

4.4 Behavioral study: PrP knock-out partially recovers pathological aSyn mediated behavior deficits 56

4.5 Differences in the behavior of Tgm83 and TgmPrP00 mice lines .57

4.5.1 Alteration in nest-building behavior 57

4.5.2 Alteration on mobility and fear behavior in Open-Field test........................... 58

4.5.3 $\quad \operatorname{PrP}^{\mathrm{C}}$ dependent alteration in anxiety behavior 59

4.6 Changed behavior in ThySyn and ThySynPrP00 mice..............................................60

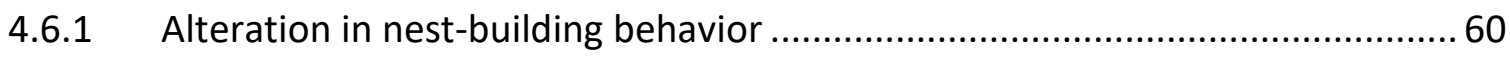

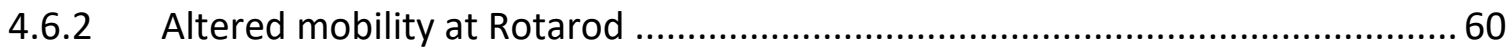

4.6.3 Alteration on mobility and fear behavior in Open-Field-Test...........................6 61

4.6.4 Analysis of the cognitive performance of mice applying the Novel-ObjectRecognition test.....

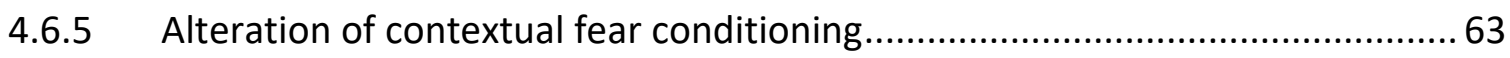

4.6.6 Alteration of tone depending fear conditioning ............................................. 63

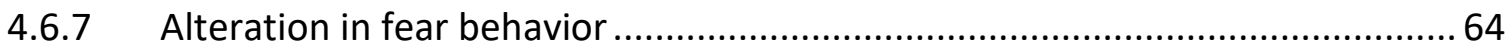

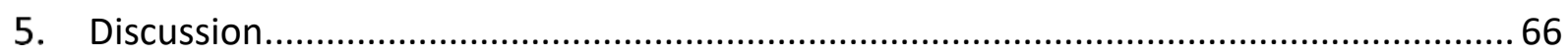

5.1 Uptake and localization of alpha-synuclein in cells..........................................66

5.2 Influence of $\mathrm{PrP}^{\mathrm{C}}$ on alpha-synuclein expression and isoform composition .............67

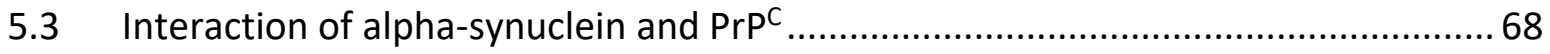

5.4 Knockout of $\operatorname{PrP}^{\mathrm{C}}$ may rescue the pathological aSyn-induced phenotype in transgenic mice

5.5 Involvement of clathrin-coated-vesicles in alpha-synuclein internalization via $\operatorname{PrPC} 72$

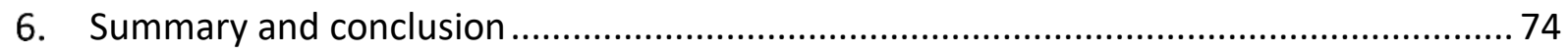

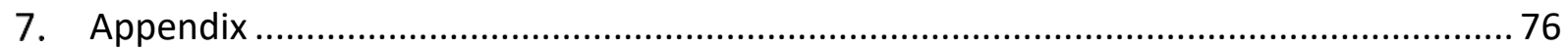

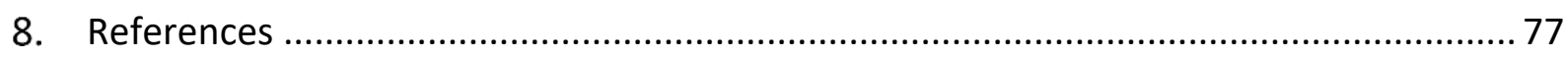




\section{List of Abbreviations}

$A D$

Alzheimer's Disease

ALS

Amyotrophic lateral sclerosis

aSyn

alpha-Synuclein

$A \beta$

Amyloid $\beta$

$\mathrm{FFI}$

Fatal Familial Insomnia

GL

Glimepiride

GSS

Gerstmann-Sträussler-Scheinker-syndrome

$\mathrm{kDa}$

Kilodalton

LB

Lewy body

LBD

Lewy body dementia

mGluR5

Metaprotrope Glutamate receptor 5

MSA

Multiple system atrophy

NAC

Non-amyloid- $\beta$ component

PAGE

Polyacrylamide gel electrophoresis

PCR

Polymerase chain reaction

PD

Parkinson's disease

$\operatorname{PrPC}$

Cellular prion protein

PrPSc

Scrapie prion protein

PTM

Posttranslational modification

PVDF

Polyvinylidene fluoride

sCJD

Sporadic Creutzfeldt-Jakob-disease

SDS

Dodium dodecyl sulfate

$\mathrm{SH}$

SH-SY5Y

SH-PrP

SH-SY5Y with PrPC overexpression

SPR

Surface plasmon resonance

TEM

Transmission Electron Microscope

TEMED Tetramethyl ethylenediamine

Tris

Tris-hydroxymethyl-aminomethane

WB

Western Blot

WT

Wildtype 


\section{List of figures}

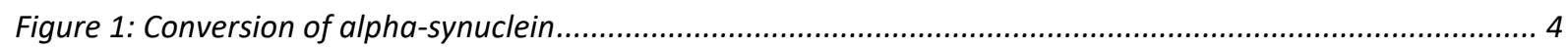

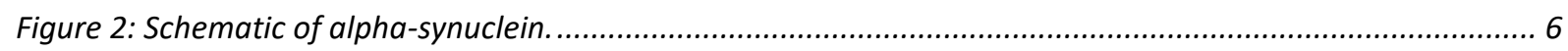

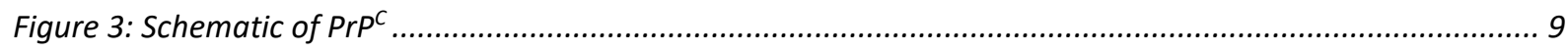

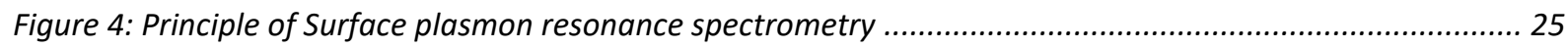

Figure 5: Schematic curve progression of an protein interaction ................................................................ 26

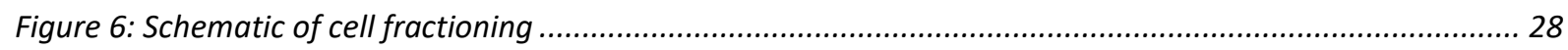

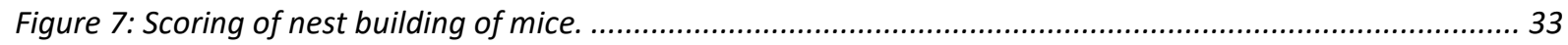

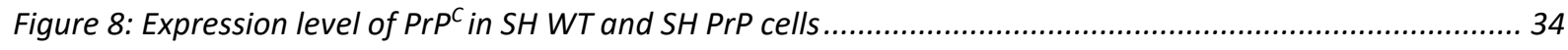

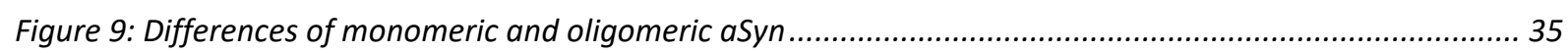

Figure 10: Comparison of monomeric and oligomeric aSyn treatment in SH WT and SH PrP cells.......................36

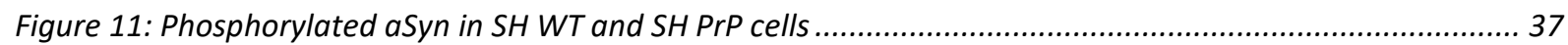

Figure 12: Reduction of GPI anchored PrPC in SH PrP cells after glimepiride treatment .................................. 38

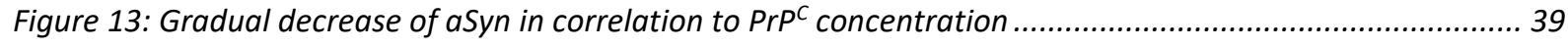

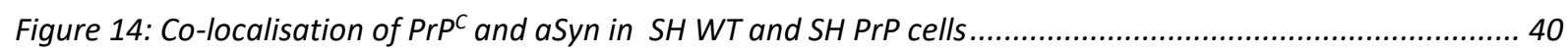

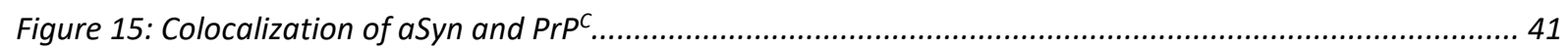

Figure 16: Analysis of cellular localization of $\operatorname{PrP}^{C}$ and aSyn via cell fractionation .........................................42

Figure 17: SPR Sensorgram of chimeric hamster-sheep $\operatorname{Pr} P^{C}$ and monomeric/oligomeric aSyn ........................ 43

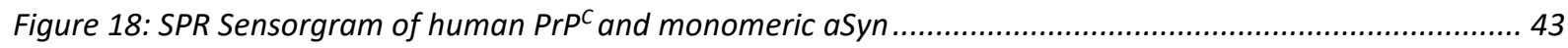

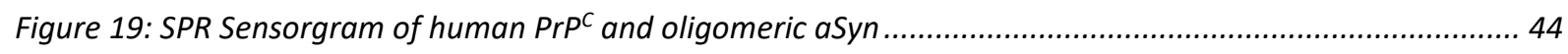

Figure 20: Expression of aSyn in Tgm83 and TgmPrPOO at different ages ....................................................46

Figure 21: Measurement of total aSyn levels in Tgm83 and TgmPrP00 mice ................................................47

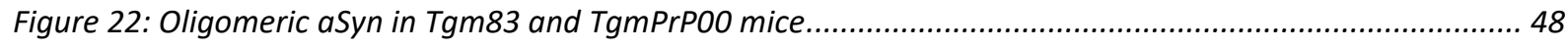

Figure 23: Phosphorylation level of S129 of aSyn in Tgm83 and TgmPrP00 mice..........................................49

Figure 24: Comparison of total aSyn and varying phosphorylation sites (s87, s125 and s129) of aSyn in ThySyn and

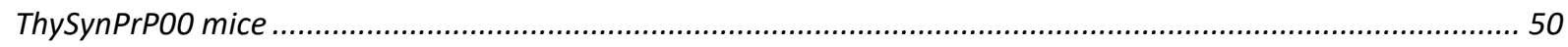

Figure 25: ELISA of total and oligomeric aSyn of ThySyn and ThySynPrPOO mice ........................................ 51

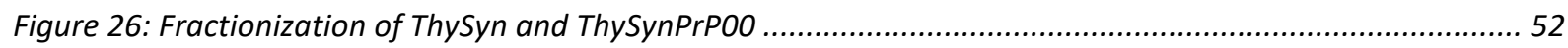

Figure 27: Quantification of aSyn in membrane and cytosol expression of aSyn inThySyn and ThySynPrP00 mice

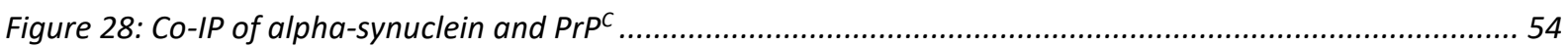

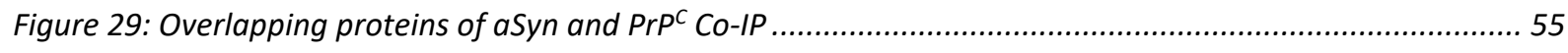

Figure 30: Molecular functions of the identified proteins ........................................................................5 55

Figure 31: Detection of clathrin in ThySyn and ThySynPrPOO mice ............................................................... 56

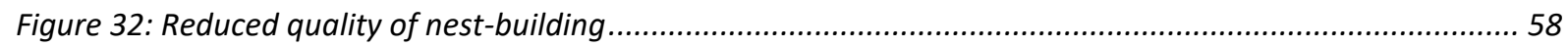

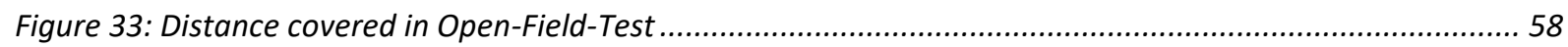

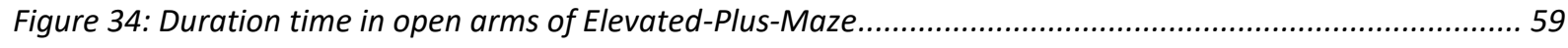

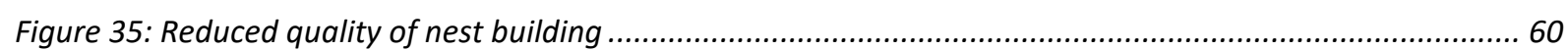




\section{Tables}

Figure 36: Comparison of motoric performance in the Rotarod test ........................................................... 61

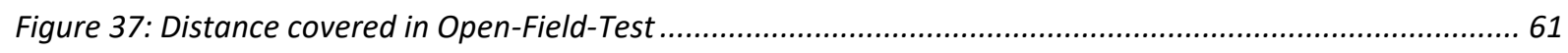

Figure 38: Crossings and duration in the inner zone measured in Open-Field test .........................................62

Figure 39 Comparison of cognitive performance via Novel-Object-Recognition test.........................................62

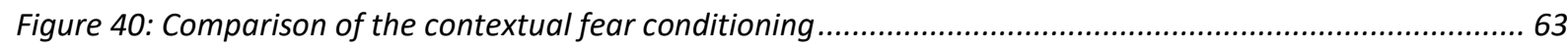

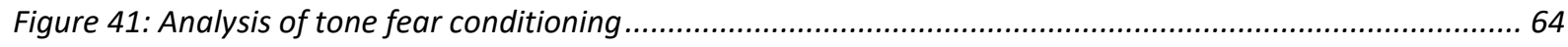

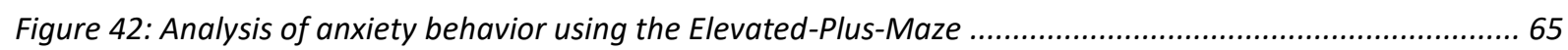

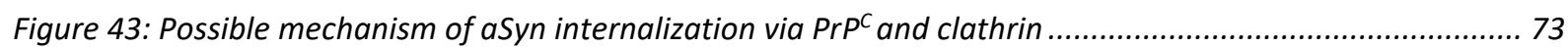




\section{List of tables}

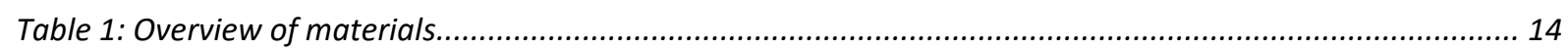

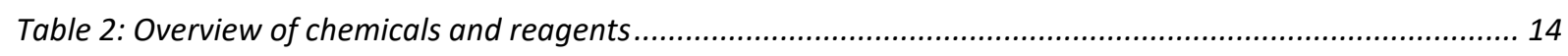

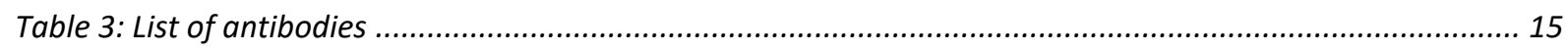

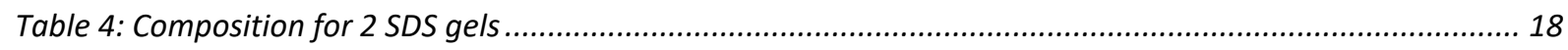

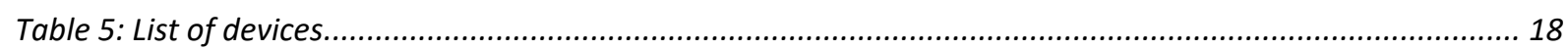

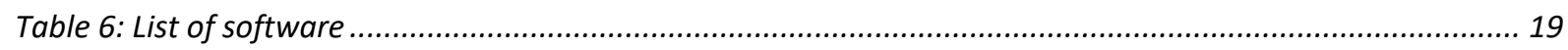

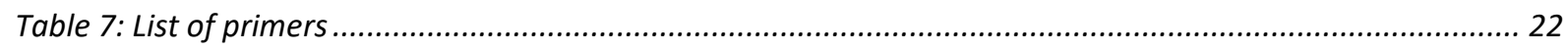

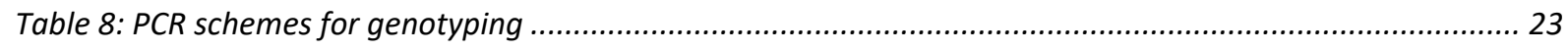

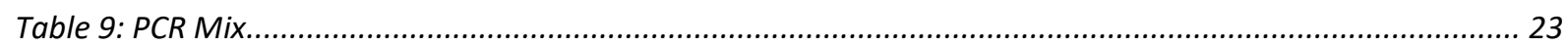

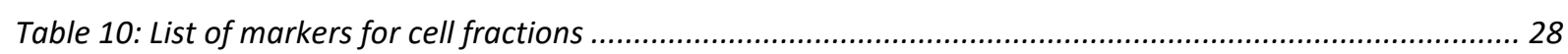

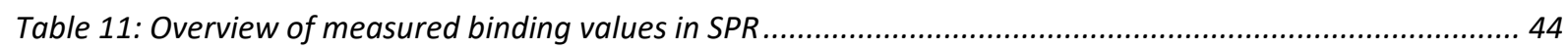

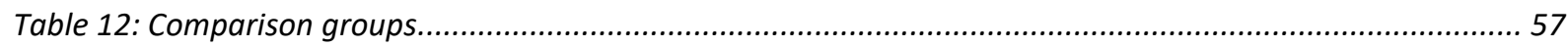

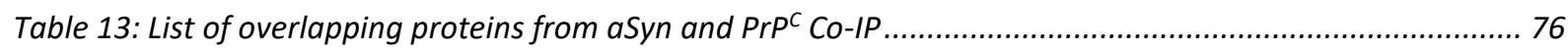




\section{Abstract}

Synucleinopathies comprise a group of neurodegenerative diseases, characterized by deposits of aggregated alpha-synuclein (aSyn) in neurons and glia. The special hallmark is the presence of Lewy bodies and Lewy neuritis, in which Parkinson's disease is the most prevalent representative of this disease group. It is assumed, that misfolded oligomeric aSyn converts natively-folded monomeric in a templated-induced conversion process (prion-like way) into toxic oligomers, which can advance to the formation of pathologic fibrils. The cause of the misfolding is still unknown, such as the mechanism for the cell-to-cell spreading of pathologic aSyn is not yet completely understood.

In this work, we analyzed the effect of cellular prion protein $\left(\mathrm{PrP}^{\mathrm{C}}\right)$ on the internalization of aSyn. Secondary cells (SH-SY5Y) were treated with monomeric and oligomeric aSyn. The comparison of SH-SY5Y WT cells and stable PRNP transfected SH-SY5Y PrP cells, with an approximately 5-fold overexpression of $\mathrm{PrP}^{\mathrm{C}}$ showed a significantly higher amount of internalized oligomeric aSyn compared to SH-SY5Y WT cells. Fractionization of the cells into distinct compartments revealed a colocalization of both proteins in the cytosol.

Moreover, we explored the potential binding of aSyn and $\mathrm{PrP}^{\mathrm{C}}$ by surface plasmon resonance spectroscopy. Here, a stable direct binding affinity of $\operatorname{PrP}^{\mathrm{C}}$ could be measured for monomeric and oligomeric aSyn.

In vivo studies were conducted with transgenic mice (Tgm83 and ThySyn), exhibiting an aSyn pathology. Crossbreeding the aSyn mouse models with a PrP-KO line (Zurich I) resulted in new double transgenic mouse lines (TgmPrPOO and ThySynPrP00). We observed that PrPC depletion in these mice did not change the expression of transgenic aSyn nor the phosphorylation of the crucial Serine 129. Though, the analysis of the cell compartments of brain lysates revealed a different distribution of aSyn in the subcellular fractions. Mice lacking $\mathrm{PrP}^{\mathrm{C}}$ had an increased level of aSyn in the cytosol compared to aSyn transgenic mice with intact PrPC WT. In addition to the biochemical analysis, the behavior of these mouse lines was tested, resulting in the rescue of certain deficits induced by the pathological aSyn phenotype in $\operatorname{PrPC}$ deficient mice. To identify further proteins involved in aSyn internalization, brain lysates were used to analyze $\mathrm{PrP}^{\mathrm{C}}$ and aSyn via co-immunoprecipitation (Co-IP). Precipitation of aSyn was successfully tested for $\mathrm{PrP}^{\mathrm{C}}$ and vice versa has the precipitation of cellular prion resulted in the presence of aSyn. Furthermore, these Co-IPs were analyzed via mass spectrometry to identify 
additional involved proteins, possibly influencing the interaction of $\operatorname{PrP}^{\mathrm{C}}$ and aSyn. There, clathrin was successfully detected in both Co-IPs as a possible additional protein.

Altogether, our results implicate the involvement of $\operatorname{PrP}^{\mathrm{C}}$ as a receptor for aSyn, promoting the internalization and potentially the spreading of misfolded aSyn in a prion-like mechanism that may contribute to a better understanding of the pathological mechanism in synucleinopathies which is important for future therapies or diagnostics. 


\section{Introduction}

\subsection{Alpha-Synuclein}

\subsubsection{Pathogenic alpha-synuclein in synucleinopathies}

The group of synucleinopathies includes several neurodegenerative diseases with its most prevalent representative Parkinson's disease (PD). It is characterized by the deposits of aSyn in the substantia nigra (SN) and the resulting death of dopaminergic neurons (Bridi and Hirth 2018). The reduction of striatal dopamine causes particular motoric symptoms. This includes bradykinesia, tremor, postural abnormalities and rigor, which are characteristic for PD. The majority of the PD patients are classified as spontaneous, meaning that the cause of the disease is unknown. Additionally, familiar PD cases linked to genetic mutations are also known. Genes that are involved in the pathogenesis of PD are summarized as PARK genes. Several PARK genes were already discovered and numbered chronologically to their finding (Chandra et al. 2004; Sriram et al. 2005). Next to some of the well-established genes like LRRK2 and DJ1, SNCA is the most important representative (Chung et al. 2011). Accumulated aSyn is the main component of Lewy-bodies and according to genome-wide association studies, it could be shown that aSyn has a central part in familiar and spontaneous PD (Satake et al. 2009; Simón-Sánchez et al. 2009). Additionally, the duplication and triplication of SNCA can cause the early development of PD. In case of duplication, symptoms can appear at 50 years and in the case of triplication already at 40 years of age (Peelaerts and Baekelandt 2016).

Furthermore, five specific mutations in the $\mathrm{N}$-terminal area of aSyn (A30P, E46K, A53T, H50Q and G51D9) have been linked to familial PD (Kasten and Klein 2013; Roberts and Brown 2015). The A30P and A53T mutation, are also correlated to the early development of PD (Conway et al. 2000). Next to PD other diseases like Parkinson's disease dementia (PDD), dementia with Lewy bodies (DLB) and multiple system atrophy (MSA) belong to the synucleinopathies. MSA differentiates because of its aSyn aggregates in oligodendrocytes instead of the common presence in neurons (Lashuel et al. 2013).

The detailed process of the conversion from physiological aSyn towards pathological aSyn could not be shown until now. Yet, several posttranslational modifications (PTMs) are known to favor the transformation. Moreover, the amount of expressed protein, mutations, $\mathrm{pH}$, temperature and the concentration of metal ions is crucial (Emanuele and Chieregatti 2015). 


\section{$\square_{0} \square \rightarrow \square \rightarrow$ \\ Monomers Oligomers Fibrils Lewy-bodies}

Figure 1: Conversion of alpha-synuclein

In the first phase aSyn exist in its monomeric form. From this state, aSyn is also able to build a native, dimeric and also tetrameric protein. Due to further oligomerization even more complex intermediates can result in the formation of fibrils. These fibrils constitute the major part of Lewy-bodies.

One of the important traits of LBs is the change of aSyn from a structure dominated by $\alpha$ helices to a protein consisting mostly of $\beta$-sheets. The confirmation of the unfolded protein develops into a partially folded oligomeric structure. Thereby the non-amyloid- $\beta$ component (NAC) region becomes exposed and can aggregate via hydrophobic interactions. Monomeric aSyn can bind to an initial aggregate and grow to larger oligomers until protofibrils and fibrils structures are formed (Uversky et al. 2001). Due to the toxic effect of oligomeric aSyn, the following consequences may arise for the cells: Experiments showed a reduction of the presynaptic vesicle pool, mitochondrial dysfunctions, a higher level of reactive oxygen-species, pore-formation in the membrane and the inhibition of the ubiquitin-proteasome system (Emanuele and Chieregatti 2015).

Despite extensive research, it is still unknown which intermediate of aSyn represents the pathological trigger of synucleinopathies. For example, it could be shown that the injection of oligomeric aSyn with different mutations (A53T, E46K, A30P, E57K, E35K) in rats caused an increasing loss of dopaminergic neurons compared to aSyn fibrils (Winner and Jappelli 2011). Other experiments showed that the injection of human aSyn fibrils in the SNc of rats resulted in a massive decline of motoric and synaptic performance and a higher loss of dopaminergic cells compared to oligomeric aSyn (Peelaerts et al. 2015).

\subsubsection{Physiologic alpha-synuclein}

aSyn was originally identified in the Pacific electric ray independently by different groups. The protein was predominantly occurring in synaptic areas and the nucleus, resulting in the name Synuclein (Maroteaux et al. 1988). It is an intrinsic and unstructured protein with a size of 14 kDa (Lashuel et al. 2013). Additionally to aSyn two more isoforms are known, which were classified as beta and gamma synuclein. (Maroteaux et al. 1988; Lavedan 1998). The physiological 
function of aSyn is not completely understood so far, yet some features of aSyn could be described. The presynaptic localization of aSyn and knock-down experiments revealed its regulatory function on the release of neurotransmitters, synaptic functions, and plasticity (Lashuel et al. 2013). This is supported by the subcellular localization in the synapse (Maroteaux et al. 1988; Withers et al. 1997) and the colocalization of aSyn at the synaptic vesicle pool (Lee et al. 2006; Zhang et al. 2008). Studies indicate an influence on the mobilization, modulation, and endocytosis of synaptic vesicles (Bendor et al. 2013; Vargas et al. 2014). An interaction of the C-terminus of aSyn and Synaptobrevin-2 could be shown (Burré et al. 2010), which is a key player for synaptic endocytosis (Schoch et al. 2001).

The N-terminus of aSyn can bind phospholipids and promote the formation of a SNARE-complex (Burré et al. 2010). Although aSyn was initially found in the nucleus, the function and transport mechanism are still not established. It is assumed that aSyn has an impact on transcriptional regulation. GC1alpha is an important mitochondrial transcription factor which can bind to aSyn (Siddiqui et al. 2012). Additionally, an effect on the histone functions on acetylation respectively deacetylation could be shown (Kontopoulos et al. 2006). Up to one-third of aSyn is presumably bound to the membrane (Visanji et al. 2011). With that connection a folding in the $\mathrm{N}$-terminal and central region into two alpha-helices occurs, whereas the C-terminal end remains unstructured (Lorenzen et al. 2014). aSyn binds preferentially to lipids with acidic headgroups and membranes with a strong curvature (Middleton and Rhoades 2010).

The protein can be divided into three major parts. The N-terminal region (Amino acid 1-60) contains the conserved cyclic sequence KTKEGV, which also includes the above-mentioned mutations connected to familial Parkinson's disease. This region remains unstructured in solution, but it can also interact with the membrane while being affected by positively charged groups and form $\alpha$-helices. The center region including the amino acids 61 to 95 is referred to as non-amyloid- $\beta$ component (NAC) and strongly hydrophobic. This part is crucial for the aggregation of aSyn and the formation of $\beta$-sheet structures. The C-terminal rest (Amino acid 96-140) is enriched with negative charges and proline remains, giving the polypeptide high flexibility. The $\mathrm{N}$-terminal and central domain are essential for binding the membrane while the C-terminus is important for binding other proteins and smaller molecules (Breydo et al. 2012; Silva et al. 2013). 


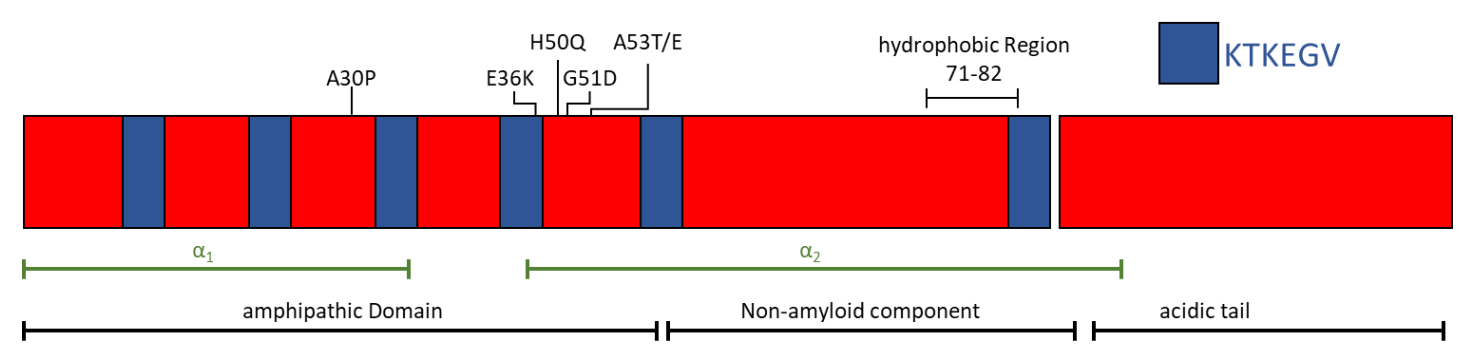

Figure 2: Schematic of alpha-synuclein.

Alpha-Synuclein is a protein consisting of 3 domains and 140 amino acids. The N-terminal amphipathic domain, a non-amyloid-beta compound including the hydrophobic region and the C-terminal acidic tail. The consensus sequence KTKEGV appears repeatedly. Together with the $\alpha$-Helices, they are important for the interaction with lipids. The PD associated mutations (A30P, E46K, H50Q, G51D, A53T, A53E) in the amphipathic region are shown (Pozo Devoto and Falzone 2017).

Different studies have shown that in vitro isolated aSyn occurs as an unstructured, soluble and monomeric protein (Uversky 2003). However, it was also possible to isolate native tetrameric aSyn with a high amount of $\alpha$-helices from human cells with a non-denaturing purification (Bartels et al. 2011). Since the results of isolated native aSyn are controversial, further investigations were performed. For that purpose, different procedures of purification for different biological sources were used. It was shown that aSyn mainly exists as an unstructured protein in the central nervous system (CNS) (Fauvet et al. 2012). Until now it is not completely clarified whether aSyn natively folds into a tetrameric protein and to what extent this is depending on the binding to the plasma membrane. Furthermore, aSyn is changed by several posttranslational modifications (PTMs), which are affecting the physiological and pathological function. The best examined PTM is the phosphorylation at Serine 129. It is of high interest because of its close correlation to aSyn deposits in different synucleinopathies (Fujiwara et al. 2002). In addition to phosphorylated Serine 129 , phosphorylation of Serine 87 is known to potentially facilitate the oligomerization of aSyn (Waxman and Giasson 2008; Paleologou et al. 2010). Furthermore, Tyrosine 125 is probably a protective phosphorylation site preventing the process of oligomerization of the protein (Chen et al. 2009). Nitrosylation of Tyrosine 125 is also possible and could be found in aSyn deposits (Giasson et al. 2000; Yamin et al. 2003). Ubiquitination is important for the degradation of aberrant and excessive aSyn. Lewy-bodies have shown a high amount of ubiquitinated aSyn leading to an overload of the proteolytic protein degradation in the cell. The insufficient proteolysis facilitates consecutive aggregation of pathological aSyn (Tofaris et al. 2003). 


\subsection{Role of $\operatorname{PrPC}^{\mathrm{C}}$ in neurodegenerative diseases}

An important aspect of the research of neurodegenerative diseases is the transmission of pathogenic aggregates to adjacent cells as a typical feature. There are different possibilities discussed for this molecular mechanism. That includes extracellular vesicles, exosomes, tunneling nanotubes and the involvement of cell surface receptors (del Río et al. 2018). A well examined binding partner of $\operatorname{PrP}^{C}$ is $\beta$-Amyloid $(A \beta)$. Here, an interaction with the oligomeric, toxic form of $A \beta$ and the prion protein could be shown (Laurén et al. 2009; Freir et al. 2011; Zou et al. 2011; Fluharty et al. 2013; Ganzinger et al. 2014). This discovery is essential for identifying mechanisms in the early pathogenesis. Studies have revealed that the regions from 23 to 27 and 94 to 110 amino acid (CC2 Region) are relevant for the interaction with A $\beta$. On top of this it was possible to inhibit the interaction by masking the binding site for $A \beta$ using an antibody against PrPC (Freir et al. 2011) or stress-inducible phosphoprotein 1 (Ostapchenko et al. 2013). Thus, the toxicity of $A \beta$ aggregates could be partially diminished. Furthermore, the metabotropic glutamate receptors 5 (mGluR 5 ) is involved in the pathogenesis by activating $\operatorname{PrP}^{\mathrm{C}}$ which then activates FYN kinase. This results in the hyperphosphorylation of Tau which can affect the development of Alzheimer's disease. (Um et al. 2013; Salazar and Strittmatter 2017b). Comparing these traits to synucleinopathies parallels can be observed to the pathogenies of Alzheimer's disease. A higher prevalence of $ß$ sheet structures is an important attribute of the toxicity of $A \beta$ (Jin et al. 2016). In addition, the above mentioned CC2 domain of $\operatorname{PrPC}^{\mathrm{C}}$ was identified as a potential binding site for aSyn (Aulić et al. 2017; Ferreira et al. 2017; Urrea et al. 2017). Tests with transgenic mice with different amounts of $\operatorname{PrP}^{\mathrm{C}}$ expressions $\left(\mathrm{PrP}^{0 / 0}, \mathrm{PrP}^{+/+}\right.$and Tga20 with $\mathrm{PrP}^{\mathrm{C}}$ overexpression) were performed in which the animals received an injection with recombinant fibrillar aSyn into a specific brain region. The result was an increased phosphorylation of $129 \mathrm{~S}$ and respectively $81 \mathrm{~A}$ aSyn in mice with a higher expression of $\mathrm{PrP}^{\mathrm{C}}$. Besides, a higher number of Lewy-bodies and Lewy-neurites could be shown in transgenic mice with increased PrPC expression (Urrea et al. 2017). HEK293 cells were transfected with a PrPC plasmid to obtain a higher amount of Prion protein in the cells and subsequently treated with aSyn protofibrils. Western blot analysis resulted in a higher yield of aSyn in HEK293 cells with a higher expression of $\operatorname{PrP}^{\mathrm{C}}$. In addition, immunocytochemical stainings showed the colocalization of the proteins (Urrea et al. 2017). A similar observation of $\operatorname{PrPC}^{\mathrm{C}}$ and Fyn kinases affecting $A \beta$ could also be made concerning aSyn. $\operatorname{PrP}^{C}$ and Fyn are present in lipid rafts and necessary for the initiation of a signal cascade leading to the hyperphosphorylation 
of the NMDA receptor. Comparable to that process an association of aSyn and the $\operatorname{PrP}^{\mathrm{C}-\mathrm{Fyn}}$ NMDA protein complex could be found. Again the mGluR 5 was involved as a connector protein for the Fyn kinases (Ferreira et al. 2017).

\subsection{Prion Protein (PrP)}

\subsubsection{Physiological Prion Protein (PrPC)}

$\mathrm{PrPC}^{\mathrm{C}}$ is a strongly conserved protein and therefore an essential biological role is assumed for the protein. However, the whole spectrum of its biological function is not completely solved until now (Rivera-Milla et al. 2005). It is bound via a glycosylphosphatidylinositol anchor to the cell membrane and is probably involved in transmembrane signal cascades (Tsui-Pierchala et al. 2002; Taylor and Hooper 2006a). This surface protein is especially present in cholesterolrich lipid rafts on the plasma membrane. $\operatorname{PrPC}^{\mathrm{C}}$ is synthesized in the endoplasmic reticulum (ER) and is subsequently post-translationally modified in the ER and the Golgi apparatus. This includes the formation of the disulfide bridge at the amino acids Cys179 and Cys214 (Pan et al. 1992), the formation of the GPI anchor at the C-terminal ending (Stahl et al. 1992) and the glycosylation of Asn 181 and Asn 197 (Haraguchi et al. 1989). Since oligosaccharides can bind to $\operatorname{PrPC}$, it can be differentiated into a non-glycosylated (27 kDa), mono-glycosylated (33 kDa) and di-glycosylated isoform. $\operatorname{PrP}^{\mathrm{C}}$ can be internalized into the cell by Clathrin-dependent endocytosis into the cell (Shyng et al. 1995) but also a Clathrin-independent pathway (Kang et al. 2009). The sequence of $\operatorname{PrPC}^{C}$ can be divided into two structurally defined areas. A long flexible N-terminal ending (around 100 amino acids) which is present in most species and consist of four or five repetitions of eight amino acids (PHGGGWGQ). The second C-terminal part forms three $\alpha$-helices and one $\beta$ sheet structure (Riek et al. 1996; Surewicz and Apostol 2011). 


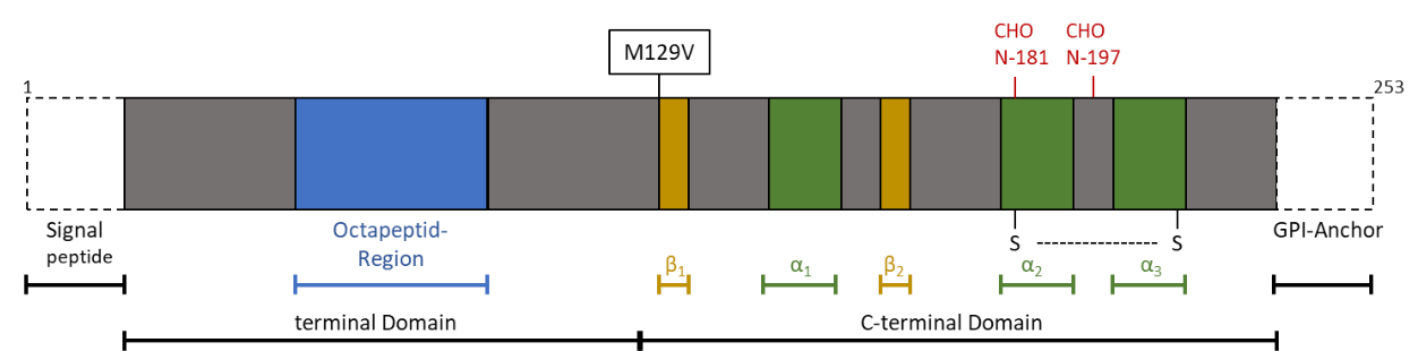

Figure 3: Schematic of $\operatorname{PrP}^{\mathrm{C}}$

The non-processed $\mathrm{PrP}^{\mathrm{C}}$ consists of 253 amino acids. The $\mathrm{N}$-terminal ending contains the signal peptide and a functional octapeptide region. This region is an unstructured and flexible domain. In comparison, the $\mathrm{C}$-terminal domain is stable and structured and contains the GPI anchor. It also includes anti-parallel $\beta$ sheets $\left(\beta_{1}\right.$ and $\left.\beta_{2}\right)$ and three $\alpha$-helices $\left(\alpha_{1}, \alpha_{2}\right.$ and $\alpha_{3}$ ). Additionally, the intramolecular disulfide bridge (S-S) and two glycosylation sites are displayed (N-181 and N-197) (Acevedo-Morantes and Wille 2014).

PrPC is encoded by the PRNP gene which is located on the short arm of chromosome 20 in humans (Puckett et al. 1991). Compared to other mammals the high sequence homology of $90 \%$ shows that $\operatorname{PrP}^{C}$ is a strongly conserved protein (Schätzl et al. 1995; Harrison et al. 2010). The classification of codon 129 is important due to its Methionine/Valin polymorphism. Humans can be classified as homozygote for Methionine (MM) or Valin (VV) or as heterozygote in case both alleles are present. This polymorphism itself is not pathogenic but it influences the pathogenesis and accessibility for sporadic Creutzfeldt-Jacob-disease. Although not all physiological functions of cellular PrP are known yet, several functional aspects could be shown. For a better understanding, transgenic $\operatorname{PrP}^{\mathrm{C}}$ knockout mice were generated. These mice did not show a particular deviation of the normal phenotype, but further studies revealed a neurological change compared to wildtype mice. Differences in the nerve strands could be found (Colling et al. 1997), changes in the circadian rhythm (Tobler et al. 1996) and diminished spatial memory performance of mice was observed (Criado et al. 2005). Furthermore, cells of $\operatorname{PrP}^{C}$ deficient mice showed a higher sensitivity towards oxidative stress, leading to the assumption that the protein has a neuroprotective role (Brown et al. 2002). Stress can be induced by hypoxia and ischemia and is distinctly stronger in $\mathrm{PrP}^{0 / 0}$ mice than in wildtype mice (McLennan et al. 2004; Spudich et al. 2005). One well-studied feature of $\operatorname{PrP}^{\mathrm{C}}$ is the binding of copper ions. The $\mathrm{N}$-terminal octapeptide is essential for the binding of up to four $\mathrm{Cu}^{2+}$ ions depending on the $\mathrm{pH}$ (Walter et al. 2006). It also determines the flexibility of the N-terminus according to the copper loading (Leclerc et al. 2006). Copper is an important co-factor for several different enzymes and it is responsible for the catalyzation of redox reactions (Westergard et al. 2007). Impairing the uptake and transport of reactive copper ions (Puig and Thiele 2002) can benefit the development of neurodegenerative diseases (Waggoner et al. 
1999). Due to the localization on the cell surface, $\operatorname{PrP}^{C}$ is assumingly involved in transmembrane signaling. One example is the interaction of $\operatorname{PrP}^{C}$ with the neural cell-adhesion-molecule (N-CAM) (Schmitt-Ulms et al. 2001). This causes increased growth of neurites recruiting $\mathrm{N}$ CAM in lipid rafts and activation of the Fyn kinases (Santuccione et al. 2005).

\subsubsection{Pathogenic Prion diseases (PrPsc)}

Pathogenic prion diseases are defined as transmissible, spongiform encephalopathies (TSE) (Prusiner and DeArmond 1994; Colby and Prusiner 2011). For humans, Creutzfeldt-Jakob-disease (CJD) is the most frequent disease next to Gerstmann-Sträussler-Scheinkersyndrome (GSS) and Fatal familial insomnia (FFI). The cellular, as well as the pathogenic derivate of the prion protein, possesses the same primary amino acid sequence encoded by the same gene. The critical difference is based on the deviating folding and the resulting change in structure and chemical as well as physical characteristics (Basler et al. 1986; Borchelt et al. 1990). PrPC is soluble and can be completely digested with proteinase $\mathrm{K}$. In contrast to cellular prion, the pathogenic $\mathrm{PrPS}^{\mathrm{Sc}}$ is entirely resistant towards any enzymatical digestion. $\mathrm{PrP}^{\mathrm{C}}$ is mainly composed of $\alpha$-helices (42\%) with a low amount of $\beta$-sheets (3\%). In comparison, $\operatorname{PrP}^{S c}$ contains mainly $\beta$ sheets (>43 \%) and a lower portion of $\alpha$ helices (30\%) (Caughey et al. 1991; Pan et al. 1993). Human prion diseases are categorized into 3 different groups. The pathology can be spontaneous, meaning the cause for its origin is not known (sporadic CJD) or the disease can be acquired by other organisms (iatrogenic CJD). Additionally, several genetic factors are known to be responsible for an inherited prion malfunction (genetic CJD, GSS, FFI) (Gambetti et al. 2003).

\subsection{Misfolding of proteins based on the prion hypothesis}

The prion hypothesis is based on the assertion of Prusiner that the pathogenic prion protein $\left(\mathrm{PrPS}^{\mathrm{Sc}}\right)$ is responsible for the emergence of prion diseases (Prusiner 1982). This represented a new paradigm of infection since the transmission of the pathogenic causative agent is solely achieved by a protein. The infectiousness is depending on the state of the prion protein, changing from a physiological $\left(\mathrm{PrP}^{\mathrm{C}}\right)$ to a pathogenic and therefore infectious condition $(\mathrm{PrPS})$. A crucial factor is the conformation of the protein, which is converted into a misfolded isoform (Marciniuk et al. 2013). Newly emerged PrPSc is then capable of promoting the ongoing 
transformation of the already existing $\operatorname{PrPC}^{\mathrm{C}}$ initiating the pathogenesis. This transformation comprises several intermediates of $\mathrm{PrP}^{\mathrm{Sc}}$ into oligomers, which can continue on to the formation of protofibrils. These protofibrils can lead to the final conversion into amyloid fibrils (Govaerts et al. 2004; Silveira et al. 2005). From these fibrils, small fragments can detach and function as a seed for the de novo dissemination of the prion agent (Saborio et al. 2001; Baskakov et al. 2002).

Due to the localization of $\operatorname{PrP}^{\mathrm{C}}$ on the cell membrane, the spreading via cell-to-cell contact to other tissues is possible (Février et al. 2005; Vella et al. 2007). This theory is supported by an experiment in which $\mathrm{PrPC}^{\mathrm{C}}$ deprived animals were infected with $\operatorname{PrPS}^{\mathrm{Sc}}$, showing no indication of a successful infection. In the case of control mice with intact $\operatorname{Pr} \mathrm{PC}^{\mathrm{C}}$, a spreading infection was observed (Mallucci et al. 2003). Next to the prion protein, several other neurodegenerative diseases based on the misfolding of proteins could be identified. This includes Alzheimer's disease, Parkinson's disease, Amyotrophic lateral sclerosis (ALS), and Huntington's disease (HD). It was assumed that the aggregation of proteins is a consequence of the disorder and not a cause. However, growing evidence revealed that the process is based on pathological, self-replicating proteins. By adding exogenic amyloid protein to cell, tissue and animal models, it was possible to induce the misfolding of the physiological protein in the corresponding model. This was successfully shown for different neurodegenerative diseases (Amyloid $\beta$ and Tau in AD, aSyn for PD and superoxidismutase 1 in ALS) (Baker et al. 1993; Chia et al. 2010; Luk et al. 2012). Another shared characteristic is the phenotypical versatility of neurodegenerative diseases. The example of AD shows the high variance in cognitive decline, age of onset, localization and extent of $A \beta$ plaques (Chui et al. 1985; Armstrong et al. 2000). Synucleinopathies are also known for different manifestations of the disease like PD, LB or MSA, which are separated by different characteristics (Goedert 2001).

Tau represents neurodegeneration within the group of tauopathies. The formation of neurofibrillary clusters caused by hyperphosphorylated aggregated Tau is a typical feature. Among others, tauopathies include AD, corticobasal degeneration and Prick's disease. Prion diseases are also showing different pathogenic phenotypes. They can affect the central nervous system, as well as the peripheral nervous system (PNS) with a distinctive pathology progression (Ironside et al. 2005; Wadsworth and Collinge 2007). One striking difference between prions and other neurodegenerations is concerning the infectiousness. After decades of intensive 
research, no spontaneous infection could be found for other diseases like $A D, P D$ or tauopathy. Prions have the unique ability to be absorbed via mucosa or food consumption into the host and spread until the brain is reached. TSEs are also capable of propagating across different species to other living creatures (zoonoses). According to current research, in other neurodegenerative diseases like $A D, P D$ and $A L S$ the spreading of misfolded proteins is limited to adjacent cells or tissues within one organism. The transmission of potential pathogenic proteins could only be demonstrated under experimental conditions (Clavaguera et al. 2009; Desplats et al. 2009; Heilbronner et al. 2013). Because of the restricted transmissibility to other hosts, these diseases are referred to as prion-like neuropathologies. Furthermore, sCJD has a shorter average disease progression time of four to six months after the diagnosis until death (Mendez et al. 2003). For other neurodegenerative pathologies, the progression takes several years to decades. Although specific differences between prion and prion-like diseases are known, the exact terminology is not yet established and heavily debated (Eraña 2019). 


\section{Aims of the project}

Synucleinopathies are characterized by the misfolding of aSyn into a pathogenic counterpart resulting in intracellular deposits, called Lewy bodies. The postulated prion-like behavior of aSyn suggests that a misfolded aSyn seed may initiate a templated-induced conversion of adjacent physiologic aSyn into a misfolded amyloid state, resulting in the oligomerization and aggregation of this protein. Endogenous pathologic aSyn is supposed to spread with a yet unknown mechanism in a cell-to-cell manner in the brain potentially influencing the course of synucleinopathies.

In this work, we were investigating the role of the prion protein in the pathogenesis of synucleinopathies and the potential function of $\mathrm{PrPC}^{\mathrm{C}}$ as a receptor molecule for pathological aSyn. Based on this hypothesis, different experimental tasks shall be addressed:

I. Secondary cell culture SH-SY5Y WT and SH PrP overexpressing cells will be treated with monomeric and oligomeric aSyn to assess the amount of extracellularly applied monomeric and oligomeric aSyn uptake and a possible colocalization of $\operatorname{PrPC}^{\mathrm{C}}$ and aSyn in subcellular fractions.

II. Interaction studies of monomeric and oligomeric aSyn with $\operatorname{PrP}^{\mathrm{C}}$ will be conducted with surface plasmon resonance spectrometry.

III. Additionally, Co-IPs of mouse brains will be analyzed and used for the mass spectrometric identification of further proteins which may also be involved in aSyn internalization.

IV. Two different aSyn transgenic mouse lines (Tgm83 and ThySyn), exhibiting an aSyn pathology, will be crossed with a PrP-KO (Zurich I) mouse line to generate double transgenic mouse lines (TgmPrP00 and ThSynPrP00). The behavior of mice will be tested in a battery of behavioral tasks to assess changes in their phenotype in dependence of $\operatorname{PrP}^{\mathrm{C}}$. Furthermore, biochemical analyses will be conducted to assess whether a PrP knockout influences the aSyn expression and the subcellular distribution of aSyn via western blotting and ELISA. 


\section{Materials and Methods}

\subsection{Materials and Devices}

\subsubsection{Consumables}

Table 1: Overview of materials

\begin{tabular}{ll}
\hline Material & Company \\
\hline 6-Multiwell-plates & Sarstedt \\
Amicon ${ }^{\circledR}$ Ultra 0.5 mL Centrifugal Filters Merck & Merck \\
DNeasy Blood \& Tissue Kits & Qiagen \\
Falcon tubes & Sarstedt \\
Filter paper Western Blot & Bio-Rad \\
PicoFrit ${ }^{\circledR}$ PF360-75-15-N-5 & New Objective \\
Pipettes & Sarstedt \\
PVDF-Membrane & GE Healthcare Life Science \\
Reaction tubes & Sarstedt \\
Cell culture flask T75 & Sarstedt \\
Cell scraper & Sarstedt
\end{tabular}

\subsubsection{Chemicals and reagents}

Table 2: Overview of chemicals and reagents

\begin{tabular}{ll}
\hline Chemicals and reagents & Company \\
\hline Acrylamid/Bisacrylamidsolution & Roth \\
Ammoniumperoxidsulfat (APS) & Biorad \\
Bradford-reagent & Biorad \\
BSA (1000 $\mu \mathrm{g} / \mathrm{ml})$ & Sigma \\
Chaps $(3-[(3-C h o l a m i d o p r o p y l)$ dimethylammonio]-1-pro- & Carl Roth \\
pansulfonat) & \\
Dithiothreitol (DTT) & Roche \\
Dynabeads Protein G for Immunoprecipitation & ThermoFisher
\end{tabular}


Glutaraldehyde

Loading buffer Roti Load Methanol

Methanol

Milk powder

PBS Dulbecco

SDS

TEMED

Trypsin/EDTA

Tween

Uranyl acetate
Science Services

Roth

Merck

Roth

Merck

Roth

Roth

Biochrom

Roth

Merck

\subsubsection{Antibodies}

Table 3: List of antibodies

\begin{tabular}{llll}
\hline Antibody & Origin & Dilution & Company \\
\hline Monoclonal Anti- $\beta$-Actin AK & Mouse & $1: 2000$ & Sigma-Aldrich \\
Monoclonal Anti-GAPDH AK & Mouse & $1: 2000$ & Sigma Aldrich \\
Prion Protein AK (Saf32) & Rabbit & $1: 3000$ & Abcam \\
Alpha-synuclein MJFR1 & Rabbit & $1: 1000$ & Abcam \\
Alpha-synuclein(phospho S129) & Rabbit & $1: 1000$ & Abcam \\
Na-K-ATPase & Rabbit & $1: 1000$ & Abcam \\
Anti Histon H3 & Rabbit & $1: 1000$ & Abcam \\
Anti-Maus IgG & & $1: 5000$ & Dianova GmbH \\
Anti Kaninchen IgG & & $1: 5000$ & Dianova GmbH \\
Alexa Flour 488 & & $1: 5000$ & Abcam \\
Alexa Flour 647 & Mouse & $1: 5000$ & Abcam
\end{tabular}




\subsubsection{Buffer and solutions}

\section{Blocking solution}

$5 \%$ milk powder

$100 \mathrm{ml} \mathrm{PBST}$

\section{Extraction buffer}

$50 \mathrm{mM}$ Tris-HCL (pH 7.5)

$150 \mathrm{mM} \mathrm{NaCl}$

2 mM EDTA

$1 \%$ Triton

Protease and Phosphatase Inhibitor

\section{Running buffer}

\section{$1 \mathrm{~g}$ SDS}

14.4 g Glycin

$3 \mathrm{~g}$ Tris

add $1 \mathrm{~L}$ on $\mathrm{VE}-\mathrm{H}_{2} \mathrm{O}$

\section{$\underline{\text { PBST }}$}

\section{9,55 g PBS}

$+0.5 \mathrm{ml}$ Tween

add $1 \mathrm{~L}$ on $\mathrm{VE}-\mathrm{H}_{2} \mathrm{O}$

\section{SH-SY5Y Cell model}

SH-SY5Y (SH) cells are commonly utilized for Parkinson's research. These cells originate from the SK-N-SH line, extracted from a bone marrow biopsy of a neuroblastoma patient in 1970 (Biedler and Schachner 1978). They are also used in the fields of AD, ALS, neurotoxicity, and ischemia (Xicoy et al. 2017). SH cells are able to exhibit neuroblast-like or epithelial-like features. Additionally, this cell line can be induced to differentiate into a neuron-like phenotype (Kovalevich and Langford 2013). Next to the SH wildtype cells, a genetically modified SH cell line was used. This additional cell line was transfected with a vector containing PRNP, leading to the constitutive overexpression of $\operatorname{PrP}^{C}$ (Weiss et al. 2010). 


\section{SH SY5Y-Medium}

Dulbecco's Modified Eagle Medium (DMEM)

$10 \%$ fetal bovine serum (FBS)

$1 \%$ Glutamine

\section{Transfer solution (10x)}

$58,2 \mathrm{~g}$ Tris

29,3 g Glycin

$3,75 \mathrm{~g}$ SDS

add $1 \mathrm{~L}$ on $\mathrm{VE}-\mathrm{H}_{2} \mathrm{O}$

\section{Enhanced chemiluminescence solution (ECL)}

Solution $1(10 \mathrm{ml})$ :

$100 \mu \mathrm{l} 250$ mM Luminol (0.44 g/10 ml DMSO)

$44 \mu \mathrm{l} 90 \mathrm{mM}$ p-coumaric acid $1 \mathrm{ml}$

$1 \mathrm{M}$ Tris/HCl pH $8.58 .85 \mathrm{ml} \mathrm{H} 2 \mathrm{O}$

Solution $2(10 \mathrm{ml})$ :

$6 \mu \mathrm{l} 30 \% \mathrm{H}_{2} \mathrm{O}_{2} 1 \mathrm{ml}$

$1 \mathrm{M}$ Tris/HCL pH $8.59 \mathrm{ml} \mathrm{H} \mathrm{H}_{2}$

\section{Transfer buffer}

$100 \mathrm{ml}$ transfer solution (10x)

$200 \mathrm{ml}$ Methanol

$700 \mathrm{ml}$ of water

\section{Upper gel buffer}

$0.5 \mathrm{M} \mathrm{Tris} / \mathrm{HCl}$

$0.4 \%$ SDS

$\mathrm{pH}=6.8$ 


\section{Bottom gel buffer}

$80.38 \mathrm{~g}$ Tris- $\mathrm{HCl}$

$119.93 \mathrm{~g}$ Tris

4 g SDS

add $1 \mathrm{~L}$ on $\mathrm{VE}-\mathrm{H}_{2} \mathrm{O}$

$\mathrm{pH}: 8.8$

Table 4: Composition for 2 SDS gels

\begin{tabular}{llll}
\hline Chemical & Bottom gel 12\% & Bottom gel (15\%) & Upper gel 6\% \\
\hline Buffer & 4 & 4 & 2,5 \\
$40 \%$ Acrylamide & 4,8 & 6 & 1,5 \\
distilled $\mathrm{H}_{2} \mathrm{O}$ & 6,9 & $5,7 \mathrm{ml}$ & $5,8 \mathrm{ml}$ \\
APS $10 \%$ & $160 \mu \mathrm{l}$ & $160 \mu \mathrm{l}$ & $100 \mu \mathrm{l}$ \\
TEMED & $160 \mu \mathrm{l}$ & $160 \mu \mathrm{l}$ & $10 \mu \mathrm{l}$
\end{tabular}

\subsubsection{Devices and Software}

Table 5: List of devices

\begin{tabular}{ll}
\hline Device & Company \\
\hline $2048 \times 2048$ CCD-Kamera & TRS Moorenweis \\
AxioObserver Z1 & Zeiss \\
ChemiDoc Imaging System & XRS+, BioRad \\
EASY-nLC 1000 liquid chromatograph & Thermo Fischer Scientific \\
Gel electrophorese Turbo-Blot & BioRad \\
Incubator & HERA Cell 150, Heraeus \\
LEO EM912 Omega & Zeiss \\
light microscope & Axiovert 25, Zeiss \\
Balance & LE6202S, Sartorius \\
ProteOn XPR36 & BioRad \\
Q Exactive Hybrid Quadrupole-Orbitrap mass & Thermo Fischer Scientific \\
spectrometer &
\end{tabular}




$\begin{array}{ll}\text { ReproSil-Pur C18 AQ } & \text { Maisch GmbH } \\ \text { Ultrospec } 2100 \text { Spectrophotometer } & \text { Amersham Biosciences } \\ \text { HERA Safe HS } 15 & \text { Heraeus } \\ \text { Thermal block } & \text { Eppendorf } \\ \text { Centrifuge } 5810 \text { Centrifuge } & \text { Eppendorf }\end{array}$

Table 6: List of software

\begin{tabular}{ll}
\hline Software & Company \\
\hline Scaffold Software (4.8.4.) & Proteome Software \\
Imagelab (6.0.1) & BioRad \\
Image & National Institutes of Health \\
Axio observer & Zeiss \\
GraphPad Prism 6 & GraphPad Software
\end{tabular}

\subsection{Methods}

\subsubsection{SDS-polyacrylamide gel electrophoresis (SDS PAGE)}

For the size-separation of proteins SDS PAGE with $6 \%$ upper gel and $12 \%$ or $15 \%$ bottom gel were utilized depending on the necessary protein size.

\subsubsection{Electro transfer of proteins (Western Blot)}

After size-separating proteins in the SDS-PAGE the bottom gel was placed into transfer buffer. A Polyvinylidene fluoride Membrane (PVDF) in the same size as the gel was equilibrated for 1 minute in Methanol. Two Western Blot filter papers in the size of the gel were also soaked in transfer buffer. Filter paper, gel and PVDF membrane were properly stacked and proteins were blotted for 60 minutes at $12 \mathrm{~V}$.

\subsubsection{Immunological detection of protein on the membrane}

After the protein transfer, the membrane was treated with specific antibodies to detect the desired proteins. Therefore, free binding sites were blocked beforehand by incubating the 
membrane for 60 minutes with blocking solution. Subsequently, the membrane was incubated with the primary antibody overnight at $4{ }^{\circ} \mathrm{C}$. Then a washing step of $2 \times 15$ minutes and $3 \times 15$ minutes was conducted. Next, the membrane was incubated with a Horseradish peroxidaselabeled secondary antibody and a second washing step was performed. For the detection of the protein band, the membrane was soaked into enhanced chemiluminescence solution (ECL) for 1 minute. The signal was measured via Chemi-Doc Systems (Biorad). Exposure time was fitted accordingly to the antibody and signal strength. The densitometric evaluation was executed with the ImageLab software from BioRad. Statistical analysis was conducted with Graph Pad Prism 6.

\subsubsection{ELISA measurement of total and oligomeric alpha-synuclein}

For the measurement of total and oligomeric aSyn in mouse brain lysates, ELISAs were acquired from Euroimmun/ADx. ELISAs were run according to the manufacture's instruction. Briefly, the wells were coated with $100 \mu$ of biotin solution and $25 \mu$ of the brain sample and incubated overnight at $4{ }^{\circ} \mathrm{C}$. Wells were washed five times and $100 \mu \mathrm{l}$ of enzyme conjugate (streptavidin-peroxidase) was applied for 30 minutes. Afterward, washing was repeated five times and $100 \mu \mathrm{l}$ of chromogen/substrate solution was added to the microplate wells and incubated for 30 minutes in the dark. Absorbance at $450 \mathrm{~nm}$ was directly measured after adding $100 \mu$ l of stop solution with the Perkin Elmer Wallac 1420 Victor microplate reader (GMI, USA).

\subsubsection{Cells and cell cultivation}

For in vitro studies secondary human SH-SY5Y cells were used (Xicoy et al. 2017). In addition, a genetically modified SH-SY5Y cell line with a constitutive $\operatorname{PrPC}^{\mathrm{C}}$ overexpression was utilized (Weiss et al. 2010). Cell cultivation was performed under sterile conditions with T75 cell culture flasks, respectively in suitable multi-well plates at $37^{\circ} \mathrm{C}$ and $5 \% \mathrm{CO}_{2}$.

\subsubsection{Cell passaging}

At a confluence of around 90 to $100 \%$, the cells were singularized and transferred into new cell culture flasks. This was done by washing the cells with PBS and 3-minute treatment of 1,5 
$\mathrm{ml}$ Trypsin/EDTA solution at $37^{\circ} \mathrm{C}$. Detached cells were freshly resuspended in new cell culture medium at a ratio of 1:10.

\subsubsection{Alpha-Synuclein Aggregations-Assay}

To generate aggregated aSyn recombinant protein was dissolved in PBS. To avoid bacterial contamination, a concentration of $0.02 \%$ sodium azide was set. The lid was sealed with Parafilm and the reaction tube was shaking for 14 days at $37^{\circ} \mathrm{C}$ at $400 \mathrm{rpm}$.

\subsubsection{Transmission Electron Microscopy}

Monomeric and oligomeric aSyn was analyzed by negative staining. A cooper EM-grid coated with Formvar was soaked in a $10 \mathrm{ml}$ sample solution with a concentration of $0.25 \%$ glutaraldehyde. After an incubation of 1 minute, the grid was washed with 3 droplets of water with 2 $\%$ uranyl acetate for 30 to 60 seconds. Droplets were then removed and excess liquid was blotted by touching the grid with a piece of filter vertically. After the negatively stained samples were dried, images were taken via the LEO EM912 Omega electron microscope. For obtaining digital micrographs an on-axis 2048×2048 CCD camera was used.

\subsubsection{Alpha-synuclein treatment of cells}

Cells were cultivated in 6 well plates until they reached a confluence of about $90 \%$. Subsequently, monomeric respectively oligomeric aSyn was added to the wells. The final concentration of $1 \mu \mathrm{M}$ was set and incubated for $24 \mathrm{~h}$. Afterward, cells were washed 3 times with PBS and detached mechanically with cell scrapers and dissolved in lysis buffer.

\subsubsection{Treatment of cells with Glimepiride}

PrPC overexpressing SH cells were treated with Glimepiride to achieve the release of prion protein from the cell surface. It activates the endogenous Glycosylphosphatidylinositol phospholipase C, cleaving $\mathrm{PrP}^{\mathrm{C}}$ at the GPI anchor (Carulla et al. 2015). An increasing concentration of Glimepiride was used to achieve different $\operatorname{PrP}^{\mathrm{C}}$ quantities on the cells. Glimepiride was solved in DMSO, which is toxic for cell culture. Therefore, all concentrations were prepared to a final concentration of $1 \%$ DMSO in the 6 well plates. 


\subsubsection{Immunofluorescent staining of SH-SY5Y cells}

Cells were washed with PBS and fixed with $3.7 \%$ formaldehyde for 25 minutes and washed again with PBS. For permeabilization, cells were incubated with permeabilization buffer (PBS/2mg/ml BSA/ $0.1 \%$ Triton-X 100) for 10 minutes. Afterward, cells were blocked with blocking solution (PBS, BSA $2 \mathrm{mg} / \mathrm{ml}$ ) for 30 minutes. The incubation with primary antibodies (concentration $0,5 \mu \mathrm{g} / \mathrm{ml}$ in blocking solution) was done overnight at $4{ }^{\circ} \mathrm{C}$. Samples were washed again 3 times for 10 minutes. The secondary antibody was incubated for $2 \mathrm{~h}$ with a concentration of $2 \mathrm{mg} / \mathrm{ml}$. Another washing step was performed and samples were stained with DAPI for 1 minute. Cells were sealed on a slide and stored at $4{ }^{\circ} \mathrm{C}$ in the dark until imaging.

\subsubsection{Keeping of animals}

Animals were kept in individually ventilated cages with standardized bedding materials. Sustenance was provided by "Zentrale Tierexperimentelle Einrichtung" of Universitätsmedizin Göttingen. Room temperature was kept at $21{ }^{\circ} \mathrm{C}$ with an average humidity of $65 \%$. The light cycle was set to 12 hours of constant light and 12 hours of darkness. As standard food, dry pellets were provided and tap water was given. Every animal was examined regularly for health issues.

\subsubsection{Genotyping of mice}

Tips of the mice tail were used for isolating the DNA. Extraction was performed with an isolation kit from the Company Qiagen. Afterward, PCR could be carried out to classify the mice into the genetic groups. The list of employed primers is shown below.

Table 7: List of primers

\begin{tabular}{|c|c|}
\hline Primer & Sequence \\
\hline PrP Forward & 5‘ ATG GCG AAC CTT GGC TAC TGG GCT G 3’ \\
\hline PrP Reverse & 5’ CAT CCC ACG ATC AGG AAG ATG 3’ \\
\hline PrPKO Forward & 5‘ ATT CGC AGC GCA TCG CCT TCT ATC GCC 3’ \\
\hline PrPKO Reverse & $5^{\prime}$ CCT GGG AAT GAA CAA AGG TTT GCT TTC AAC 3’ \\
\hline
\end{tabular}


Tgm83 aSyn for

Tgm83 aSyn rev

ThySyn for

ThySyn rev
5‘ TGT AGG CTC CAA AAC CAA GG 3’

5‘ TGT CAG GAT CCA CAG GCA TA 3’

5‘ ATG GCG AAC CTT GGC TAC TGG GCT G 3’

5' CAT CCC ACG ATC AGG AAG ATG 3'

Table 8: PCR schemes for genotyping

\begin{tabular}{|c|c|c|c|c|c|c|c|}
\hline \multicolumn{2}{|c|}{ Tgm83 } & \multicolumn{2}{|c|}{ ThySyn31 } & \multicolumn{2}{|c|}{ WT PrP } & \multicolumn{2}{|c|}{ PrP K.O. } \\
\hline Temp & Time & Temp & Time & Temp & Time & Temp & Time \\
\hline 1. $95^{\circ} \mathrm{C}$ & $10 \mathrm{~min}$ & $95^{\circ} \mathrm{C}$ & $10 \mathrm{~min}$ & $95^{\circ} \mathrm{C}$ & $3 \mathrm{~min}$ & $95^{\circ} \mathrm{C}$ & $1 \mathrm{~min}$ \\
\hline 2. $95^{\circ} \mathrm{C}$ & $30 \mathrm{sec}$ & $95^{\circ} \mathrm{C}$ & $15 \mathrm{sec}$ & $95^{\circ} \mathrm{C}$ & $30 \mathrm{sec}$ & $95^{\circ} \mathrm{C}$ & $30 \mathrm{sec}$ \\
\hline 3. $58^{\circ} \mathrm{C}$ & $45 \mathrm{sec}$ & $60^{\circ} \mathrm{C}$ & $1 \mathrm{~min}$ & $56^{\circ} \mathrm{C}$ & $45 \mathrm{sec}$ & $62^{\circ} \mathrm{C}$ & $2 \mathrm{~min}$ \\
\hline 4. $72^{\circ} \mathrm{C}$ & $40 \mathrm{sec}$ & $72^{\circ} \mathrm{C}$ & $10 \mathrm{~min}$ & $72^{\circ} \mathrm{C}$ & $1 \mathrm{~min} 15 \mathrm{sec}$ & $72^{\circ} \mathrm{C}$ & $1 \mathrm{~min}$ \\
\hline 5 & & & & $72^{\circ} \mathrm{C}$ & $10 \mathrm{~min}$ & $72^{\circ} \mathrm{C}$ & $5 \mathrm{~min}$ \\
\hline
\end{tabular}

Table 9: PCR Mix

\begin{tabular}{lc}
\hline Component & Quantity $(\mu \mathrm{l})$ \\
\hline Forward Primer & 1 \\
Reverse Primer & 1 \\
Taq Puffer & 2,5 \\
dNTPs & 1 \\
Taq Polymerase & 0,5 \\
$\mathrm{H}_{2} \mathrm{O}$ & 20
\end{tabular}

\subsubsection{Co-immunoprecipitation (Co-IP)}

Dynabeads were fixed into a reaction tube via magnets and washed with $200 \mu$ PBS. Afterward, Dynabeads were washed twice with $200 \mu \mathrm{l}$ of 0,3\% CHAPS solution. For binding primary antibodies, $10 \mu \mathrm{l}$ of its stock solution was diluted in $250 \mu \mathrm{l}$ PBS and added to the Dynabeads solution. The reaction tube was incubated 30 minutes at $4{ }^{\circ} \mathrm{C}$ while rotating at $8 \mathrm{rpm}$. The sample of interest was diluted in PBS with protease inhibitors to a concentration of $1 \mu \mathrm{g} / \mu \mathrm{l}$ 
and subsequently added to the antibody solution. The total amount of protein and antibody solution was filled up to $400 \mu \mathrm{l}$ PBS and incubated overnight at $4{ }^{\circ} \mathrm{C}$ while rotating at $8 \mathrm{rpm}$. After this binding step, the Dynabeads were magnetically fixed and washed four times with $300 \mu \mathrm{l} 0.3 \%$ CHAPS solution. Then the sample was resuspended in $100 \mu \mathrm{l}$ CHAPS and transferred into a new reaction tube. For denaturation 2x Laemmli Buffer with DTT (15 mg/ml) was added. The buffer did not contain $\beta$ mercaptoethanol. Finally, the sample was heated to $95^{\circ} \mathrm{C}$ for 5 minutes.

\subsubsection{Mass spectrometry}

\section{Peptide digestion and extraction}

Samples were diluted in loading buffer and cooked at $95^{\circ} \mathrm{C}$ for 5 minutes, loaded into $12 \%$ SDS PAGE and run until the dye was completely in the gel. Afterward, the gel was stained with Coomassie Blue and protein bands were cut out of the gel, shredded and washed in $\mathrm{dd}_{2} \mathrm{O}$. Samples were reduced (10 mM DTT in $100 \mathrm{mM} \mathrm{NH}_{4} \mathrm{HCO}_{3}$ ) for 30 minutes at $56^{\circ} \mathrm{C}$. Alkylation ( $55 \mathrm{mM}$ lodoacetamide in $100 \mathrm{mM} \mathrm{NH}_{4} \mathrm{HCO}_{3}$ ) took place at room temperature for 60 minutes. The remaining solution in the Gel fraction was removed by adding acetonitrile and a 15 minutes speed vac spin. Final products were stored at $-20^{\circ} \mathrm{C}$.

\section{Peptide identification}

The peptide mixture was concentrated on a reverse-phase C-18 precolumn. For the separation, a reversed-phase C-18 nanoflow chromatography column was used with a 60-minute linear gradient and a flow rate of $240 \mathrm{~nL} / \mathrm{min}$ in an Easy $\mathrm{nLC} 100$ nanoflow-chromatography system. Eluted peptides were analyzed on Q Exactive hybrid quadrupole/orbitrap mass spectrometry system instructed by Xcalibur 3.1.66.10 software. The MS/MS spectrum was evaluated via Mascot Software using the UniProt/SwissProt database and the Mus Musculus reference proteome with a mass tolerance of $5 \mathrm{ppm}$ for the precursor ions and 0,02 Da for peptide fragments. The Scaffold software was used to validate MS/MS based peptide and protein identification. Peptide identification was accepted when confidence greater than $95 \%$ was established with at least two confident peptide identifications with a confidence threshold of $99 \%$. 


\subsubsection{Surface plasmon resonance spectroscopy}

This method allows an effective detection of the quantitative binding of unmarked molecules. It is based on polarized light going through a prism on a sensor chip while the reflection is detected. The angle of the reflected lights depends on the immobilized molecules on the sensor chip. The chip is under a constant flow of sample buffer until the sample is added. The change on the surface of the chip leads to a change of the angle of reflection and can be measured.

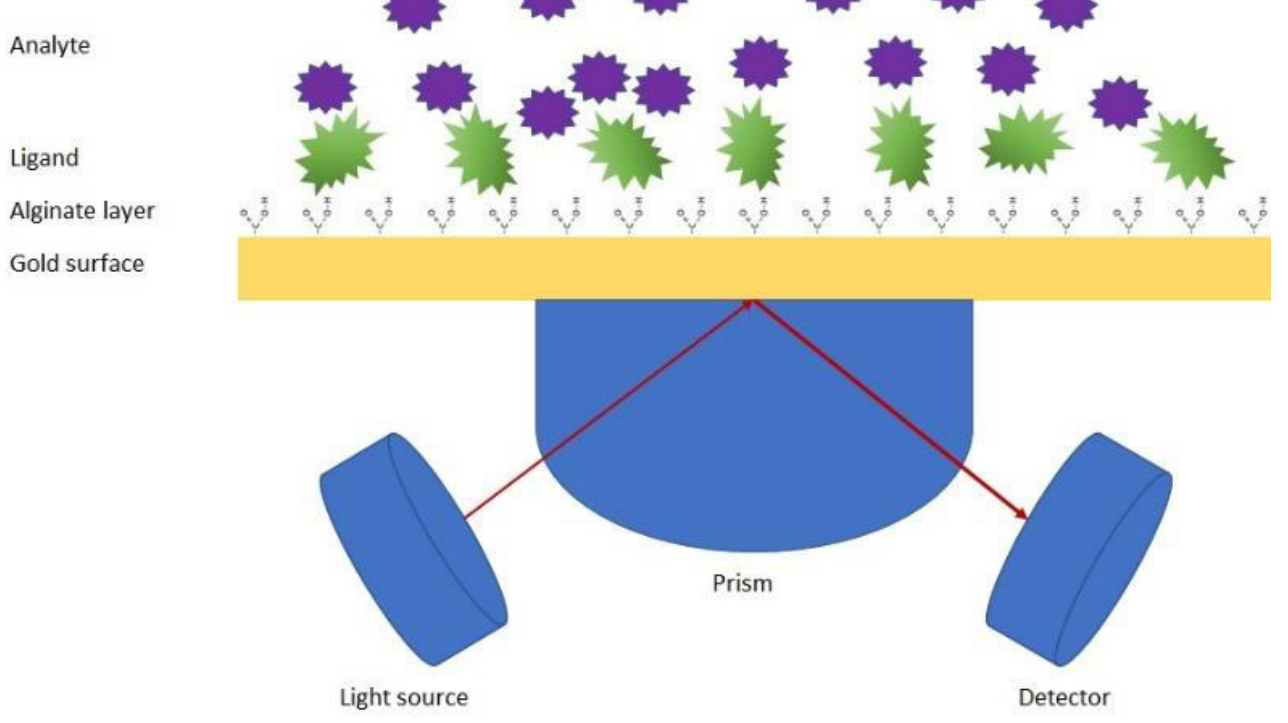

Figure 4: Principle of Surface plasmon resonance spectrometry

Laser constantly emits light onto the gold-layered chip containing an immobilized ligand while the reflected light is permanently detected. Depending on the surface-bound ligand on the chip, the angle of reflection changes. During the flowtime of the analyte, a specific curve based on the shift in the measured angle can be obtained. This data allows the calculation of binding strengths of molecules.

For the spectroscopic measurement, the ProteOn XPR36 (Bio-Rad) was used. The sensor chip is covered with a thin gold layer and an alginate polymer layer for an optimized immobilization of ligands. Due to the binding and the change of the reflection angle the kinetics of the interaction can be determined. 


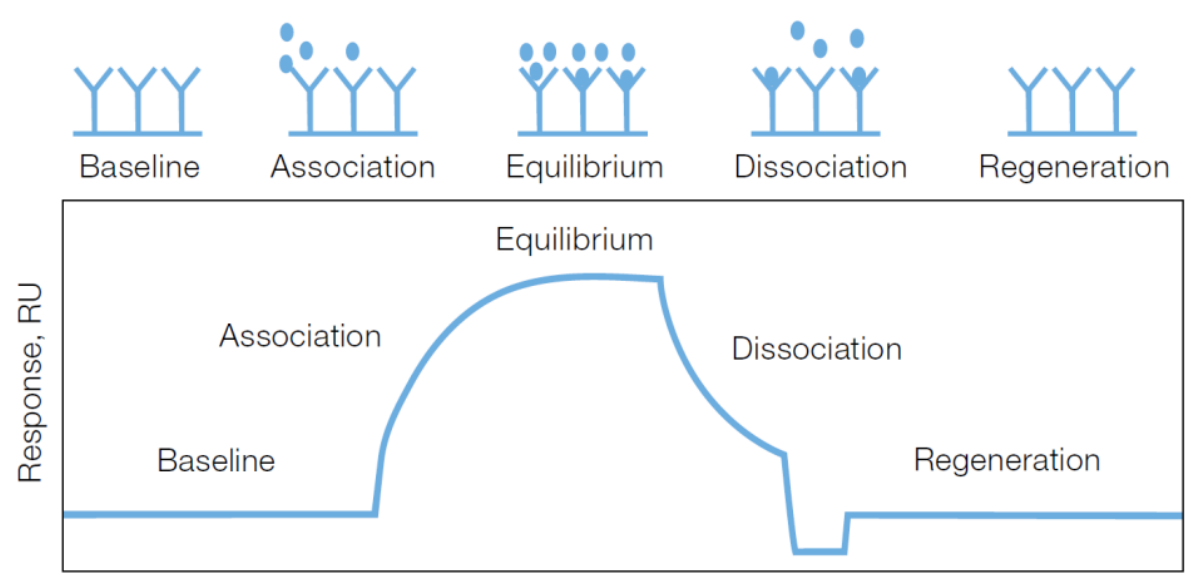

Time, sec

Figure 5: Schematic curve progression of a protein interaction

Curve progression of a protein interaction can be differentiated into several phases (Association, Equilibrium, Dissociation). Depending on the amplitude measurement the quantitative binding kinetics can be determined and an equilibrium constant can be calculated.

The baseline represents the buffer solution without an analyte. Once the analyte is added, the association phase begins. The equilibrium represents the point when the association and dissociation of the analyte are equal. Dissociation starts with the depletion of the analyte and the release of molecules from the sensor chip. The equilibrium constant $K$ is based on curve progression during the measurement. $\mathrm{K}$ is defined as the quotient of the dissociation constant $\mathbf{k}_{\mathbf{d}}$ divided by the association constant $\mathbf{k}_{\mathbf{a}}$.

$$
\frac{k_{d}}{k_{a}}=K
$$

For interaction studies, a GLC sensor chip was used. After the initialization step with $50 \%$ glycerol, the chip was conditioned horizontally and vertically in the following order: $0.5 \%$ SDS, $50 \mathrm{mM} \mathrm{NaOH}, 100 \mathrm{mM} \mathrm{HCL}$. For the immobilization step, the surface was activated by running a mixture of $400 \mathrm{mM}$ 1-ethyl-3-(3-dimethyl aminopropyl) carbodiimide (EDC) and 100mM Nhydroxysulfosuccinimide (sulfo-NHS). Carboxyl groups react and become sulfo-NHS esters so the ligand can bind in the next to step to the esters via an amino coupling on the chip. Protein ligands were immobilized with a concentration of $20 \mu \mathrm{g} / \mathrm{ml}$. Antibodies were used with a concentration of $10 \mu \mathrm{g} / \mathrm{ml}$. The injection of $1 \mathrm{M}$ ethanolamine deactivated any remaining sulfoNHS ester groups. For the stabilization of the baseline, running buffer was injected in short bursts until a stable baseline achieved. 


\subsubsection{Cell fractioning}

For fractioning the Qproteome Cell Compartment Kit from Qiagen was used resulting in the separated fractions of cytosol, membrane, nucleus, and the cytoskeleton. All centrifugation steps were conducted at $4{ }^{\circ} \mathrm{C}$. $20 \mathrm{mg}$ of brain lysate was homogenized for 20 seconds at 20 Hertz in the homogenizer. The sample was added to the included "QIAshredder homogenizer" with $500 \mu \mathrm{l} \mathrm{CE1} \mathrm{buffer}$ and centrifuged. The supernatant represented the cytosolic fraction. The cell pellet was resuspended in $1 \mathrm{ml} \mathrm{CE2}$ buffer and incubated for 30 minutes on ice and then centrifuged. Newly gained supernatant was stored as the membrane fraction. The new cell pellet was resuspended in $500 \mu \mathrm{l}$ of CE3 buffer and incubated for 10 minutes on ice. Afterward, the sample was centrifuged for 10 minutes. The supernatant was stored as the nucleus fraction. Finally, the pellet was resuspended in CE4 buffer containing mainly the cytoskeletal proteins. 


\section{Qproteome Cell Compartment \\ Fractionation Procedure}

Cell pellet $\left(5 \times 10^{6}\right.$ cells $)$, tissue $(20 \mathrm{mg})$<smiles>[CH]1C=C1</smiles>

Add Extraction Buffer CE1

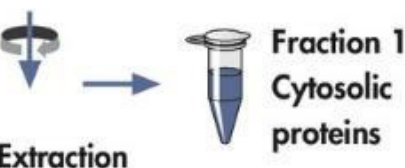

Add Extraction proteins

Buffer CE2

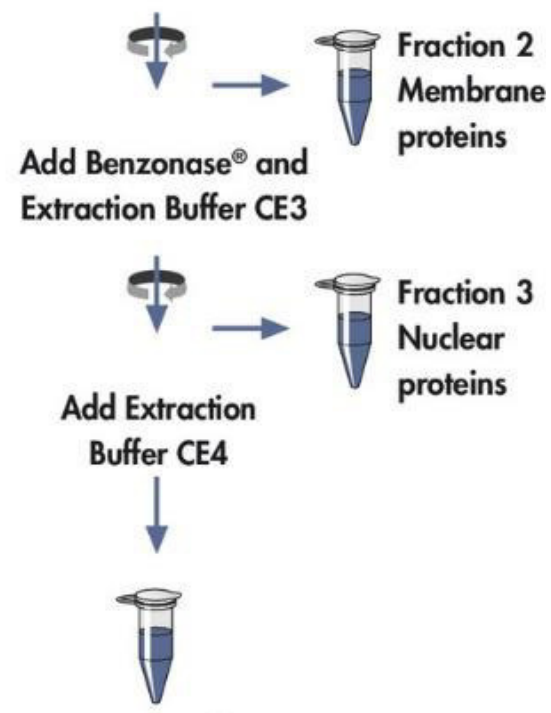

Fraction 4

Cytoskeletal proteins

Figure 6: Schematic of cell fractioning

Fractionization was performed according to manufactures protocol. Cytosol, membrane, nucleus and cytoskeletal fraction were obtained in separated tubes.

To control the separation for each fraction housekeeping genes were detected via Western blot. The list for the specific antibodies is shown below.

Table 10: List of markers for cell fractions

\begin{tabular}{ll}
\hline Fraction & Antibody \\
\hline Cytosol & GAPDH \\
Membrane & Na-Ka-ATPase \\
Nucleus & Histon H3 \\
cytoskeleton & $\beta$-Actin
\end{tabular}




\subsection{Mouse models}

Mice are the preferred animal model for the simulation of human neurodegenerative diseases due to their similar neuronal structure and disease-associated gene homology (Waterston et al. 2002). By using a transgenic animal model a better molecular understanding of neurodegenerative processes could be achieved. For the investigation of the protein interaction, several different transgenic mouse lines were utilized in this work. It is of critical importance to reproduce the traits of human Parkinson's disease in the murine animal model. Parkinson's is classified by a certain set of characteristics (Savitt et al. 2006) but not all of these symptoms can be observed in the genetically modified mouse lines. The different traits of these transgenic mouse lines depend on, for example, whether a pan-neuronal or a dopaminergic specific promoter was used. Furthermore, wildtype aSyn or aSyn with a certain mutation known for PD can be cloned. Due to this variance of different mouse models, differences in the amount, the phenotype and the symptoms are a consequence (Lee et al. 2012). In this project, the mouse line Tgm83 was employed which contains mutated human A53T aSyn regulated by the murine prion promoter. Therefore a high expression in neurons can be observed (Giasson et al. 2002). In addition, the mouse model "Line 61 " was used, having the wildtype aSyn, regulated by the murine Thy 1 promoter (Rockenstein et al. 2002). To assess the influence of PrPC on the pathogenesis of the Synucleinopathy mouse model the mouse line Zürich I with a PRNP knockout was introduced (Büeler et al. 1992a). These mice do not have a distinctive pathological phenotype (Büeler et al. 1992a; Manson et al. 1994). Still, studies revealed several changes e.g. deviation of the circadian rhythm and in the oxidative stress response (Steele et al. 2014). 


\begin{tabular}{|c|c|c|c|}
\hline Mouse line & Tgm83 & ThySyn (Line 61) & PrP00 (Zürich) \\
\hline Gene description & Tg(Prnp-SNCA*A53T)83Vle & $\operatorname{Tg}($ Thy1-SNCA)61Ema & Prnp ${ }^{\text {tm1Cwe }}$ \\
\hline Reference & (Giasson et al. 2002) & (Rockenstein et al. 2002) & (Büeler et al. 1992a) \\
\hline Alpha-Synuclein & $\mathrm{A} 53 \mathrm{~T}$ & Wildtype & - \\
\hline Gene localisation $^{1}$ & gonosomal & autosomal & autosomal \\
\hline Expression level $^{2}$ & 5 to 20 fold & 2 to 3 fold & - \\
\hline Strain of origin & $\mathrm{C} 57 \mathrm{BL} / 6 \times \mathrm{C} 3 \mathrm{H}$ & $\mathrm{C} 57 \mathrm{BL} / 6 \times \mathrm{DBA} / 2$ & 129S7/SvEvBrd-Hprt ${ }^{+}$ \\
\hline Backcrossing & C57BL/6J & C57BL/6J & C57BL/6J \\
\hline
\end{tabular}

${ }^{1}$ (Chesselet et al. 2012) ${ }^{2}$ (Magen uad Chesselet 2011)

\subsection{Behavioral tests}

To evaluate the motoric and cognitive performance of mice, several behavioral tests were conducted in the European Neuroscience Institute Göttingen in collaboration with the DZNE supervised by Prof. Andre Fischer. The equipment for these tests was acquired by TE-System.

\subsubsection{Elevated Plus Maze Test}

Elevated plus-maze allows the assessment of the anxiety behavior of mice. The natural aversion of mice towards open, elevated and unprotected areas is used, which is in contrast to the intrinsic curiosity of new areas. For this test, a plus-shaped maze is elevated $60 \mathrm{~cm}$ above the ground. The mice can move in all directions. Opposing arms are either surrounded by walls (closed arms) or without any borders (open arms). The mouse is positioned the center of the maze and can move freely for 5 minutes while the activity is measured by a camera system. The anxiety behavior is determined by the ratio of the time spent in the open and closed arms.

\subsubsection{Rotarod}

The motoric performance was evaluated with a mouse rotarod apparatus. It consists of a rotating beam separated by five partition walls so up to five mice could be tested simultaneously. Mice were trained to balance on the beam at $10 \mathrm{rpm}, 3$ consecutive days before the measurement. Mice have to move towards the opposing direction of the spinning beam to avoid falling. After conditioning the mice, the measurement was conducted. The beginning 
rotation velocity was set to $5 \mathrm{rpm}$ which increased over 180 seconds to a maximum of $40 \mathrm{rpm}$. Time was measured with the start of the rotating beam and stopped once the mouse fell off the beam. The longer mice were able to remain on the beam, the higher was the motoric performance of the mice.

\subsubsection{Context fear conditioning}

Contextual fear conditioning is one of the most basic conditioning procedures. It is used to quantify the associative learning of an animal. The test subject is placed into a novel environment, exposed to an aversive stimulus and eventually removed from that environment. Once the animal is returned to the surroundings, it will show a freezing response due to negative conditioning, depending on the associative learning. This freezing reaction is considered as an absence of movement except for respiration. A camera system tracks the freezing time, representing the associative learning performance so the comparison to other subjects can be made.

The mouse was placed into a plexiglass chamber with a steel grid on the floor. Via speaker, the mouse was exposed to a static noise for 3 minutes which then switched to a high-pitched sound for 1 minute. By the end of the experiment, the mouse received an electric shock of 0,4 $\mathrm{mA}$ for 2 seconds through the grid. After a resting period of 24 hours, mice were placed in the same chamber for 5 minutes. Due to the negative conditioning, a typical reaction of mice is to stop any movement (freezing) except for breathing and heartbeat. The movement was measured with the camera system connected to the chamber.

\subsubsection{Tone fear conditioning}

In addition to the environment, a tone stimulus was used for fear conditioning. Shortly before receiving an aversive stimulus, the mouse was exposed to a specific tone and removed after the shock stimulus. Before placing the mouse back to the test setup, the surrounding of the shock chamber was masked. In that way, the environmental stimulus did not interfere with tone conditioning. The mouse was subjected to the same specific tone while the freezing time was acquired to assess the associative learning skills 


\subsubsection{Open Field Test}

The examination of rodents via Open-Field testing is a widespread method among behavior studies. It is easy to conduct and assess the motoric skills, without any prior training of the animals. In case of significant differences between test subjects, the influence of cognitive impairment or motoric insufficiencies should be taken into account. A further criterion for the activity of mice was the movement within different areas of the field. By dividing it into inner and outer zones, conclusions can be made about the exploration behavior. The typical behavior of rodents is the avoidance of unknown and bright places. Therefore, the comparison of the duration of time in the inner and outer zone can reflect the anxiety behavior of mice. Additionally, thigmotaxis at the edge of the Open-Field can be a measure for fear assessment. The more a mouse remains in the inner zones the less anxious the animal is. The mouse was placed into an area of $80 \mathrm{~cm} \times 80 \mathrm{~cm}$ surrounded by walls. Due to its curiosity, the mouse is motivated to explore the new surroundings but because of its avoidance behavior, it will try to evade the open, free center. Rodents could explore the area for 5 minutes while the camera was tracking the animal. The field was divided into 16 same-sized areas. Time spent in the inner fields was compared to the time spent in the peripheral fields.

\subsubsection{Novel object recognition}

The Novel-Object-Recognition test was conducted to analyze the learning and memory performance of mice. This test is based on the natural character of rodents to explore new objects preferably, compared to objects which are already familiar (Ennaceur 2010). Therefore, positive or negative conditioning is not necessary. The mouse was placed into a field with two equivalent objects for 5 minutes. 24 hours later the mouse was placed in the same area with the same objects again for 5 minutes. Afterward, the mouse was kept for minutes in its cage. For the third 5 minutes trial, one object was exchanged with a new distinctively different object. The camera system tracked the mouse movement and the dwelling time at both objects was recorded to calculate the recognition index.

$$
\text { Recognition index }=\frac{\text { Time on new object }}{(\text { time on new object }+ \text { time on old subject })}
$$




\subsubsection{Nest building}

In order to assess the general health and welfare of mice, their nest building capability was tested. Mice were held in single cages with standard litter and one paper towel without any other toys. After $24 \mathrm{~h}$ the nest was evaluated according to a 5 point scheme (Deacon 2006).

1. Nest material is almost untouched (>90\% intact) (1point)

2. Nest material is partially torn (50-90 \% intact) (2 points)

3. Nest material is mostly torn but no clear nesting place can be recognized. Less than 50 $\%$ is intact but less than $90 \%$ are in a particular area of the cage. (3 points)

4. Perceptible but flat nest. $90 \%$ of material is torn and in a specific cage area. Height of the nest is less than $50 \%$ of the body height of the mouse (4 Points)

5. (Almost) perfect nest. Minimum of $90 \%$ of material is torn and forms a crater, walls are higher than mouse height. (5 points)
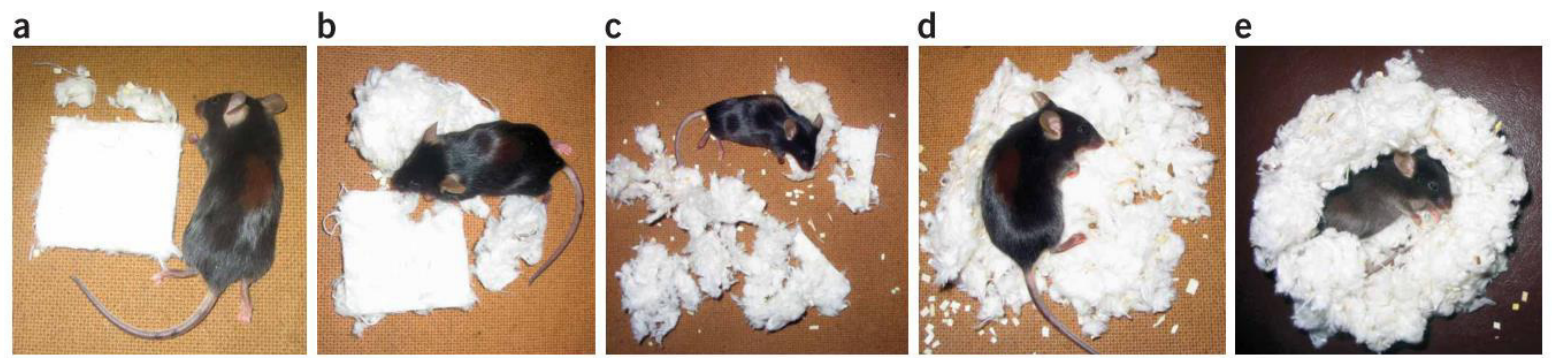

Figure 7: Scoring of nest building of mice.

Figure a-e display exemplary nests for the scoring from 1 to a maximum of 5 points (Deacon 2006).

\subsubsection{Statistical analysis}

For the statistical evaluation of the data, GraphPad Prism 6 was used. All data are expressed as mean \pm SEM. Statistical significance was calculated by nonparametric unpaired Student's ttest. Significant results were accepted as $* p<0.05, * * p<0.01$ and $* * * p<0.001$. 


\section{Results}

\subsection{Effect of alpha-Synuclein in SH-SY5Y Cells}

\subsubsection{Quantification of PrPC expression in SH-SY5Y and SH-SY5Y-PrP cells}

To analyze the influence of $\operatorname{PrP}^{\mathrm{C}}$ towards the aSyn uptake, two genetically distinct SH-SY5Y (SH WT) and SH-SY5Y PrP (SH PrP) cell lines were used in this study. SH cells exhibit a low endogenous expression of $\operatorname{PrP}^{\mathrm{C}}$ whereas SH PrP cells, stably transfected with PRNP for a constitutive overexpression of the prion protein, contained an approximately 5-fold up-regulation of $\operatorname{Pr} \mathrm{P}^{\mathrm{C}}$ expression (Weiss et al. 2010) (Figure 8).

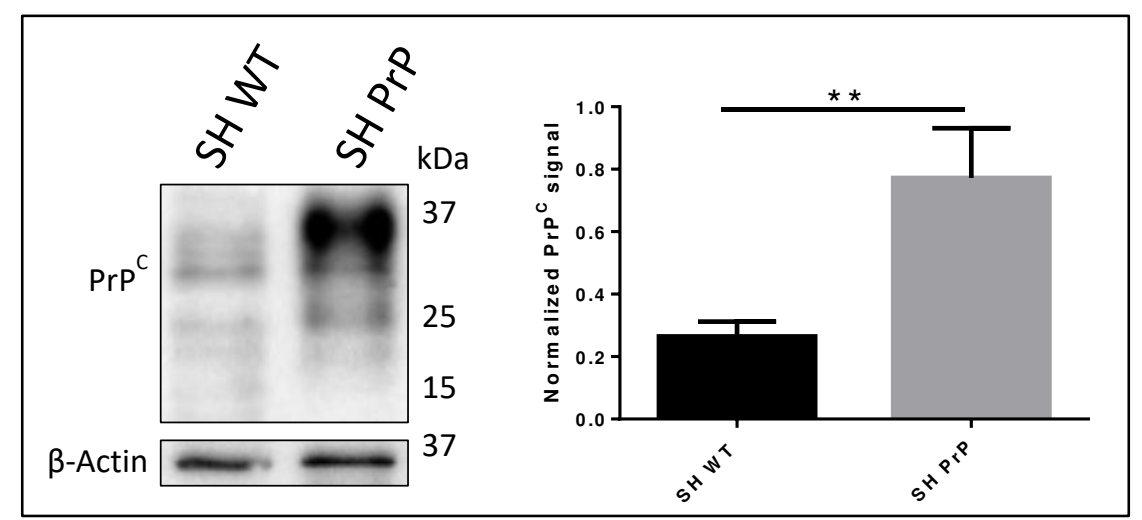

Figure 8: Expression level of $\mathrm{PrP}^{\mathrm{C}}$ in SH WT and SH PrP cells

Comparison of physiological PrPC expression level in SH WT and SH PrP cells. Western blot analysis showed an approximately 4 to 5 fold upregulation of PrPC level in SH PrP compared to SH WT cells. Data are presented as mean \pm SEM. Statistical analysis was performed by unpaired Student's t-test $\left({ }^{*} p<0,05 ;{ }^{* *} p<0,01 ; * * p<0,001\right)$.

\subsubsection{Characterization of monomeric and oligomeric alpha-synuclein}

Recombinantly produced monomeric and oligomeric aSyn were used for cell treatment to examine the $\operatorname{PrP}^{C}$ dependent internalization of both forms of aSyn. Figure 9 presents both isoforms in the Western blot analysis and TEM. Monomeric aSyn showed a band at $15 \mathrm{kDa}$. An additional SDS resistant aSyn dimeric intermediate was also detected at around $30 \mathrm{kDa}$. Oligomeric aSyn exhibits the same bands with a higher intensity in the upper bands. Examining both aSyn derivates by TEM oligomeric aSyn revealed a cluster formation compared to spherical shaped monomeric aSyn. 


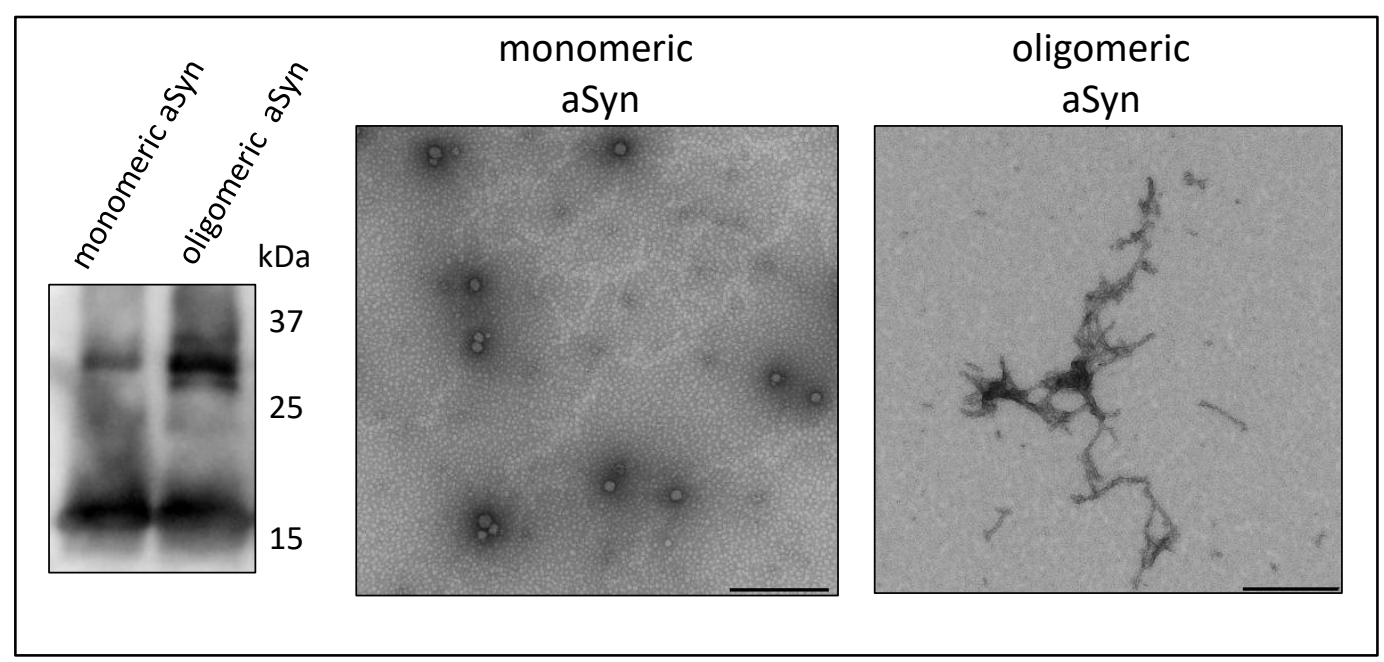

Figure 9: Differences of monomeric and oligomeric aSyn

Distinctions of aSyn isoforms show a higher amount of dimeric aSyn in oligomeric aSyn and a cluster-like structure in TEM compared to spherical monomeric aSyn. Scale bar in TEM represents 500nm.

\subsubsection{Treatment of SH-SY5Y cells with recombinant alpha-synuclein}

SH WT and SH PrP cell lines were treated with monomeric and oligomeric aSyn and analyzed by Western blot. Corresponding to the input, monomers could be detected at $15 \mathrm{kDa}$ and SDS resistant dimers at $30 \mathrm{kDa}$ (Figure 10). The signal intensity of monomeric aSyn bands (densitometrically quantified by Image $L a b$ ) did not show a significant difference applied to SH WT and SH PrP cells. SH WT cells, treated with oligomeric aSyn, displayed a comparable band intensity without a significant difference to the tested monomeric aSyn, while SH PrP cells revealed significantly higher levels of aSyn (monomeric and dimeric) (Figure 10). 

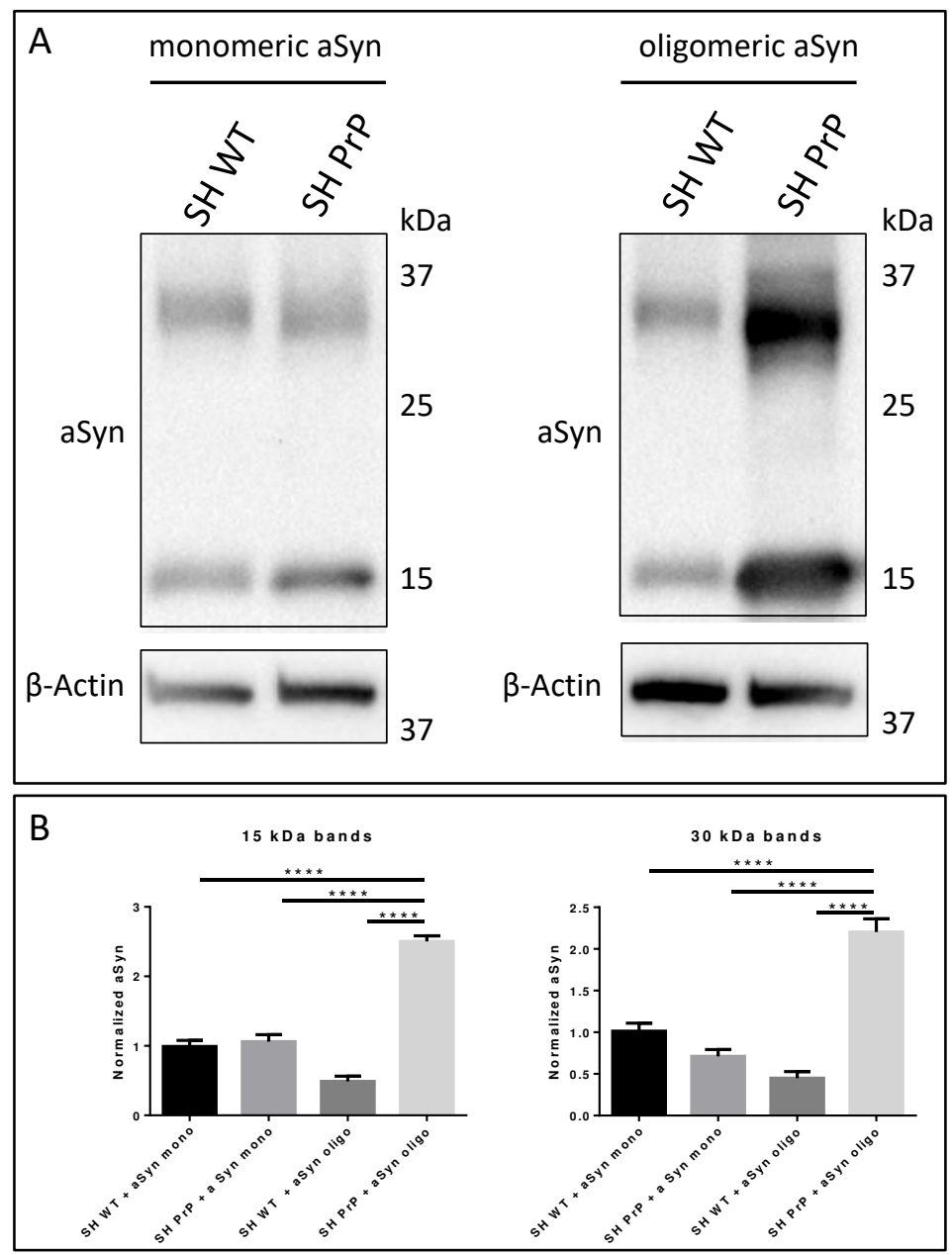

Figure 10: Comparison of monomeric and oligomeric aSyn treatment in SH WT and SH PrP cells

Treatment of SH cell lines with aSyn overnight with a concentration of $1 \mu \mathrm{M}$ A Western blot of SH and SH PrP cell lysates, treated with monomeric (left) and oligomeric (right) aSyn. B Statistic evaluation of the $15 \mathrm{kDa}$ bands (left) and $30 \mathrm{kDa}$ bands (right) in different groups. Oligomeric aSyn internalization was increased in SH PrP cells compared to SH WT. Data are presented as mean \pm SEM. Statistical analysis was performed by unpaired Student's ttest $\left({ }^{*} p<0,05 ;{ }^{* *} p<0,01 ;{ }^{* * *} p<0,001\right)$.

\subsubsection{Phosphorylation of alpha-synuclein after uptake in SH-SY5Y cell lines}

A well-known indication for pathogenic aSyn structures is an increased occurrence of phosphorylated p129 aSyn. In its physiological form, the p129 aSyn is only represented by approx. $4 \%$, whereas pathological aSyn can be increased by more than $90 \%$ (Oueslati 2016). Therefore, the level of phosphorylated aSyn was also tested in SH WT and SH PrP cells, after overnight treatment with monomeric or oligomeric aSyn $(1 \mu \mathrm{M})$. Phosphorylated aSyn was de- 
tected by the aSyn (phospho S129) antibody and exhibited a molecular weight of $15 \mathrm{kDa}$. Similar to total aSyn, p129 aSyn expression could be only observed in SH PrP cells treated with oligomeric aSyn. Other groups exhibited no detectable p129 aSyn (Figure 11).

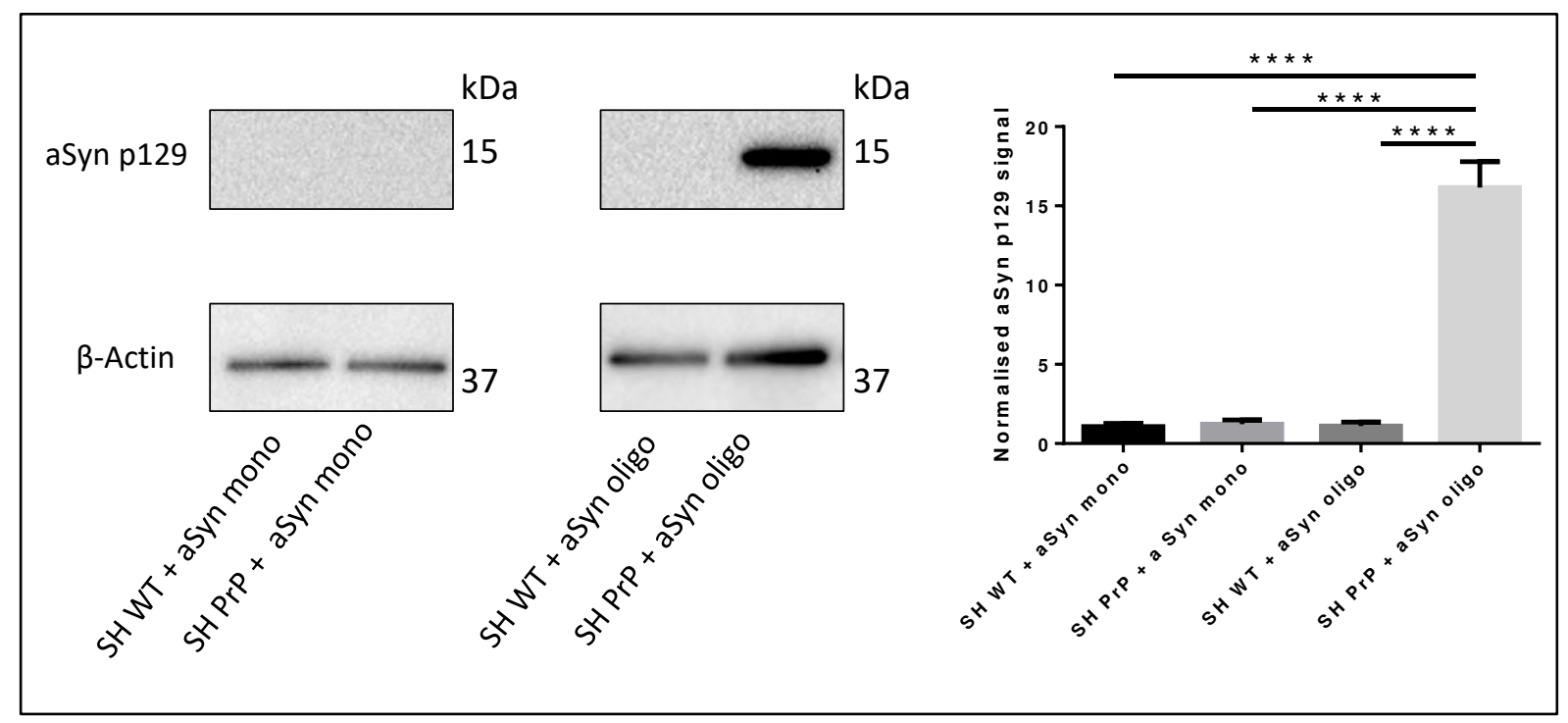

Figure 11: Phosphorylated aSyn in SH WT and SH PrP cells

SH WT and WH PrP cells were treated with monomeric or oligomeric aSyn. The detection of p129 aSyn has only exhibited a visible band for SH PrP cells treated with oligomeric aSyn. Data are presented as mean \pm SEM. Statistical analysis was performed by unpaired Student's t-test $\left({ }^{*} p<0,05 ;{ }^{* *} p<0,01 ;{ }^{* *} p<0,001 ;{ }^{* * * *} p<0,0001\right)$.

\subsubsection{Removal of membrane-bound $\operatorname{PrP}^{\mathrm{C}}$ by glimepiride}

For further analysis, SH PrP cells were treated with sulfonylurea glimepiride to generate a PrPC gradient on the membrane. This substance activates cell-specific phospholipases, destroying the $\mathrm{GPI}$ anchor of the $\mathrm{PrP}^{\mathrm{C}}$ and thereby releasing the membrane-bound prion protein (Bate et al. 2009). After $\operatorname{PrP}^{\mathrm{C}}$ was cleaved off, the cells were treated with the oligomeric aSyn. 


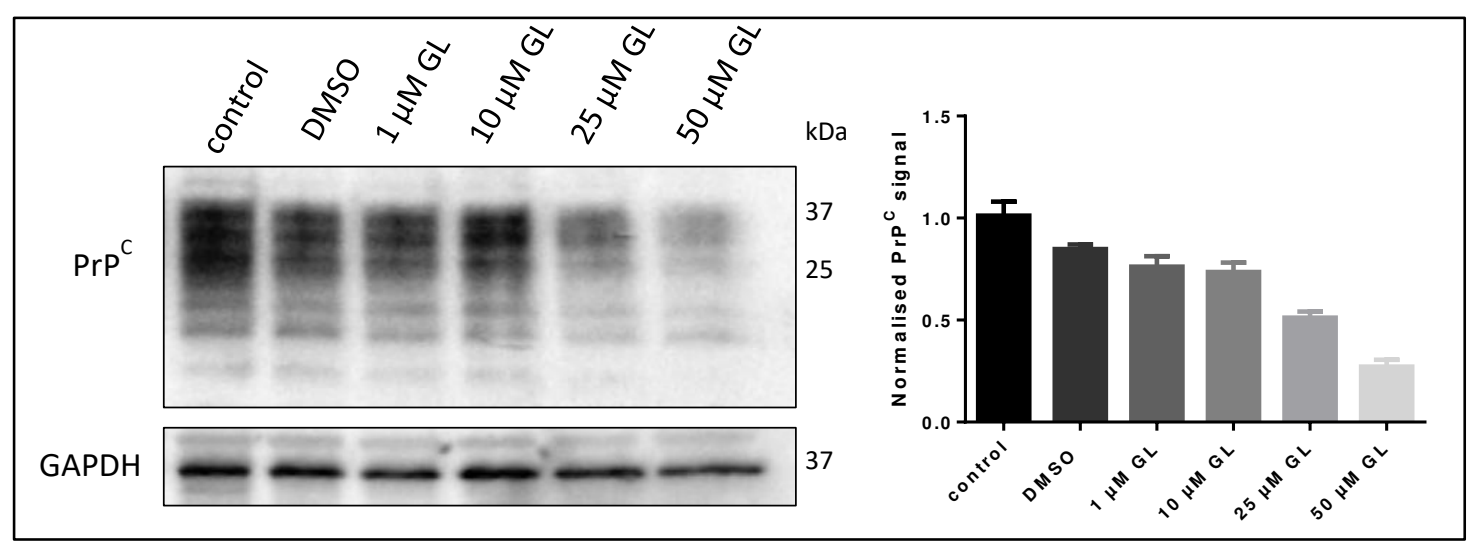

Figure 12: Reduction of GPI anchored $\mathrm{PrP}^{\mathrm{C}}$ in SH PrP cells after glimepiride treatment

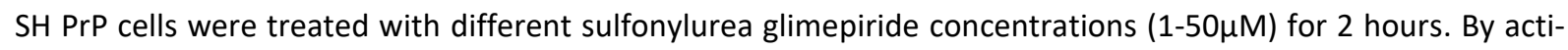
vating endogenous phospholipases the GPI anchor $\mathrm{PrP}^{\mathrm{C}}$ was cleaved and the protein released from the membrane. With increasing concentrations of glimepiride, a smaller amount of $\operatorname{PrP}^{\mathrm{C}}$ was detected on the Western blot. Data are presented as mean \pm SEM.

With an increasing amount of glimepiride, a concentration depended decrease of $\operatorname{PrPC}$ could be observed (Figure 12). DMSO was used as a solvent for glimepiride. Due to its toxicity, untreated cells and cells treated only with DMSO (without glimepiride) were included as controls. The detection of aSyn in Western blot analysis showed a decrease of monomeric as well as SDS resistant dimeric aSyn, correlating with the decrease of $\operatorname{PrP}^{\mathrm{C}}$. 


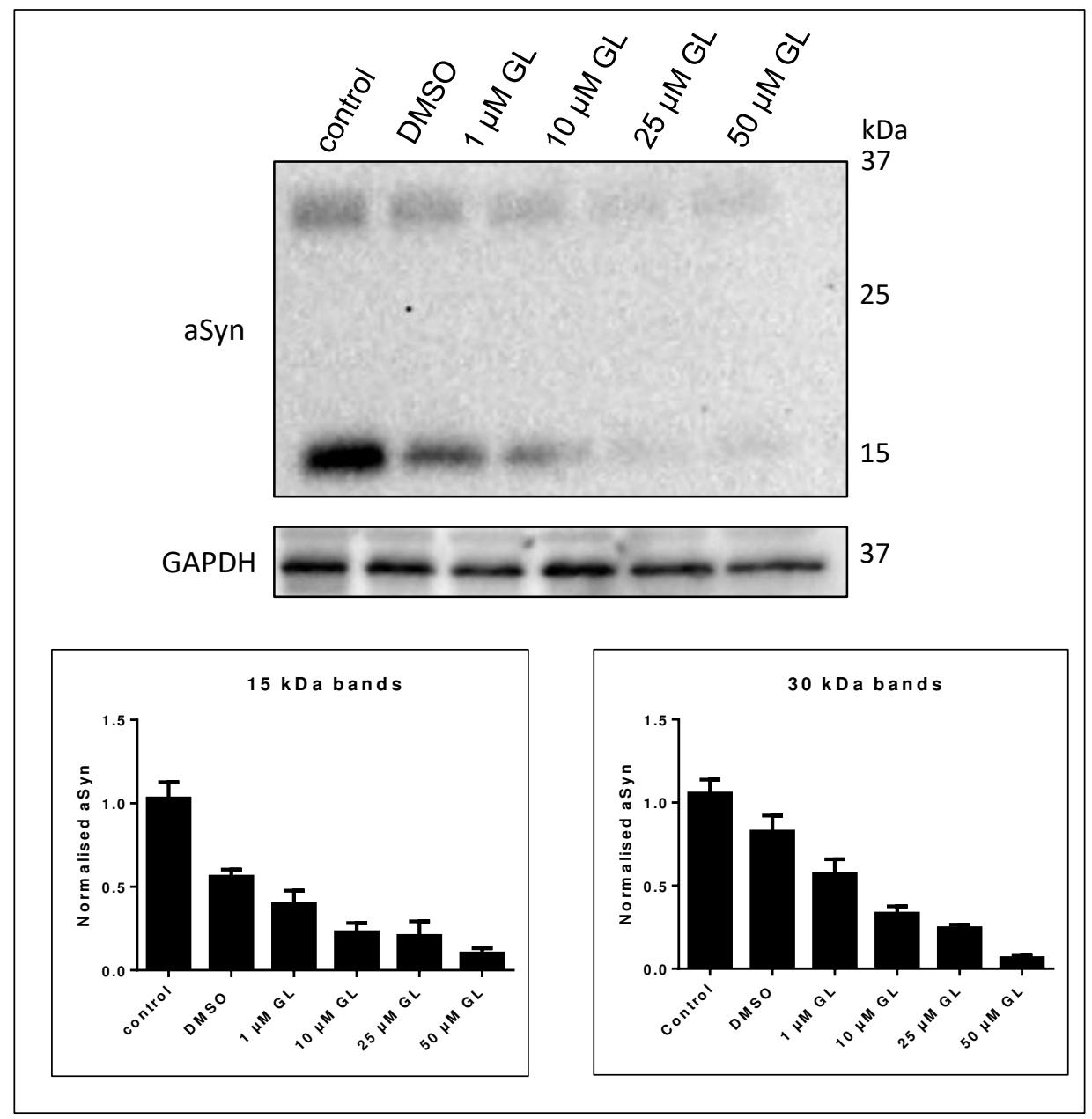

Figure 13: Gradual decrease of aSyn in correlation to $\mathrm{PrP}^{\mathrm{C}}$ concentration

After treating cells with glimepiride for 2 hours, cells were immediately incubated with oligomeric aSyn overnight. The decreasing amount of monomeric and dimeric aSyn detected in WB was in correlation with the gradual depletion of $\operatorname{PrP}^{\mathrm{C}}$. Data are presented as mean \pm SEM.

\subsubsection{Colocalization of alpha-synuclein and PrPC in SH-SY5Y cells}

In order to test a possible colocalization of $\mathrm{PrP}^{\mathrm{C}}$ and aSyn, SH WT and SH PrP cells were treated with monomeric and oligomeric aSyn $(1 \mu \mathrm{M})$ overnight. The fixed cells were immunostained for PrPC (SAF32), aSyn (MJFR1) and the nucleus was stained with DAPI. Considering that PrPC is mostly localized on the plasma membrane (Stahl et al. 1987) the homogeneous distribution of $\mathrm{PrP}^{\mathrm{C}}$ in SH WT cells is less cytosolic but more on the cell surface. For SH PrP cells an ubiquitous expression of $\operatorname{PrP}^{\mathrm{C}}$ can be observed, but also several areas of accumulated $\mathrm{PrP}^{\mathrm{C}}$ spots can be detected. Monomeric and oligomeric aSyn (stained in red with total aSyn MJFR1 antibody) were uniformly disseminated in SH WT cells. In SH PrP cells, spots of higher aSyn quantity could be detected which partially overlap with $\operatorname{PrP}^{\mathrm{C}}$ staining areas. 


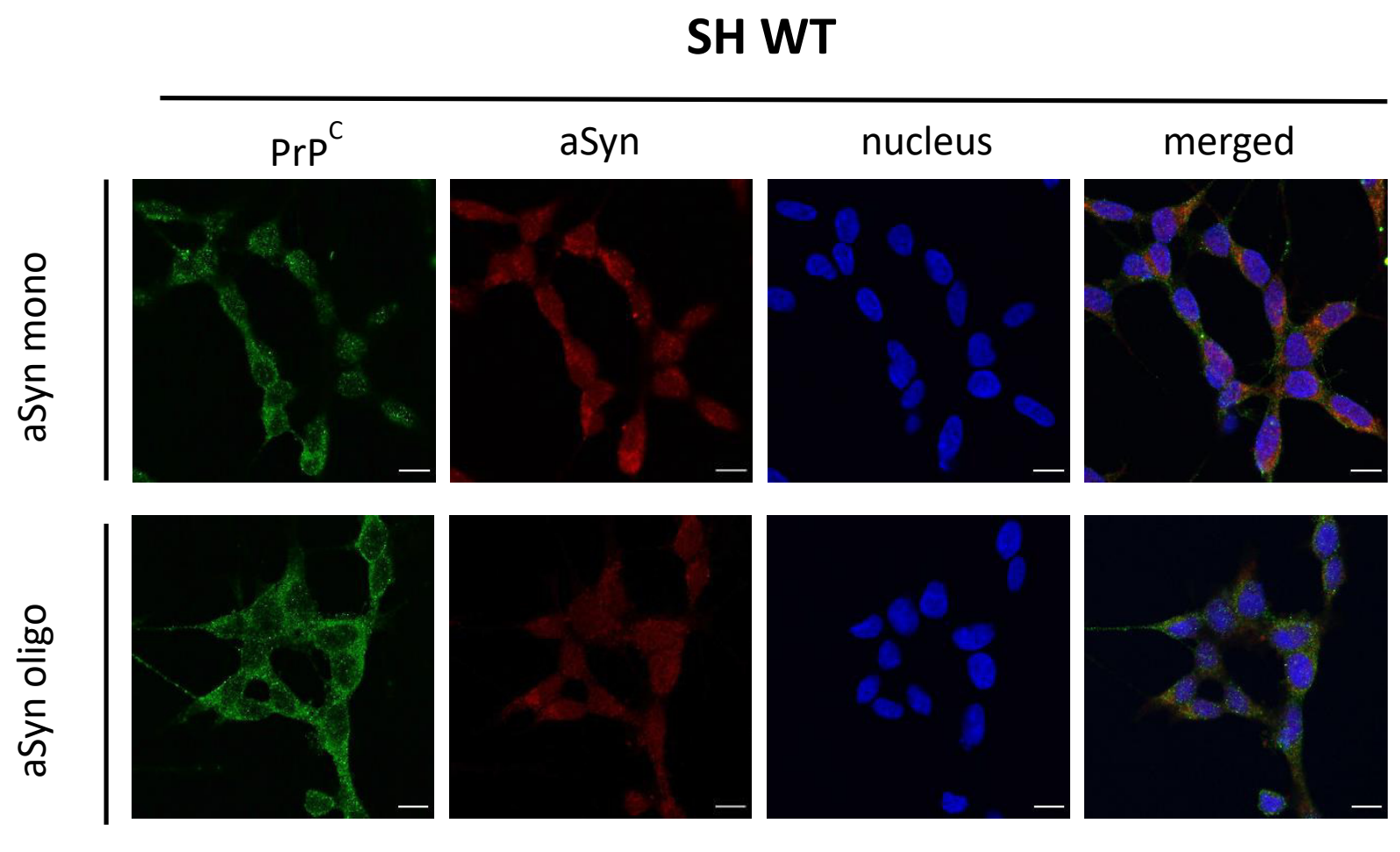

SH PrP

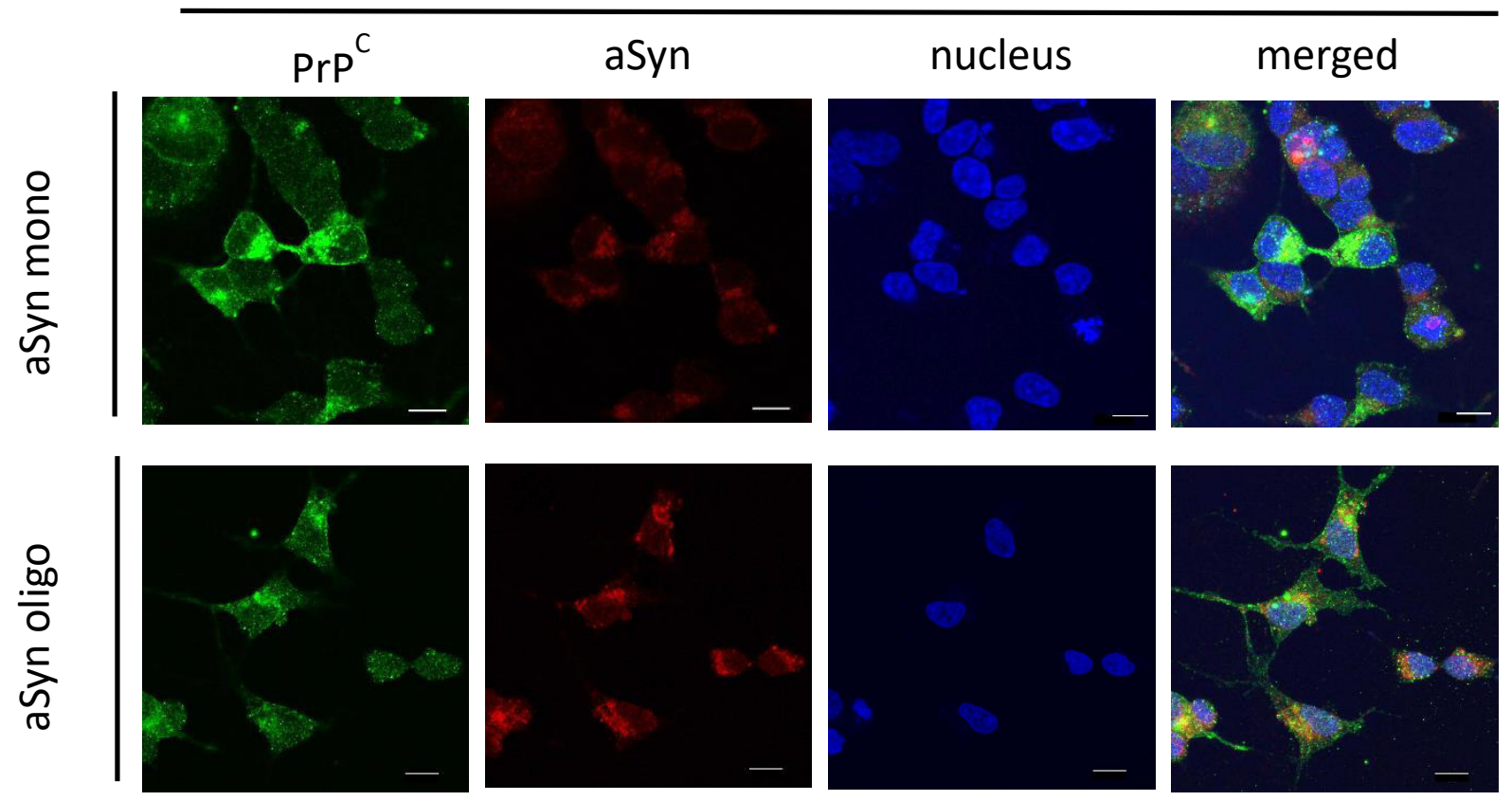

Figure 14: Co-localisation of PrPC and aSyn in SH WT and SH PrP cells

SH WT and SH PrP cells were treated with monomeric and oligomeric aSyn. Staining was performed for $\operatorname{PrPC}$ (green) and aSyn (red) and the nucleus (DAPI) showing the overlapping regions as colocalization in yellow. The scale bar represents $10 \mu \mathrm{m}$.

To quantify the colocalization intensity of aSyn and PrPC, the Manders' coefficient was calculated using the graphic software ImageJ. Since $\mathrm{PrPC}^{\mathrm{C}}$ is ubiquitously distributed on the cell membrane, the whole cell area was used to determine the coefficient. SH PrP cells treated with oligomeric aSyn showed a slightly higher colocalization coefficient of $52 \%$ compared to the other test conditions with $43-45 \%$. 


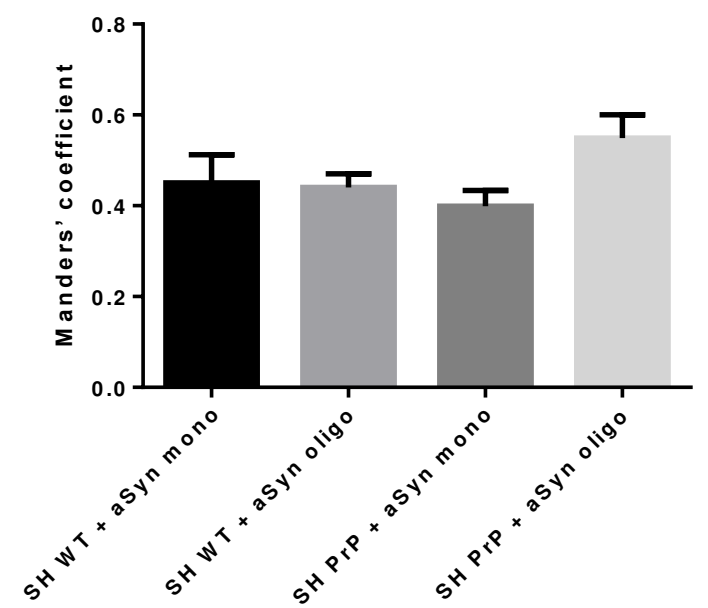

Figure 15: Colocalization of aSyn and PrPc

Colocalization of aSyn and PrPC was estimated by Mander's Colocalization Coefficient. SH PrP treated with aSyn oligo showed the highest colocalization $(n=25)$. Data are presented as mean \pm SEM. Statistical analysis was performed by unpaired Student's t-test $\left({ }^{*} p<0,05 ;{ }^{* *} p<0,01 ; * * * p<0,001 ;{ }^{* * * *} p<0,0001\right)$

\subsubsection{Localization of $\operatorname{PrP}^{\mathrm{C}}$ and alpha-synuclein in common cell com- partments after subcellular fractioning}

To gain information about the cellular localization of the internalized aSyn, SH WT and SH PrP cells were treated with oligomeric aSyn and separated into 4 different cellular compartments by using the Qproteome Cell Compartment Kit. We isolated the cytosolic, membranous, nuclear, and the cytoskeletal fraction from SH WT and SH PrP cells. The genetic modification of $\mathrm{SH} \operatorname{PrP}$ cells resulted in a higher amount of $\mathrm{PrPC}$, especially in the cytosolic and membrane fraction compared to SH WT cells. In the nuclear and cytoskeletal fraction, weak bands for $\operatorname{PrP}^{\mathrm{C}}$ could be detected (Figure $16 \mathrm{~A}, \mathrm{~B}$ ).

Analyzing aSyn localization, both cell lines incorporated the protein. $\operatorname{PrP}^{\mathrm{C}}$ overexpression was promoting the uptake of oligomeric aSyn into the cytosol. The simultaneous presence of both proteins in the cytosol could indicate a possible colocalization (Figure $16 \mathrm{~A}, \mathrm{~B}$ ). All fractions are shown with a compartment-specific loading control (Figure 16 C, D). 
SH WT
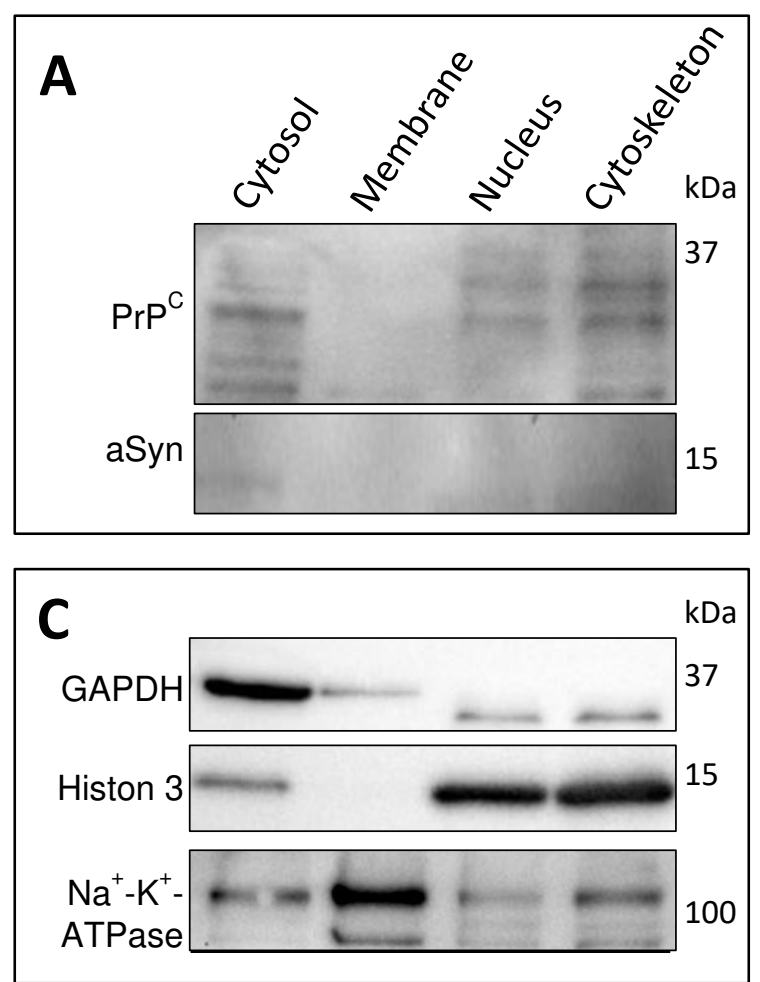

SH PrP
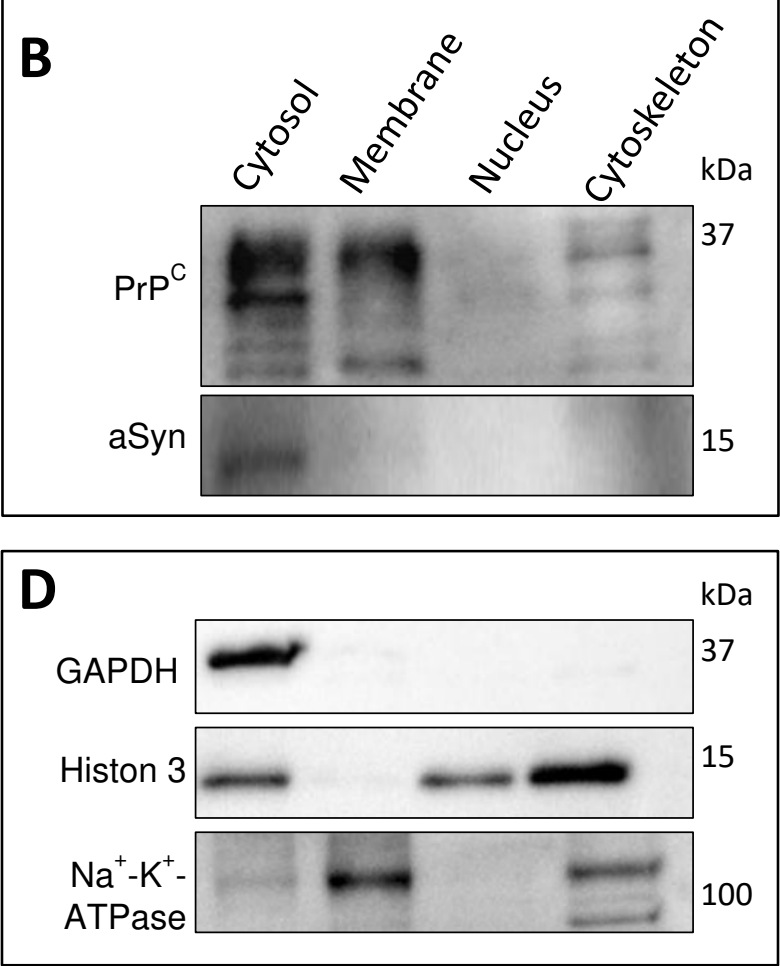

Figure 16: Analysis of cellular localization of $\operatorname{PrP}^{\mathrm{C}}$ and aSyn via cell fractionation

To evaluate a potential colocalization of aSyn and PrPC, SH WT and SH PrP cells were separated into 4 fractions (cytosol, membrane, nucleus, cytoskeleton) A showing endogenous $\mathrm{PrP}^{\mathrm{C}}$ expression of SH WT cells and a localization of aSyn in the cytosol. B shows elevated PrPC expression of SH PrP cells in the membrane and the cytosol, co-localized with aSyn in the cytosol. $\mathbf{C}$ and $\mathbf{D}$ represent the respective loading control for cell compartments.

\subsection{Direct interaction of alpha-Synuclein and PrPC}

In order to establish if $\mathrm{PrP}^{\mathrm{C}}$ can directly bind to aSyn, the possible interaction was examined via surface plasmon resonance spectrometry. Chimeric hamster-sheep prion protein was bound as ligand on a GLC chip at a concentration of $870 \mathrm{nM}$. After immobilizing the ligand human monomeric and oligomeric aSyn (357 nM) were applied. According to the detected curve, no interaction of chimeric $\mathrm{PrPC}^{\mathrm{C}}$ and human aSyn was observed (Figure 17). 


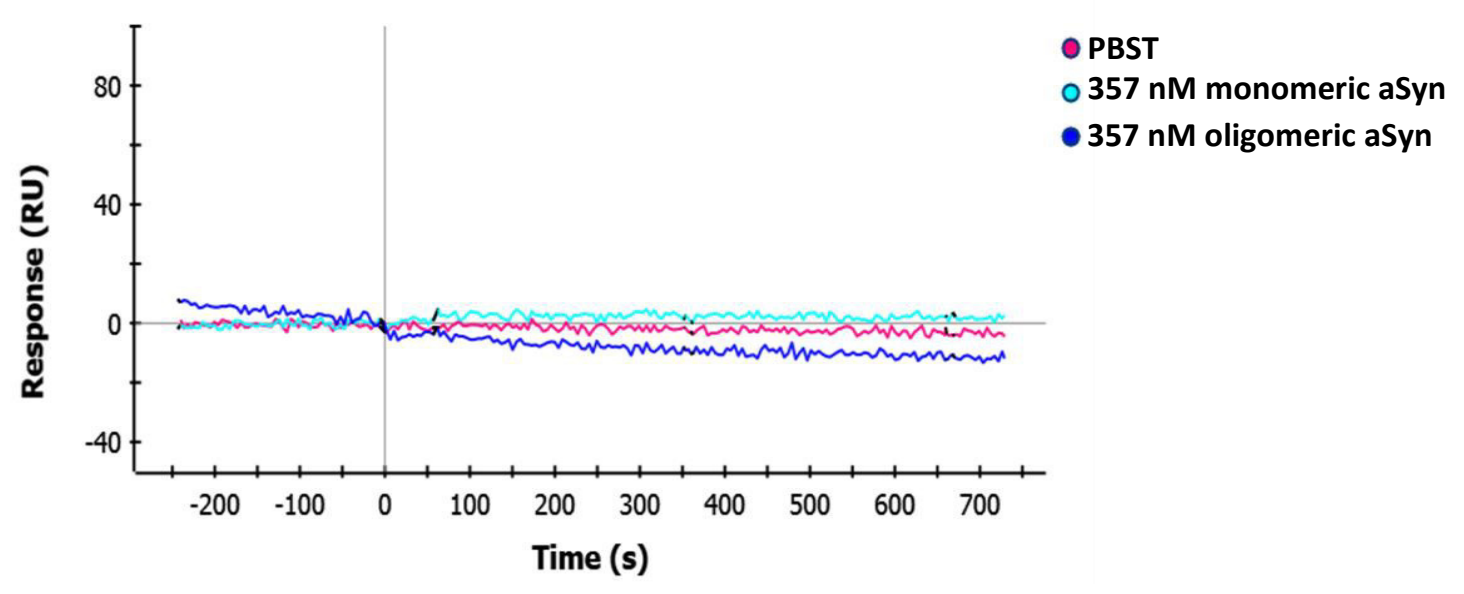

Figure 17: SPR Sensorgram of chimeric hamster-sheep $\operatorname{PrP}^{\mathrm{C}}$ and monomeric/oligomeric aSyn

Sensorgram shows chimeric hamster-sheep PrPC bound as ligand. Monomeric and oligomeric aSyn (357 nM) was injected as analytes. PBST was run as negative control.

In addition to chimeric prion protein, the human $\operatorname{PrPC}^{C}$ was also bound on the GLC chip at a concentration of $870 \mathrm{nM}$. After immobilization monomeric aSyn was applied with the same concentrations of $357 \mathrm{nM}$ and $714 \mathrm{nM}$. For the evaluation, the 1:1 Langmuir model was used to calculate the equilibrium constant $\left(K_{D}\right)$ value of $2.39 \mathrm{nM}$ (Figure 18) which is characteristic for the binding affinity. To reference the curves an empty flow cell on the chip was used to run the sample combined with the provided option of interspot reference of the ProteOn 36.

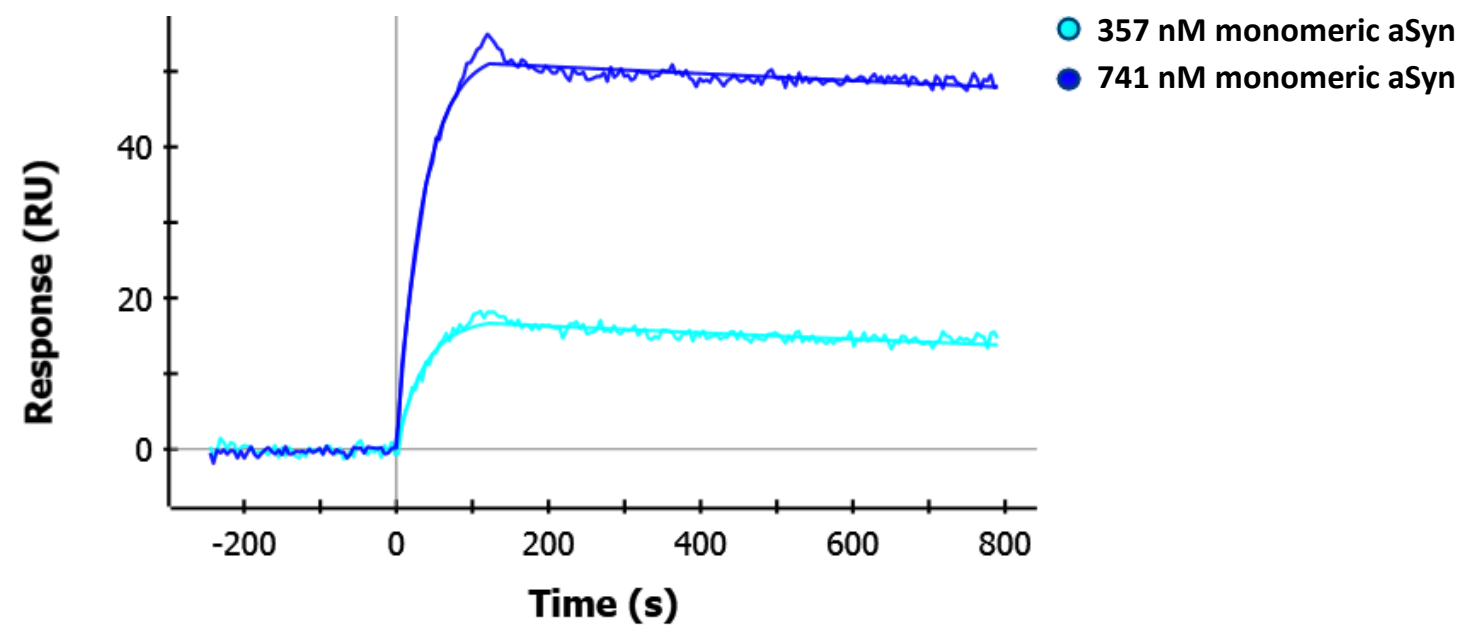

Figure 18: SPR Sensorgram of human PrPC and monomeric aSyn

The sensorgram shows human $\mathrm{PrP}^{\mathrm{C}}$ bound as ligand. Monomeric aSyn ( $357 \mathrm{nM}$ and $714 \mathrm{nM}$ ) was injected as an analyte. For fitting 1:1 Langmuir was used.

After regenerating the ligand with $0.85 \%$ phosphoric acid, the same $\operatorname{PrP}^{\mathrm{C}}$ Ligand was used to test the binding of oligomeric aSyn. The protein was applied in two concentrations (714 nM 
and $1428 \mathrm{nM}$ ) (Figure 19). The Bivalent analyte model was used as fitting model since oligomeric aSyn is of higher complexity than monomeric aSyn with a multitude of aSyn molecules providing more than one binding site. The resulting $\mathrm{K}_{\mathrm{D}}$ was $3.7 \mathrm{nM}$. The individual association and dissociation constants are listed in Table 11 , stated as $k_{a}$ and $k_{d}$.

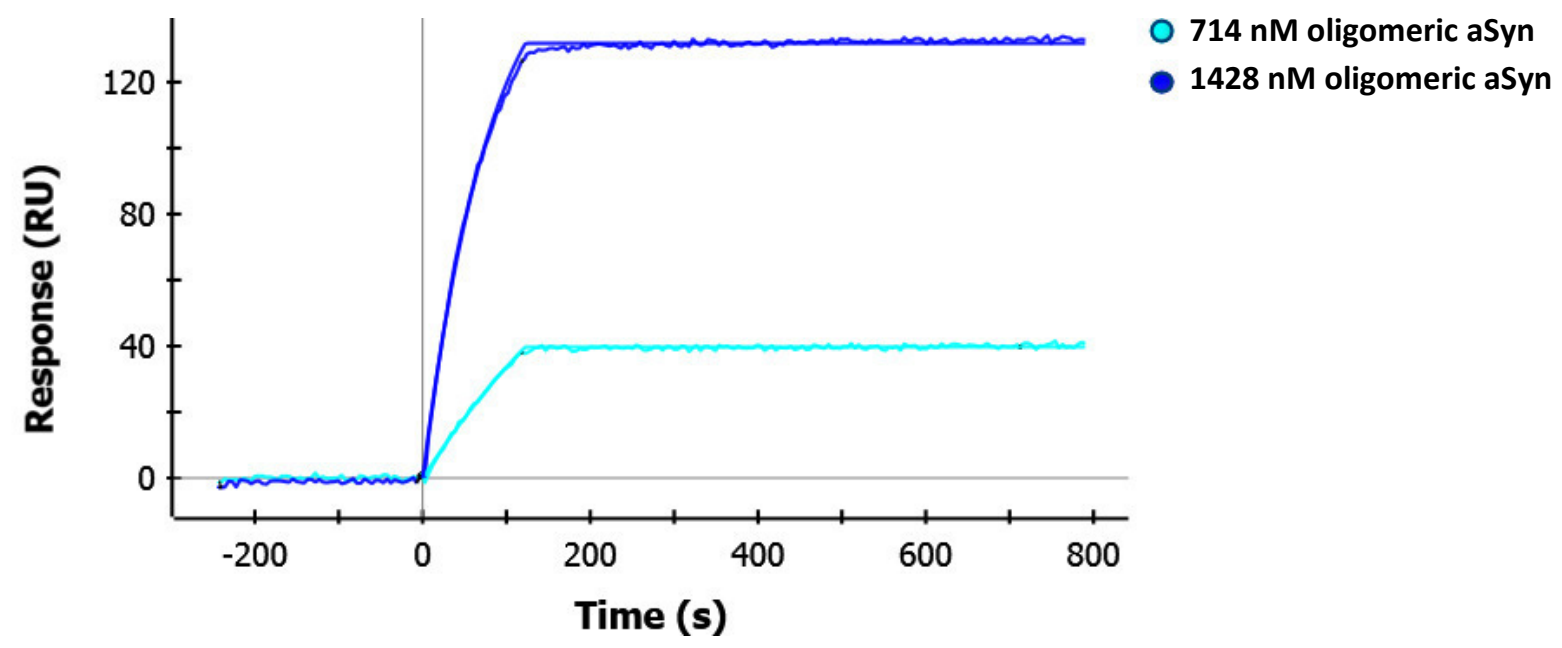

Figure 19: SPR Sensorgram of human $\operatorname{PrP}^{\mathrm{C}}$ and oligomeric aSyn

The sensorgram shows PrPC bound as ligand. Monomeric aSyn (357 nM and $714 \mathrm{nM}$ ) was injected as analyte. For fitting the bivalent analyte model was used.

Table 11: Overview of measured binding values in SPR

\begin{tabular}{|l|r|r|r|r|r|}
\hline & \multicolumn{1}{|c|}{$\mathrm{k}_{\mathrm{a}}$} & \multicolumn{1}{c|}{$\mathrm{k}_{\mathrm{a}}$ (error) } & \multicolumn{1}{c|}{$\mathrm{k}_{\mathrm{d}}$} & \multicolumn{1}{c|}{$\mathrm{k}_{\mathrm{d}}$ (error) } & \multicolumn{1}{c|}{$\mathrm{K}_{\mathrm{D}}$} \\
\hline monomeric aSyn & $7,62 \mathrm{E}+04$ & $2,20 \mathrm{E}+03$ & $2,82 \mathrm{E}-04$ & $1,17 \mathrm{E}-05$ & $3,70 \mathrm{E}-09$ \\
\hline oligomeric aSyn & $3,91 \mathrm{E}+04$ & $4,53 \mathrm{E}+02$ & $9,36 \mathrm{E}-05$ & $4,48 \mathrm{E}-06$ & $2,39 \mathrm{E}-09$ \\
\hline
\end{tabular}

Altogether, our SPR analyses indicated monomeric and oligomeric aSyn as direct interaction partners of $\mathrm{PrP}^{\mathrm{C}}$, whereat oligomeric aSyn showed a higher binding affinity to PrPC than monomeric aSyn. 


\subsection{In vivo studies of PrPC-mediated toxicity indicated by al- tered biochemical properties and behavioral deficits}

Synucleinopathies do not occur naturally in rodents. Since no mouse model is able to recreate all the typical characteristics of PD, several mice models have been created to reproduce the different toxic effects of pathological aSyn. In this work, two different mouse lines have been used (ThySyn and Tgm83) to examine the effect of $\operatorname{PrP}^{\mathrm{C}}$ on diseases associated with aSyn. These lines are substantially distinctive in their genomic design. Tgm83 mice include a murine $\mathrm{PrPC}^{\mathrm{C}}$ promoter for the expression of mutated A53T aSyn whereas the ThySyn mouse line contains a Thy 1 promoter controlling the expression of WT aSyn. Therefore, different traits of synucleinopathies are covered in these mice models. Both mouse lines were crossed with the PrP-KO mouse line (Zurich 1) to generate two new double transgenic TgmPrPOO and ThySynPrP00 mice lines.

\subsubsection{Comparison of the expression level of alpha-synuclein in Tgm83 mice in dependence from PrPC}

To determine if $\operatorname{PrP}^{C}$ can influence the expression level of transgenic human aSyn in Tgm83 mice, the mouse line was genetically modified. A second line with a PrPC-Knockout (PrP-KO) was crossed with Tgm83 mice. This resulted in the double transgenic mouse line TgmPrP00 which possesses the mutated A53T transgenic aSyn combined with the prion protein knockout. Various age groups (3, 9 and 18 months) were analyzed by Western blotting to assess a possible difference in aSyn levels throughout the pathogenesis. The total human aSyn expression in Tgm83 and TgmPrP00 brains homogenates was compared for each age group. The knockout of PrPC in TgmPrPOO mice did not significantly alter the overall level of human aSyn significantly compared to Tgm83 mice (Figure 20). 

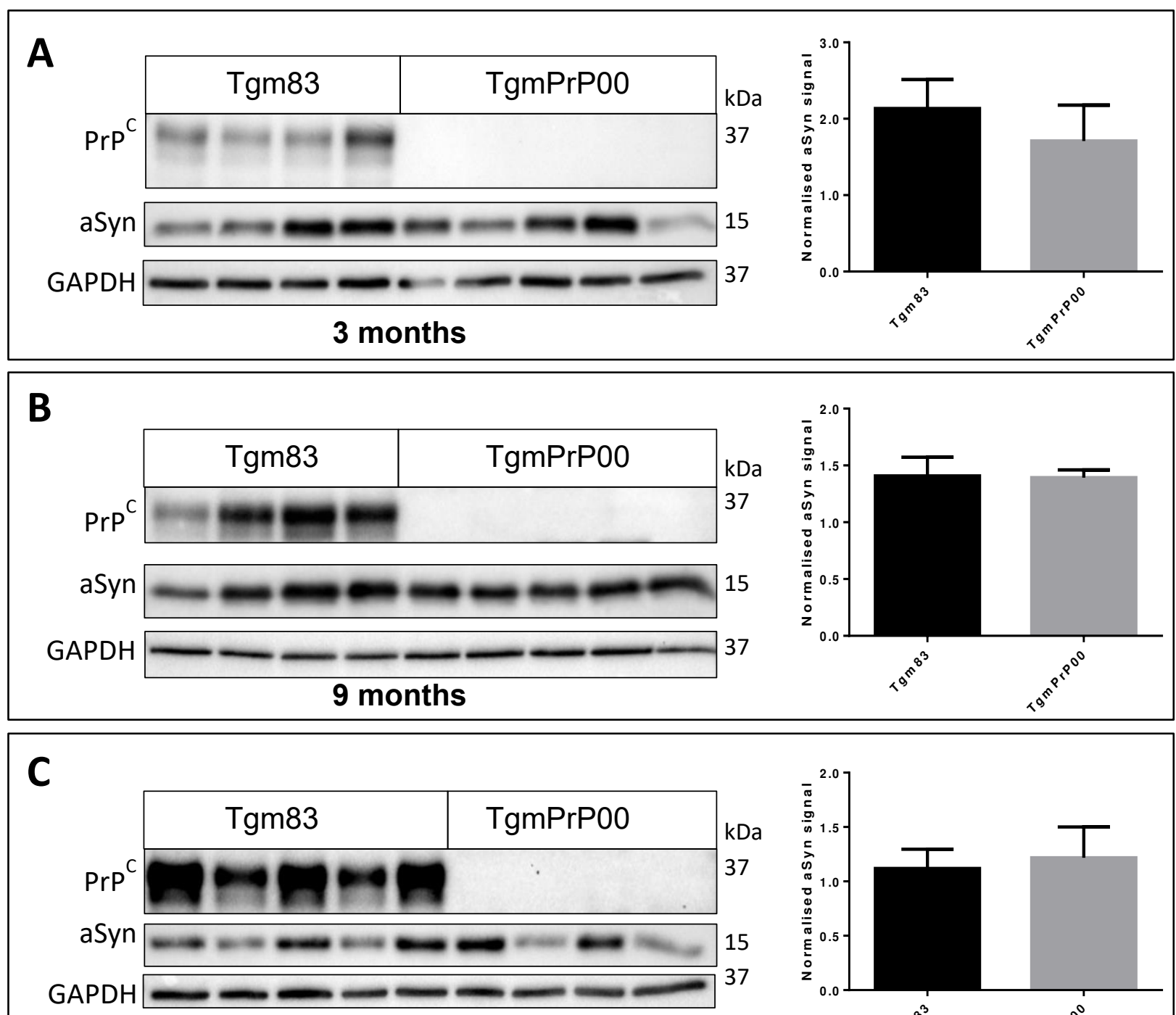

18 months

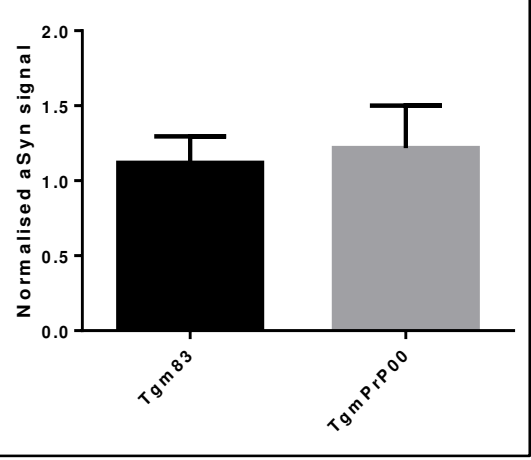

Figure 20: Expression of aSyn in Tgm83 and TgmPrP00 at different ages

Expression levels of 3, 9 and 18 months old Tgm83 and TgmPrP00 mice were tested by Western blot analysis. Blots were normalized with the house-keeping gene GAPDH. All age groups did not show a significant difference in aSyn expression depending on $\mathrm{PrP}^{\mathrm{C}}$. Statistical analysis was performed by unpaired Student's t-test. Data are presented as mean \pm SEM.

\subsubsection{Analysis of total and oligomeric aSyn in Tgm83 and TgmPrP00 brains via ELISA}

Additionally to Western Blot analysis, brain samples were age-matched and aSyn level was quantified by Enzyme-linked Immunosorbent Assay (ELISA). The concentration of total aSyn and oligomeric aSyn was measured by a specific ELISA acquired from Euroimmun/ADx. Detection of total aSyn in mice did not show any differences neither after 9 months (Tgm83) (764.6 
$\pm 37.89 \mu \mathrm{g} / \mathrm{ml})$ and TgmPrP00 $(773.2 \pm 48.35 \mu \mathrm{g} / \mathrm{ml})$ nor after 18 months (Tgm83 (611.7 \pm $42.63 \mu \mathrm{g} / \mathrm{ml})$ and TgmPrP00 (662.4 $\pm 32.73 \mu \mathrm{g} / \mathrm{ml}$ ) (Figure 21).

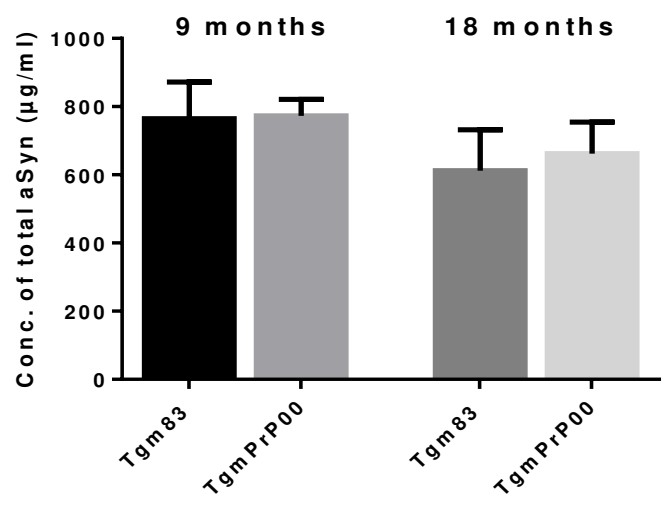

Figure 21: Measurement of total aSyn levels in Tgm83 and TgmPrP00 mice

Comparison of the total amount of aSyn in Tgm83 and TgmPrp00 of 9 and 18 months old mice $(n=8)$. Minor changes in the expression level of aSyn can be seen within the same age group. A slight decrease of aSyn occured in older mice. Statistical analysis was performed by unpaired Student's t-test. Data are presented as mean \pm SEM.

An important characteristic of pathological aSyn is the progressive oligomerization of the protein, therefore the brain samples have been analyzed additionally with an oligomer specific ELISA (Figure 22). At the age of 9 months, Tgm83 $(40.25 \pm 5.574 \mathrm{pg} / \mathrm{ml})$ had a similar amount of oligomeric aSyn compared to TgmPrP00 (45.62 $\pm 8.802 \mathrm{pg} / \mathrm{ml})$. With 18 months, Tgm83 showed a stronger increase of oligomeric aSyn $(82.63 \pm 25.21 \mathrm{pg} / \mathrm{ml})$ compared to TgmPrP00 $(57.84 \pm 15.25 \mathrm{pg} / \mathrm{ml})$. In other words, the PrP-KO mouse line showed a slightly lower tendency (not significant) to form transgenic oligomeric aSyn though both mouse lines had an increased concentration of the protein with ongoing age. 


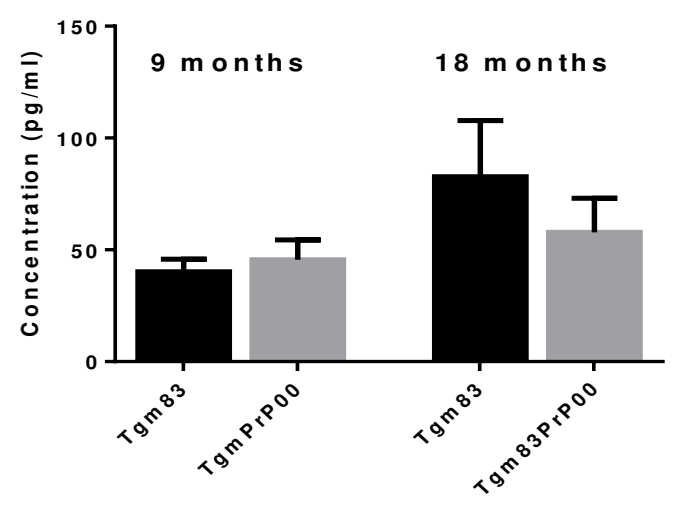

Figure 22: Oligomeric aSyn in Tgm83 and TgmPrP00 mice

Comparison of oligomeric aSyn in Tgm83 and TgmPrp00 of 9 and 18 months old mice $(n=8)$. Oligomeric aSyn at 9 months in both mice lines is within the same range. At 18 months a stronger increase of oligomeric aSyn occurred in Tgm83 compared to TgmPrP00. Statistical analysis was performed by unpaired Student's t-test. Data are presented as mean \pm SEM.

\subsubsection{Analysis of phosphorylated alpha-synuclein levels in connection with PrPC expression}

Phosphorylation is a major hallmark of pathogenic aSyn, therefore phosphorylation levels were compared between Tgm83 and TgmPrP00 at 3, 9 and 18 months of age (Figure 23). Similar to the total aSyn concentration, the amount of phosphorylated aSyn129 was not significantly changed in any of the tested age groups. 

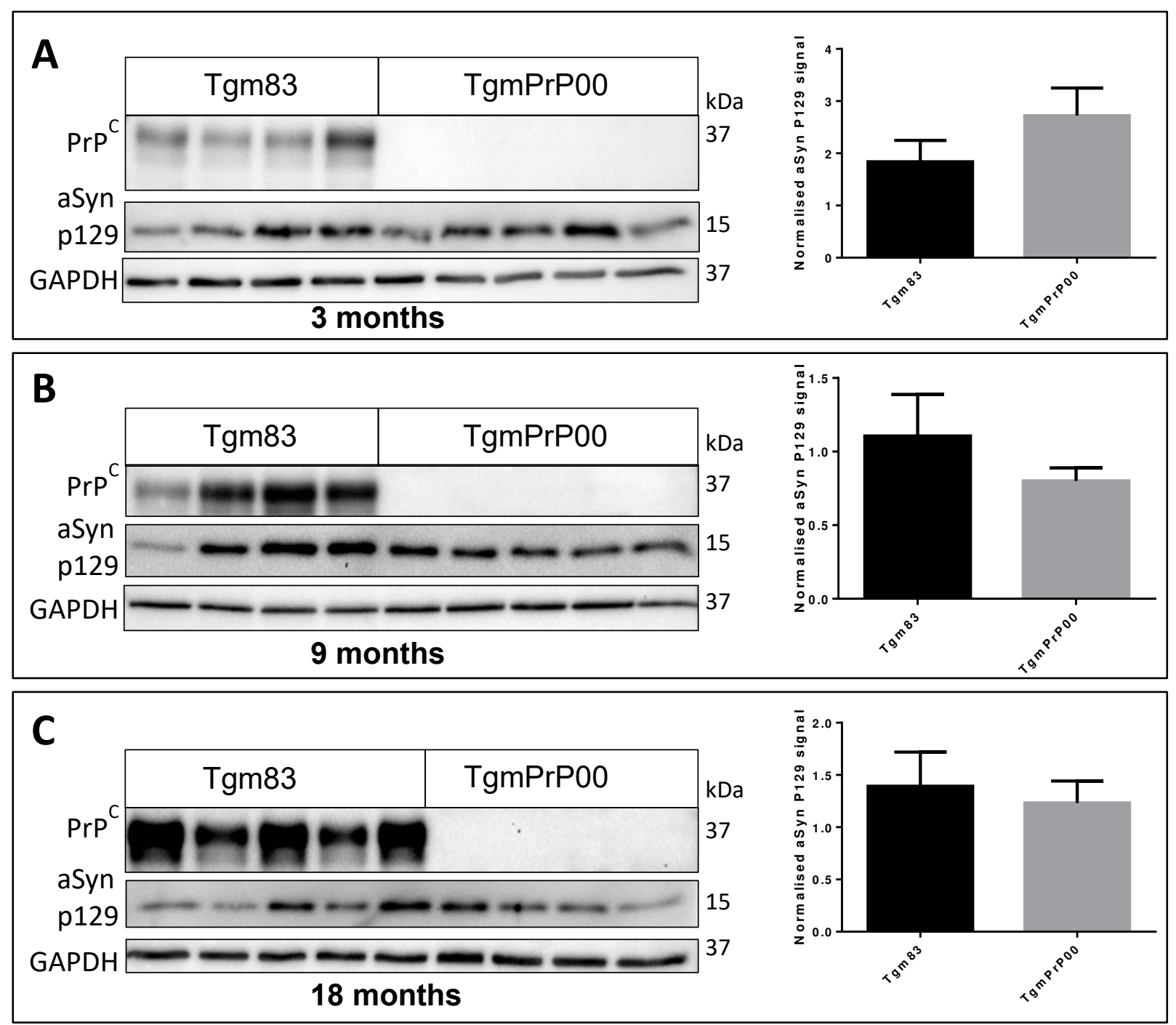

Figure 23: Phosphorylation level of S129 of aSyn in Tgm83 and TgmPrP00 mice

The expression level of p129 aSyn in 3, 9 and 18 months old mice of Tgm83 and TgmPrP00. Statistical analysis was performed by unpaired Student's t-test. Data are presented as mean \pm SEM.

\subsubsection{Analysis of alpha-synuclein characteristics in ThySyn and Thy- SynPrP00 mice}

As a second mouse model, ThySyn mice have been used to expand the insights of the PrP-KO, affecting the pathogenesis of transgenic aSyn. ThySyn mice contain wildtype PrPC and the additional gene construct of wildtype human aSyn gene under the control of a strong Thy1 promotor causing an upregulation of aSyn level. They were compared to the ThySynPrP00 mouse line containing the PrP-KO and the transgenic aSyn. In addition to the total aSyn and phosphorylated aSyn129, the phosphorylation site S87 and Y125 were also tested in Western blot 
analysis. In conformity with Tgm83 and TgmPrP00, the amount of total and S129 phosphorylated aSyn was not significantly changed in ThySyn compared to ThySynPrP00 mice. The regulation of the additionally tested phosphorylation site Y125 was also not changed and S87 was not detectable (Figure 24).

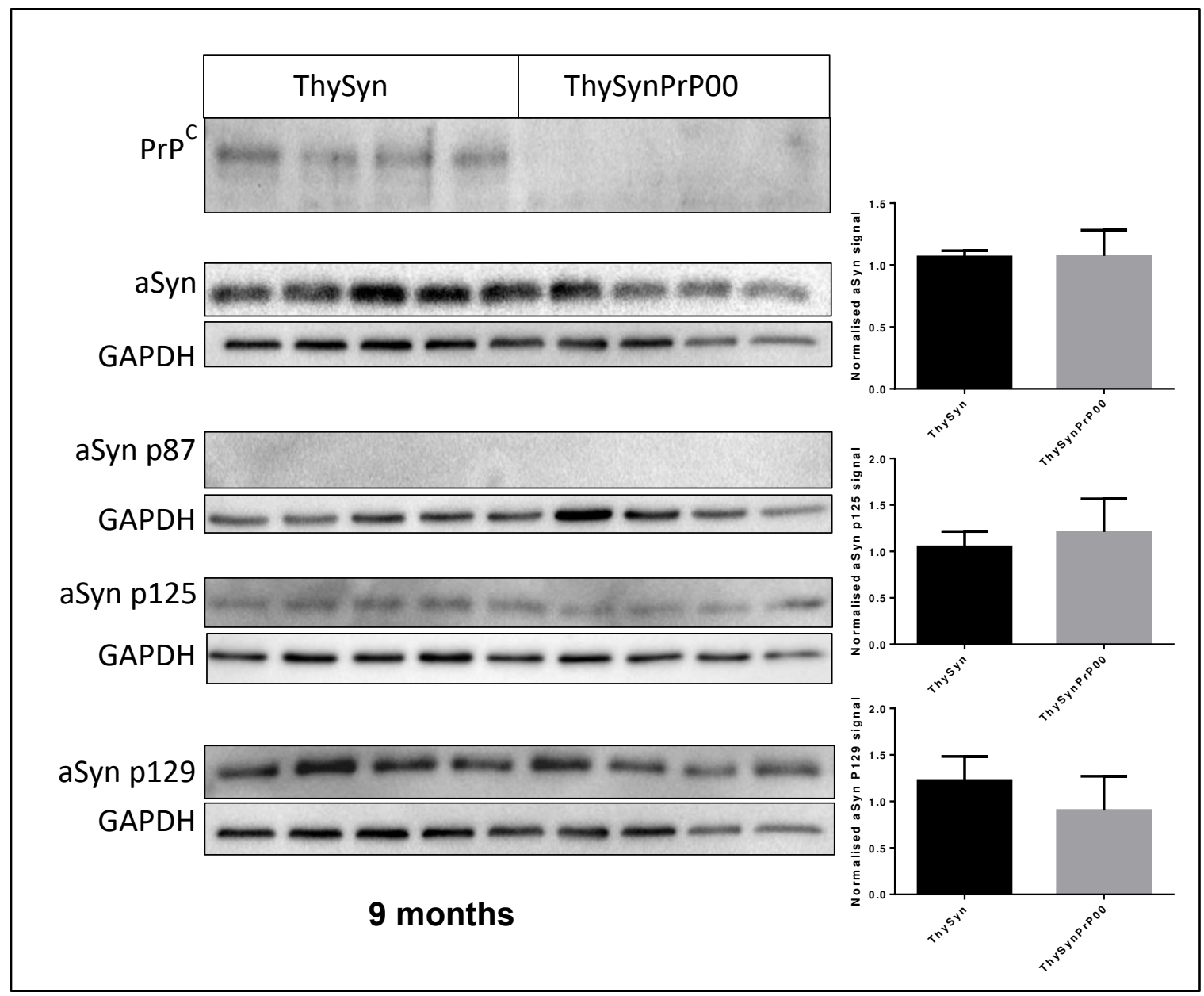

Figure 24: Comparison of total aSyn and varying phosphorylation sites (s87, s125 and s129) of aSyn in ThySyn and ThySynPrP00 mice

The expression level of total ThySyn and ThySynPrP00 showed no significant difference. Phosphorylated S87 aSyn could not be detected and S125 aSyn did also not deviate significantly. The mice were 9 months old. Statistical analysis was performed by unpaired Student's t-test. Data are presented as mean \pm SEM.

\subsubsection{ELISA of total and oligomeric alpha-Synuclein in ThySyn and Thy- SynPrP00}

The concentration of total and oligomeric aSyn was determined for ThySyn and ThySynPrP00 mice at an age of 9 months with a sample size of $n=8$. In case of total aSyn no significant difference between ThySyn $(44,64 \pm 0,9184 \mu \mathrm{g} / \mathrm{ml})$ and ThySynPrP00 $(42,22 \pm 3,918 \mu \mathrm{g} / \mathrm{ml})$ was detectable. With oligomeric aSyn the value for ThySyn $(139,6 \pm 59,06 \mu \mathrm{g} / \mathrm{ml})$ was almost twice 
as high as for ThySynPrPOO $(77,51 \pm 52,54 \mu \mathrm{g} / \mathrm{ml})$. The PrP-KO did not influence the total expression level of the protein. The decrease in oligomeric aSyn in ThySynPrP00 was not significant.

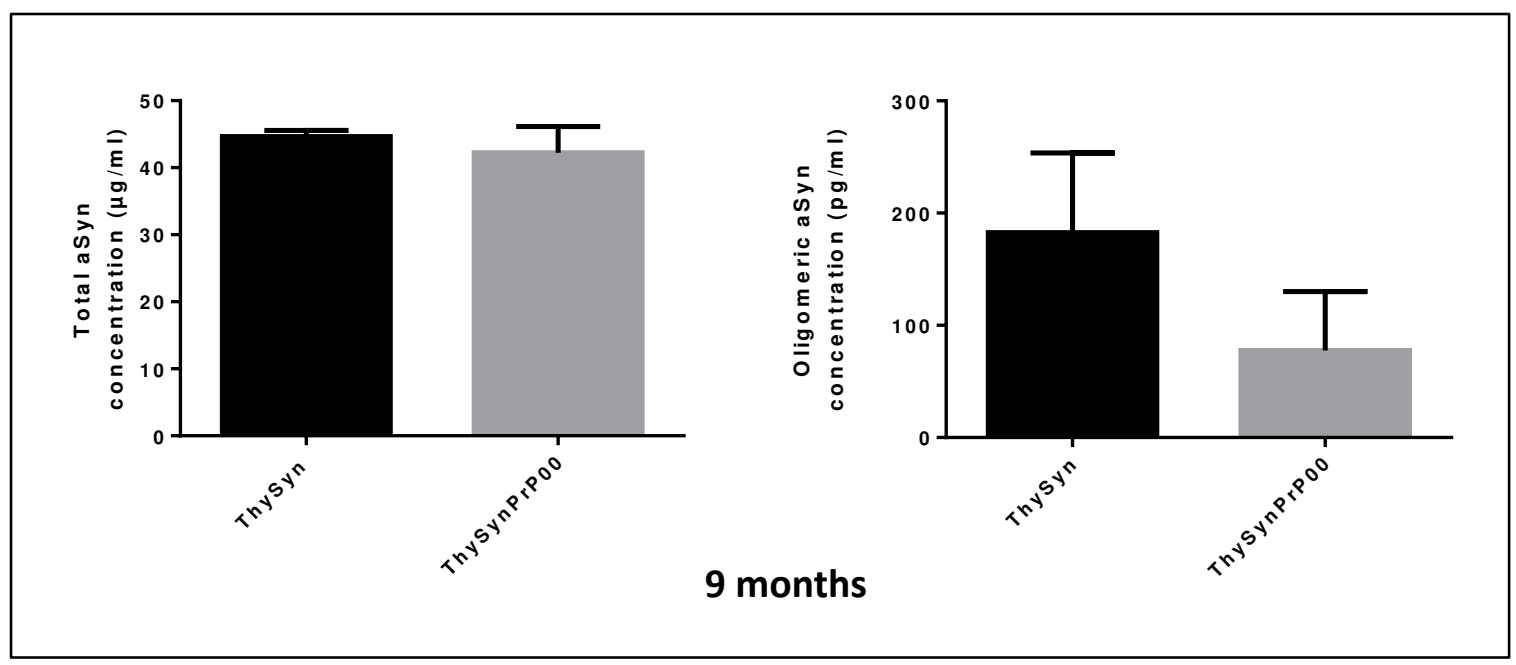

Figure 25: ELISA of total and oligomeric aSyn of ThySyn and ThySynPrP00 mice

Age-matched, 9 months old ThySyn and ThySynPrP00 were compared for total and oligomeric aSyn. There was no difference in total aSyn. ThySynPrP00 showed less amount of oligomeric aSyn compared to ThySyn mice $(n=10)$. Statistical analysis was performed by unpaired Student's t-test. Data are presented as mean \pm SEM.

\subsection{Subcellular fractioning of aSyn and PrPc in ThySyn and ThySynPrP00}

Brain homogenates obtained from ThySyn and ThySynrP00 mice were fractionated and four individual cytosolic, membranous, nucleus and cytoskeletal compartments were isolated (Figure $26 \mathrm{~A}-\mathrm{D})$. $\operatorname{PrP}^{\mathrm{C}}$ could be detected in the membrane and nuclear fraction of ThySyn mice, whereas PrPC was not expressed in ThySynPrP00 mice. In both lines, transgenic aSyn could be detected in the cytosolic and in the membrane fraction. The major amount of aSyn in ThySyn mice was expressed in the membrane fraction unlike in ThySynPrP00 mice, which contained the major amount of aSyn in the cytosol (Figure $26 \mathrm{~A}, \mathrm{~B}$ ). To confirm the isolation of the compartments, suitable markers have been used as a loading control (Figure 26 C, D). 


\section{ThySyn}
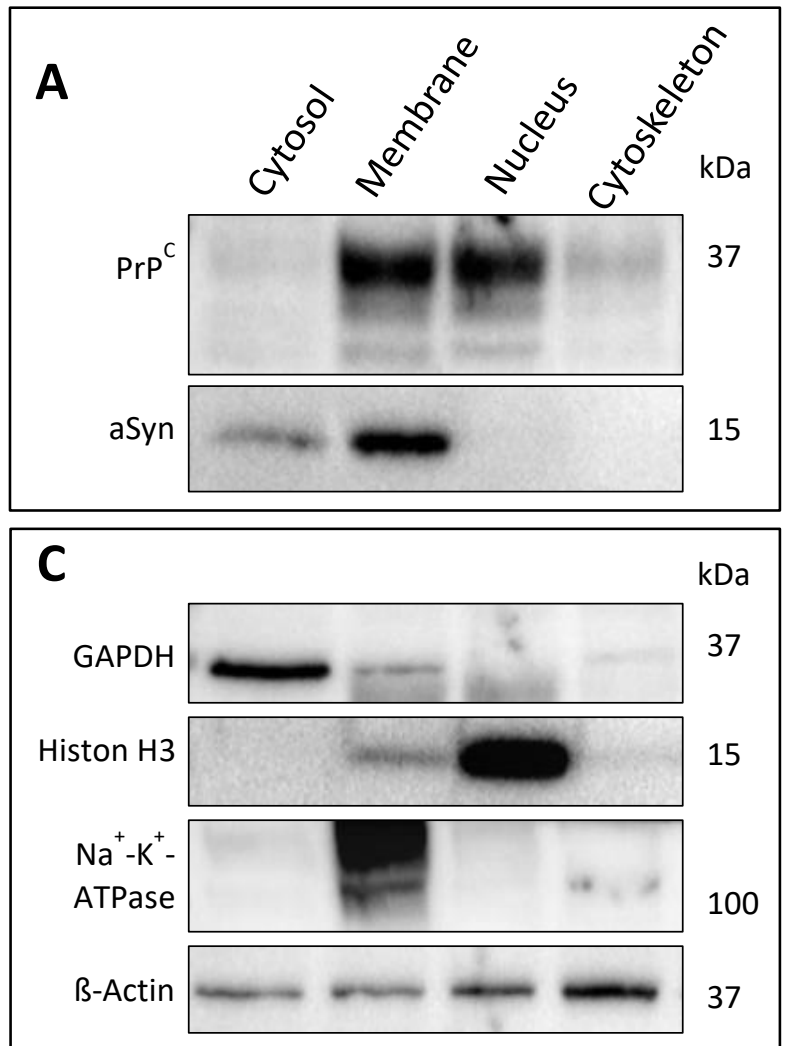

ThySynPrP00
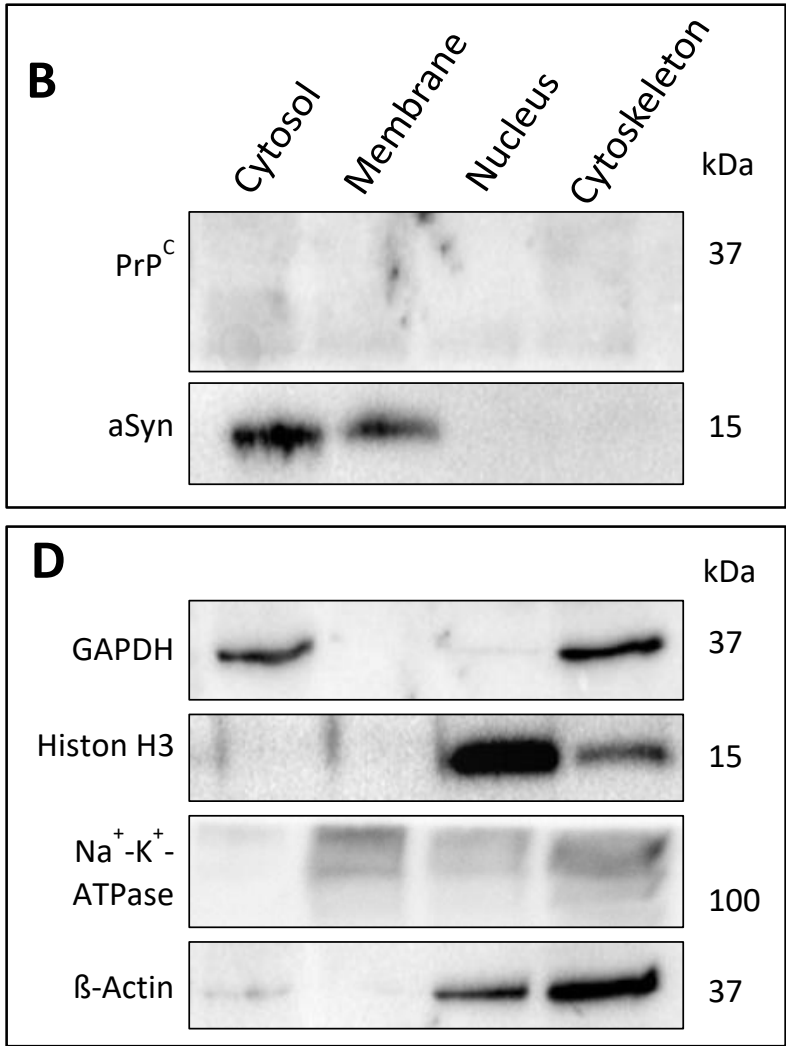

Figure 26: Fractionization of ThySyn and ThySynPrP00

One cortex sample of each mouse line was fractionated into the cytosol, membrane, nucleus, and cytoskeleton and tested for $\operatorname{PrP}^{\mathrm{C}}$ and $\mathrm{aSyn} . \mathrm{A} \mathrm{PrP}^{\mathrm{C}}$ is mainly present in the membrane and nucleus of ThySyn mouse. Expression of aSyn was predominantly in the membrane B Due to the PrP-KO, the ThySynPrPOO does not PrPC. aSyn was mostly located in the cytosol. C and D Loading controls for compartments.

A quantitative analysis of 4 different mice per group revealed significant differences of aSyn distribution in the cytosol and membrane (Figure 26A, B). Normalization was performed according to the loading control of the respective compartment (GAPDH for cytosol, Na-KATPase for membrane). The cytosolic fraction of ThySynPrP00 mice showed a significantly higher quantity of aSyn compared to ThySyn mice (Figure 27 A-D). After the normalization of aSyn in the membranous fraction, the amount of the protein in ThySyn and ThySynPrP00 was at a comparable level. Figure $27 \mathrm{C}$ shows the control blot of the nucleus and cytoskeleton fractions. 

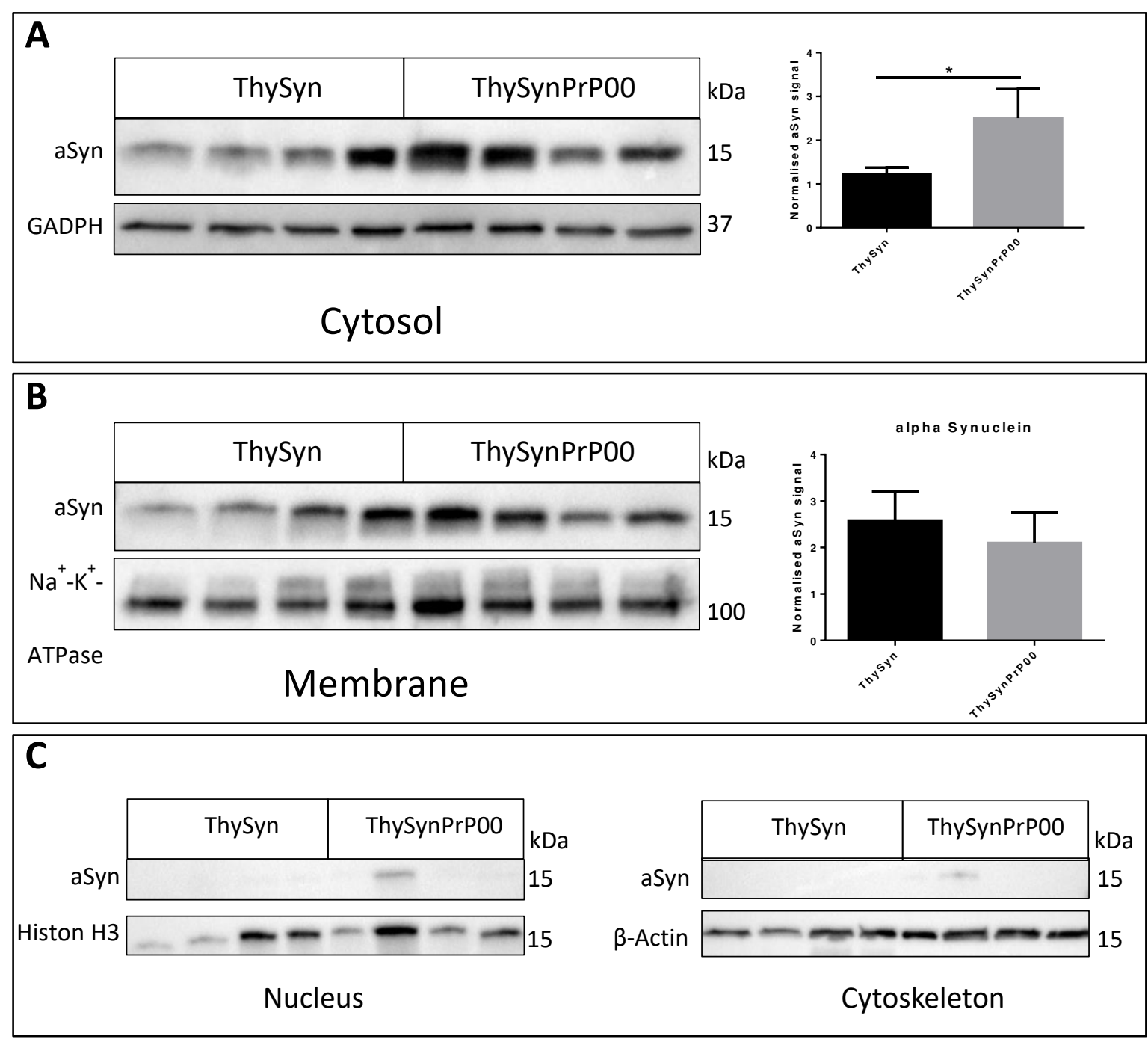

Figure 27: Quantification of aSyn in membrane and cytosol expression of aSyn inThySyn and ThySynPrP00 mice A Comparison of cytosolic aSyn in ThySyn and ThySynPrP00 mice. A higher amount of aSyn was detected in ThySynPrP00 mice. B Comparison of membranous aSyn in ThySyn and ThySynPrP00. Similar aSyn quantities are shown in ThySyn and ThySynPrP00 line. C Control of the nucleus and cytoskeletal fraction. Statistical analysis was performed by unpaired Student's t-test. Data are presented as mean \pm SEM.

\subsection{Co-immunoprecipitation of $\operatorname{PrPC}^{\mathrm{C}}$ and alpha-synuclein in ThySyn mice}

In order to validate an interaction of aSyn and $\mathrm{PrP}^{\mathrm{C}}$, a ThySyn cortex sample was used for coimmunoprecipitation (Co-IP) (Figure 28). Both proteins were confirmed as input. The Co-IP of aSyn was tested for $\operatorname{PrP}^{C}$ and was detected at around $32 \mathrm{kDa}$. Smaller bands of $\operatorname{PrP}^{\mathrm{C}}$ are covered by the light chain of the antibody (Figure 28B). Vice versa the Co-IP of $\operatorname{PrP}^{\mathrm{C}}$ showed also 
bands for aSyn at $15 \mathrm{kDa}$ (Figure 28B). The successful detection of both proteins in the Co-IPs implies an interaction between aSyn and $\mathrm{PrPC}^{\mathrm{C}}$ in ThySyn mouse brains.
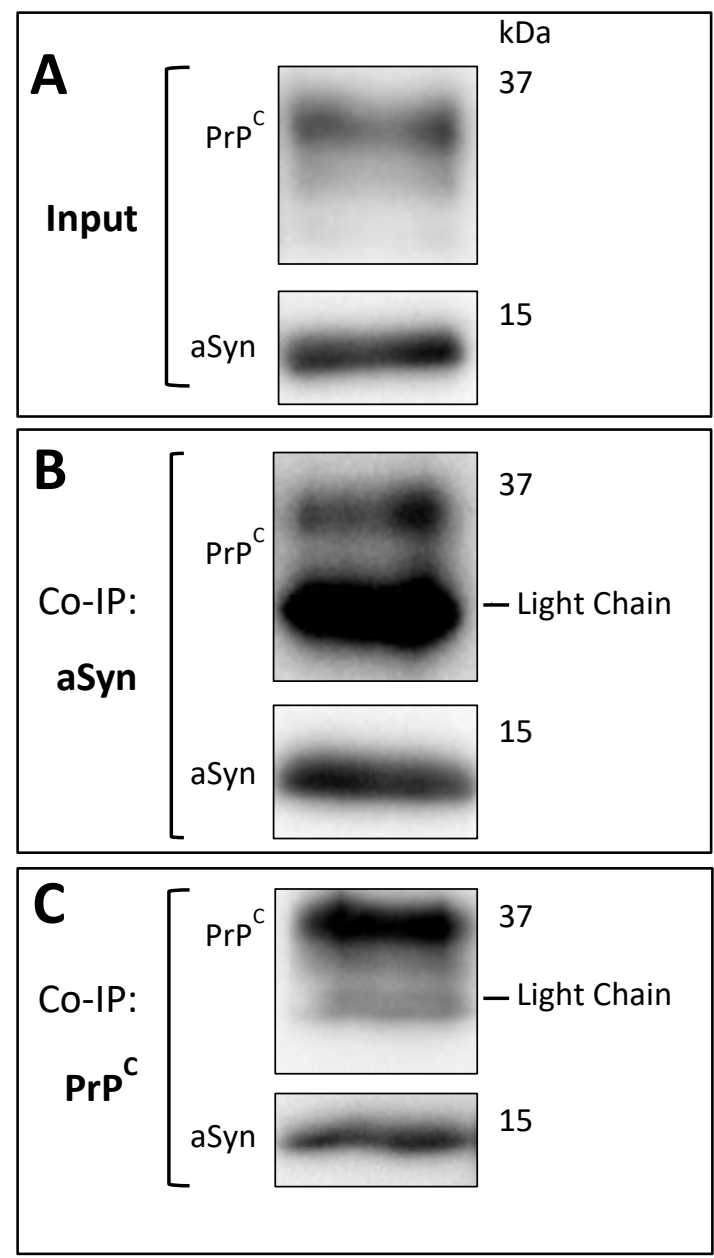

Figure 28: Co-IP of alpha-synuclein and PrPC

For Co-IP, cortex brain lysate of ThySyn mice was used. A Positive control of PrPC and aSyn Input. B Co-IP of aSyn. $\mathrm{PrP}^{\mathrm{C}}$ was detected in the aSyn precipitate. C Co-IP of PrPC . aSyn could be detected in $\operatorname{PrP}^{\mathrm{C}}$ precipitate. The light chain around $25 \mathrm{kDa}$ was marked.

\subsubsection{Characterization of common interaction partners of $\mathrm{PrP}^{\mathrm{C}}$ and aSyn by mass spectrometric analysis of Co-IP lysates}

The results of the Co-IP suggested an interaction of aSyn and $\mathrm{PrP}^{\mathrm{C}}$. To gain more information about further binding partners of both proteins, Co-IPs were analyzed via qualitative mass spectrometry. This allows a better understanding of the interactome of $\operatorname{PrPC}^{\mathrm{C}}$ and aSyn and other proteins that might be involved in aSyn uptake via $\operatorname{PrP}^{\mathrm{C}}$. Analyzing proteins of the $\operatorname{PrP} \mathrm{P}^{\mathrm{C}}$ Co-IP created a list of 131 proteins. For the aSyn Co-IP, 42 proteins were detected in mass 
spectrometry. Comparing both results, 38 common interaction partners could be found (Figure 29). The list of all detected 38 proteins is attached in the appendix.

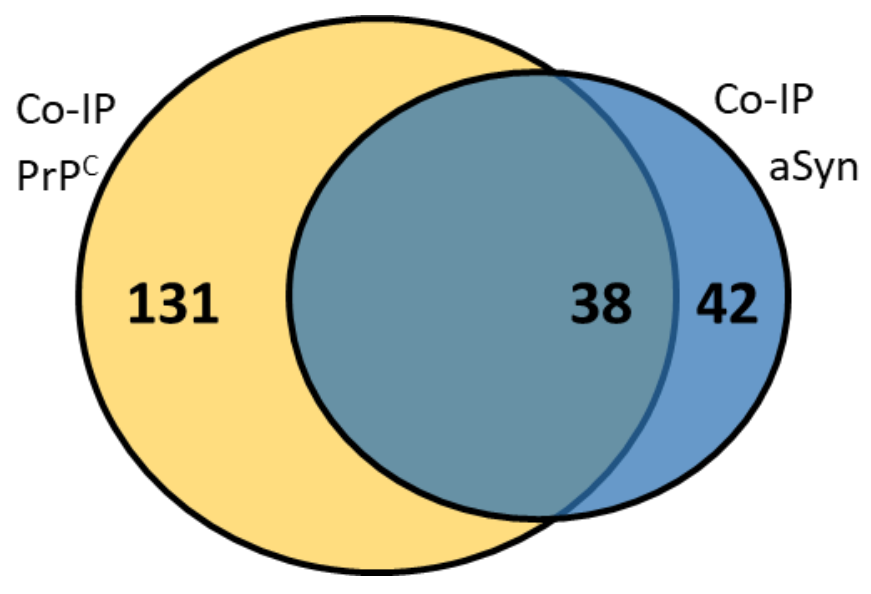

Figure 29: Overlapping proteins of aSyn and PrPC Co-IP

Co-IP samples were used for qualitative mass spectrometry. A comparison of the identified proteins in both samples resulted in 38 shared proteins.

After identifying shared interaction partners, the potential functions were determined via Uniprot. The obtained proteins covered several different molecular tasks (Figure 30).

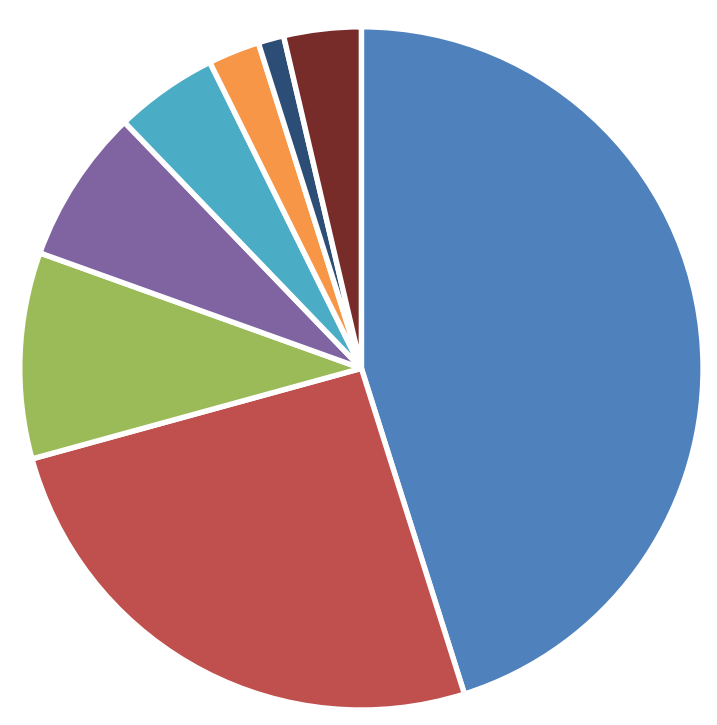

- protein binding (37)

- catalytic activity (21)

- transmembrane transporter activity (8)

- molecular function regulator (6)

- protein folding chaperone (4)

- structural molecule activity (2)

- clathrin adaptor activity (1)

- other (3)

Figure 30: Molecular functions of the identified proteins

Proteins identified in the Co-IP of the MS/MS are presented according to their molecular function.

Comparing the shared Co-IPs for relevant proteins, clathrin was of special interest since studies for aSyn and $\operatorname{PrPC}^{\mathrm{C}}$ with this protein are already published. Clathrin participates in the cargo uptake at the plasma membrane, forming cage-like lattices for the clathrin-coated pits of classical endocytosis (Kirchhausen et al. 2014). Therefore, ThySyn and ThySynPrP00 mice were compared regarding the expression of clathrin (Figure 31). Interestingly, ThySynPrP00 mice 
expressed significantly less clathrin (Figure $31 \mathrm{~B}$ ) indicating an important role of clathrin. To exclude $\mathrm{PrPC}^{\mathrm{C}}$ as a single regulator, WT mice were compared to PrP-KO mice without any transgenic aSyn. The expression of clathrin was not significantly changed (Figure 31 A).
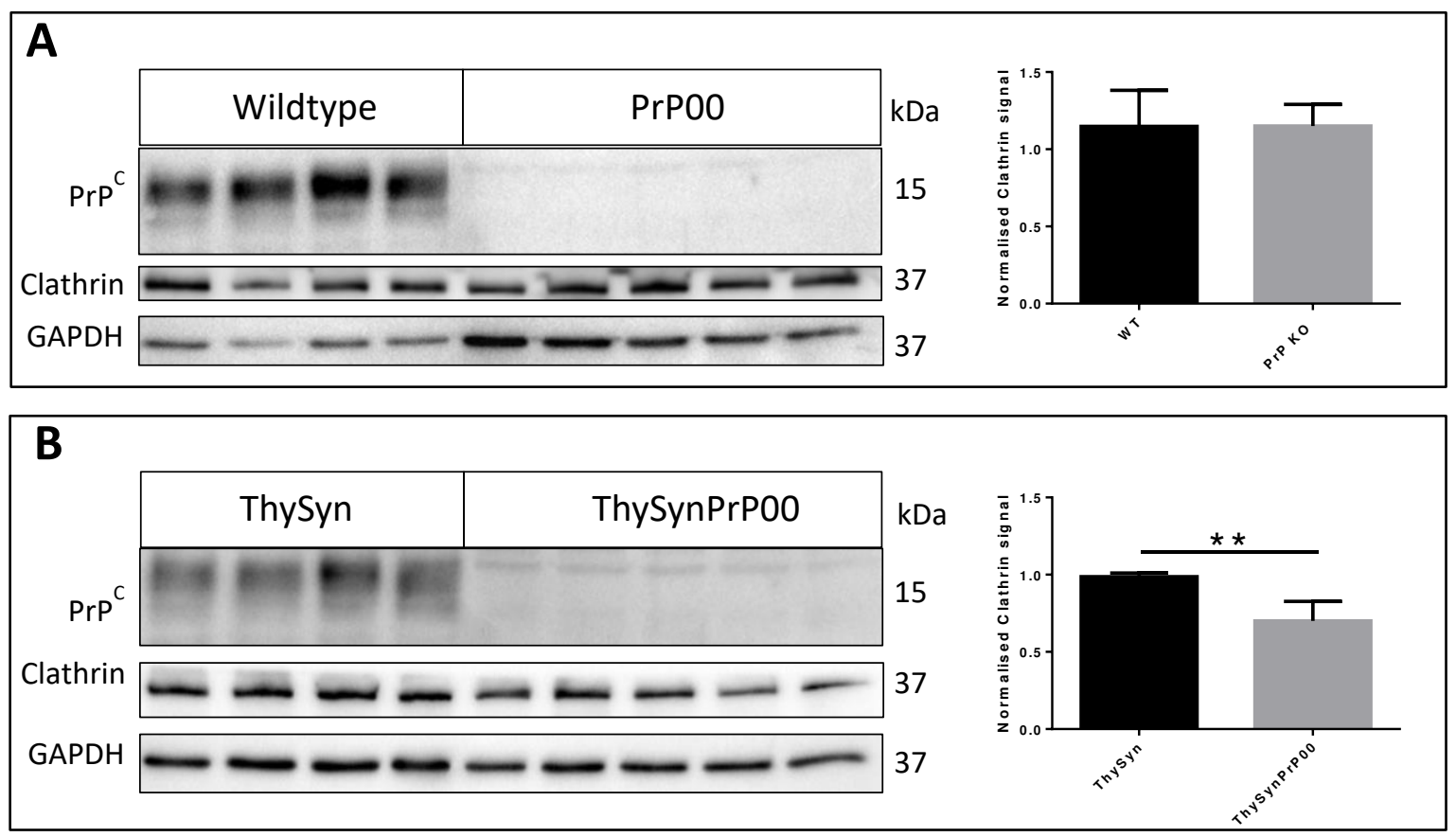

Figure 31: Detection of clathrin in ThySyn and ThySynPrP00 mice

A Comparison of WT and PrP-KO mice did not show a significant difference in the clathrin expression level. B ThySyn mice showed a significantly higher expression of clathrin compared to ThySynPrP00 mice. Missing PrP implies a deviating clathrin quantity in transgenic aSyn mice. Data are presented as mean \pm SEM. Statistical analysis was performed by unpaired Student's t-test $\left({ }^{*} p<0,05 ;{ }^{*} p<0,01\right)$

\subsection{Behavioral study: PrP knock-out partially recovers patho- logical aSyn mediated behavior deficits}

The objective of the behavior study was to determine if a $\mathrm{PrP}^{\mathrm{C}}$ knockout alters the pathological phenotype induced by misfolded aSyn in mice. Two different transgenic aSyn mouse lines (Tgm83 and ThySyn) were employed. A general problem is that all available mouse models created as an aSyn pathology model, do not display all features of Parkinson's disease observed in humans. Therefore, two mouse lines with distinctly different genetical designs were utilized. Both mouse lines were crossed with PrP-KO mice to create double transgenic mouse lines. The evaluation of the behavior test was focused on two comparison groups. In one group the difference between wildtype and aSyn mice is analyzed. In the second group, PrP-KO mice were compared to aSyn mice with the additional $\operatorname{PrP}^{\mathrm{C}}$ knockout allele. 
Table 12: Comparison groups

\begin{tabular}{|l|c|c|l|}
\hline \multicolumn{2}{|c|}{ Group 1 } & \multicolumn{2}{c|}{ Group 2 } \\
\hline Wildtype & Synucleinopathy & PrP-KO & Synucleinopathy + PrP-KO \\
\hline
\end{tabular}

Additionally, the behavior of PrP-KO mice was surveyed as a comparison for the double transgenic mice to ensure that a possible change of behavior was not inflicted by the PrP-KO. The evaluation of the different aSyn mouse lines was done separately from each other since different characteristics are prevalent. Male as well as female mice were used for testing.

\subsection{Differences in the behavior of Tgm83 and TgmPrP00 mice lines}

\subsubsection{Alteration in nest-building behavior}

To assess the impairment of the nest-building behavior, mice were provided with one tissue. After 24 hours the classification on the five-point scale was carried out according to the fivepoint scale (Deacon 2006). At 9 months of age, a slight decrease in the nest building could be observed in WT mice compared to Tgm83. This difference becomes stronger at 18 months of age with around twice the scoring in WT $(3,0 \pm 0,6)$ compared to Tgm83 $(1,4 \pm 0,1)$. PrP-KO mice exhibited the same low scoring compared to TgmPrP00 at 9 and 18 months of age. Deficits in nest building in PrP-KO were not observed (Figure 32). 


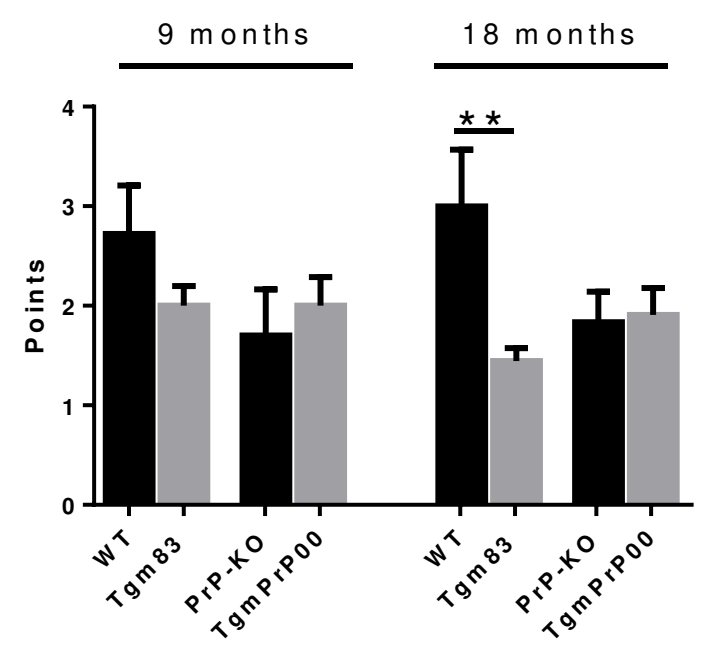

Figure 32: Reduced quality of nest-building

Comparison between WT and Tgm83 as well as PrP-KO and TgmPrPOO at 9 and 18 months of age ( $n \geq 8)$. WT mice performed better than Tgm83 mice at 9 and 18 months of age. No performance differences were detected between PrP-KO and TgmPrPOO at 9 and 18 months of age. Data are presented as mean \pm SEM. Statistical analysis was performed by unpaired Student's t-test $\left({ }^{*} p<0,05 ;{ }^{* *} p<0,01\right)$.

\subsubsection{Alteration on mobility and fear behavior in Open-Field test}

The covered distance in the Open-Field was assessed to evaluate the test groups. Tgm83 mice and the wildtype control group had a similar travel distance without a significant difference at 9 months and also 18 months. For PrP-KO mice and the corresponding TgmPrPOO mice, 9 months as wells 18 months old mice did not exhibit a statistical difference in the covered distance (Figure 33).

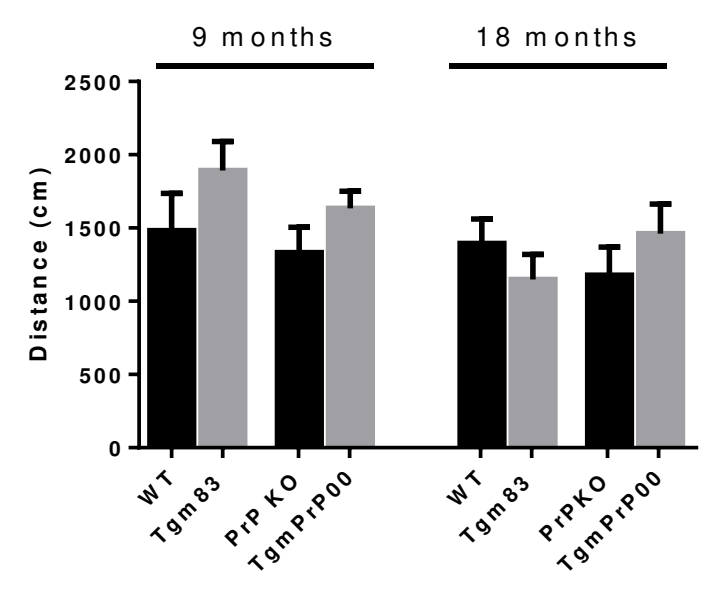

Figure 33: Distance covered in Open-Field-Test

The motoric activity was evaluated by the distance covered in the Open-Field test $(n \geq 8)$. Tgm83 mice had no significant difference to wild-type mice at the age of 9 and 18 months. Also, TgmPrP00 mice did not deviate severely to PrP-KO mice at 9 and 18 months $(n \geq 8)$. Data are presented as mean \pm SEM. Statistical analysis was performed by unpaired Student's t-test. 


\subsection{3 $\mathrm{PrPC}^{\mathrm{C}}$ dependent alteration in anxiety behavior}

WT mice at the age of 9 months remained at an average time of 7,3 $\pm 2,1$ seconds in the open arms. In contrast, Tgm83 stayed significantly longer in the open arms (23,2 $\pm 4,5$ seconds). This behavior was also observed for 18 months old mice. The retention time of WT mice in the open arms was almost unaltered (7,7 $\pm 3,3$ seconds) whereas Tgm83 mice remained around 4 times longer (40,9 $\pm 9,2$ seconds) compared to the control group (Figure 34). For PrP-KO mice at the age of 9 months, the time spent in the open arms $(12,0 \pm 2,4$ seconds) was similar to age-matched TgmPrP00 mice (14,3 $\pm 3,6$ seconds). At the age of 18 months, the retention time of PrP-KO mice $(9,4 \pm 5,0$ seconds) was half as long as that of TgmPrP00 mice $(18,2 \pm 5,0$ seconds) yet the difference was not significant (Figure 34).

This pathological change in the anxiety behavior of Tgm83 mice was also observable in TgMPrP00 mice. Here, the pathological phenotype of aSyn was rescued by the PrP-KO (Figure 34).

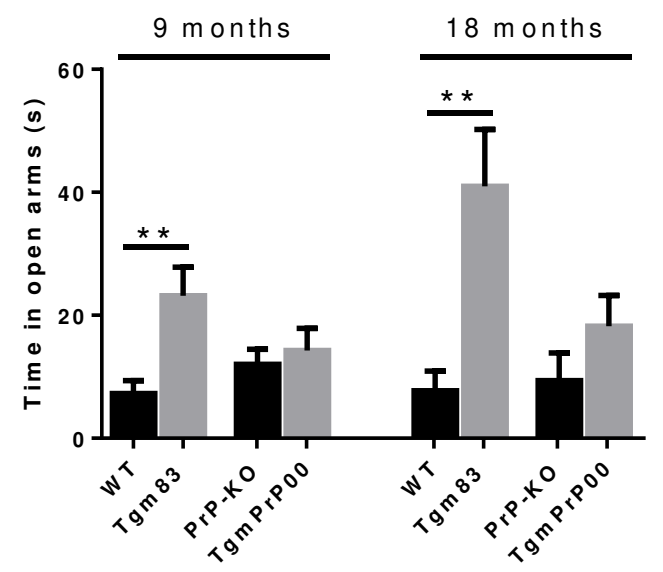

Figure 34: Duration time in open arms of Elevated-Plus-Maze

Anxiety behavior was assessed by measuring the duration time in the open arms of Elevated-Plus-Maze $(n \geq 8)$. Tgm83 mice remained significantly longer in the open arms compared to wildtype mice at 9 and 18 months. PrP$\mathrm{KO}$ and TgmPrPOO mice showed resembling anxiety behavior with no significant change in the duration time. Data are presented as mean \pm SEM. Statistical analysis was performed by unpaired Student's $t$-test $\left({ }^{*} p<0,05\right.$; $* * p<0,01)$. 


\subsection{Changed behavior in ThySyn and ThySynPrP00 mice}

\subsubsection{Alteration in nest-building behavior}

The quality of the nest building is scored on a five-point scale. WT mice $(3,0 \pm 0,4$ points $)$ scored almost three times higher than ThySyn mice (1,2 $\pm 0,1$ points). Contrary to this, PrP-KO mice performed similarly to ThySynprP00 mice with low scoring and no significant difference (Figure 35).

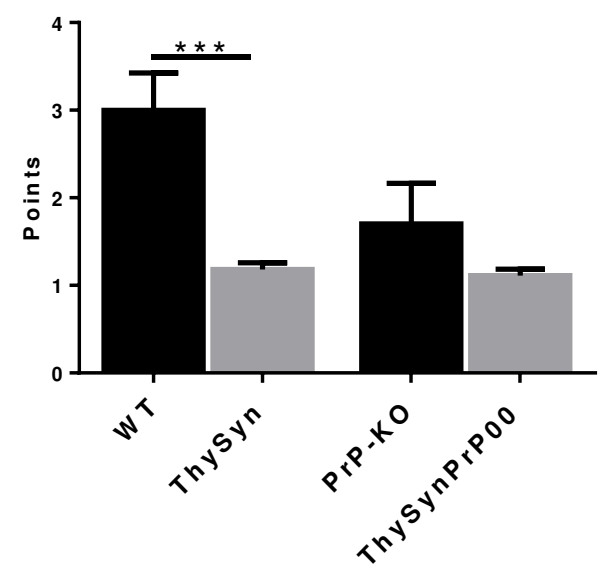

Figure 35: Reduced quality of nest building

The rating was carried out on a five-point scale. Mice were tested at the age of 9 months ( $n \geq 8$ ). Wildtype mice reached a significantly higher scoring than ThySyn mice. PrP-KO mice did not significantly differ from ThSynPrP00 mice. Data are presented as mean \pm SEM. Statistical analysis was performed by unpaired Student's t-test $(* p<0,05 ; * * p<0,01 ; * * * p<0,001)$

\subsubsection{Altered mobility at Rotarod}

ThySyn mice ( 9 moths of age) performed similarly to the wildtype control group. A pathological impairment of the aSyn mice was not observable. Furthermore, ThySynPrP00 mice and PrP-KO mice were not affected by the transgenic alteration. Therefore, no significant difference was measurable (Figure 36). 


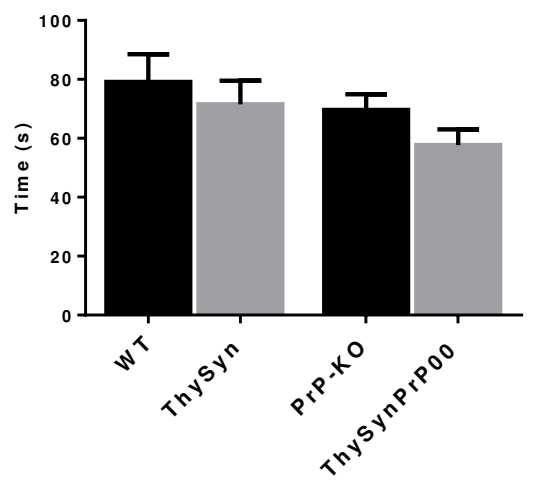

Figure 36: Comparison of motoric performance in the Rotarod test

Motoric impairment was assessed via comparison of the retention time of mice on the Rotarod $(n \geq 8)$. Mice were tested at the age of 9 months. WT mice did not show a significant change in performance compared to ThySyn mice. PP-KO mice also exhibited no significant change in motor skills. Data are presented as mean \pm SEM. Statistical analysis was performed by unpaired Student's t-test.

\subsubsection{Alteration on mobility and fear behavior in Open-Field-Test}

Additionally, mobility was assessed by the number of crossings to other sectors in the OpenField test. ThySyn mice showed a decreased number of crossings in comparison to WT mice, whereas ThySynPrPOO mice were not significantly different from PrP-KO mice. Furthermore, the exploration behavior was also tested in the Open-Field by the time spent in the inner zone. The comparison of WT to ThySyn mice and PrP-KO to ThySynPrPOO mice did not result in significant changes in the duration time in the center of the Open-Field test (Figure 37).

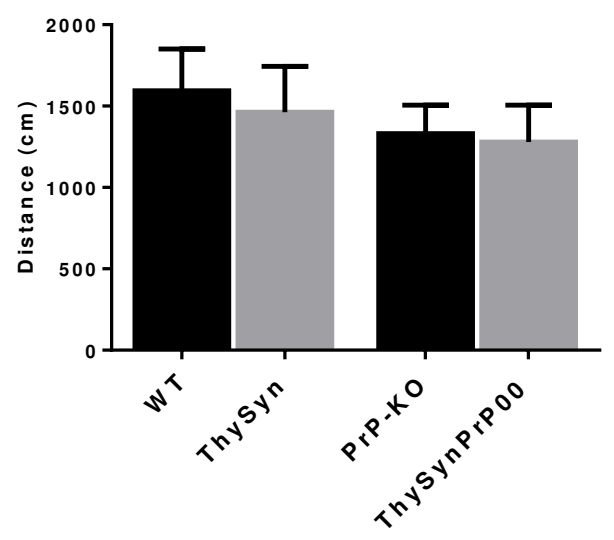

Figure 37: Distance covered in Open-Field-Test

Impairment of motoric activity was assessed by the distance covered in the Open-Field test $(n \geq 8)$. ThySyn exhibited the same movement activity as WT mice. Also, ThysSynPrP00 mice showed no significant decrease in the activity compared to the PrP-KO control group. Data are presented as mean \pm SEM. Statistical analysis was performed by unpaired Student's t-test. 
A

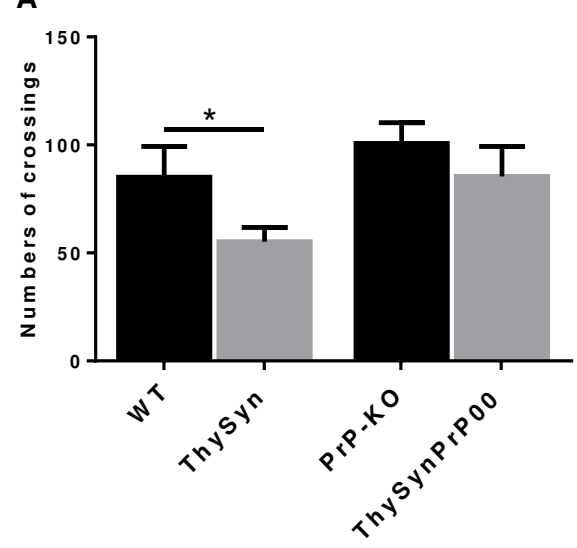

B

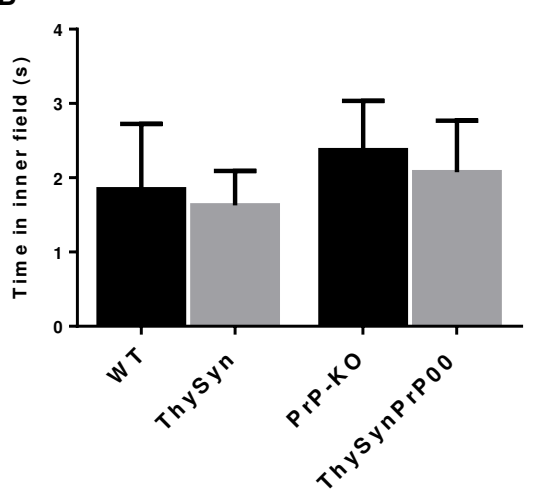

Figure 38: Crossings and duration in the inner zone measured in Open-Field test

Exploration and movement activity were assessed by the number of field crossings $(\mathbf{A})$ and duration time in the center of the Open-Field test (B) ( $n \geq 8)$. A Number of crossings was reduced for ThySyn mice in comparison to WT mice. PrP-KO mice performed similarly without a significant difference to ThySynPrPOO mice. Data are presented as mean \pm SEM. Statistical analysis was performed by unpaired Student's t-test $\left({ }^{*} p<0,05\right)$.

\subsubsection{Analysis of the cognitive performance of mice applying the Novel- Object-Recognition test}

In order to test the memory performance of mice, the Novel-Object-Recognition test (NOR) was conducted. ThySyn mice displayed a significantly reduced recognition index compared to WT mice. In contrast, PrP-KO and ThySynPrPOO mice had a lower NOR-index depending on the PrP-KO phenotype. The comparison of PrP-KO and ThySynPrPOO mice revealed no further worsening as a consequence of aSyn pathogenesis (Figure 44).

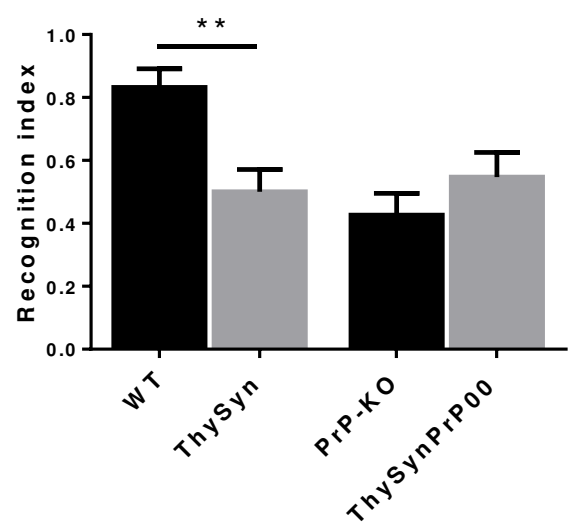

Figure 39 Comparison of cognitive performance via Novel-Object-Recognition test

Cognitive performance was assessed with the Novel-Object-Recognition-test $(n \geq 8)$. The performance is presented as the novel object recognition index (NOR-index). WT mice had a significantly higher NOR-index than ThySyn mice. Nor-index of PrP-KO and ThySynPrPOO mice did not alter significantly. Data is presented as mean \pm SEM. Statistical analysis was performed by unpaired Student's t-test. 


\subsubsection{Alteration of contextual fear conditioning}

With the use of contextual fear conditioning the associative learning performance of the mice was studied. In this test, mice were subjected to an aversive stimulus as described above (3.4.3). For ThySyn mice ( $52.3 \pm 8.4$ seconds) the measured freezing time was significantly less compared to the wildtype control group (14.0 \pm 6.0 seconds). In contrast, PrP-KO mice (53.8 \pm 7.0 seconds) had a similar freezing time as ThySynPrP00 mice $(40.9 \pm 13.1)$ (Figure 40). In this specific behavior test, the pathological effect in ThySyn mice was diminished with the additional insertion of $\mathrm{PrP}^{\mathrm{C}}-\mathrm{knockout}$.

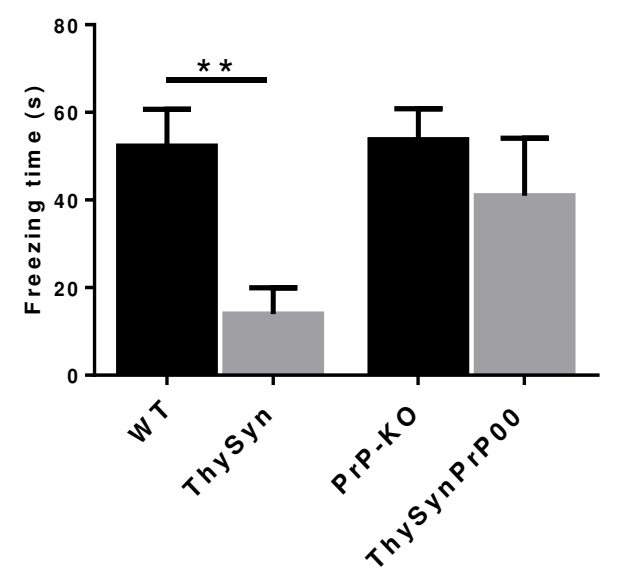

Figure 40: Comparison of the contextual fear conditioning

Associative learning was measured via the freezing time after exposing mice to an environmental stimulus $(n \geq 8)$. Freezing time of ThySyn mice was decreased compared to controls mice. ThySyn mice had a minor but insignificant decrease in the freezing time compared to PrP-KO. Data are presented as mean \pm SEM. Statistical analysis was performed by unpaired Student's t-test $\left({ }^{*} p<0,05 ;{ }^{* *} p<0,01\right)$.

\subsubsection{Alteration of tone depending fear conditioning}

The associative learning was additionally assessed with an acoustic stimulus by combining the fear conditioning with a tone stimulus. This setup resulted in a significantly higher freezing time of WT mice (64.4 \pm 8.5 seconds) compared to ThySyn mice (20.5 \pm 6.0 seconds). The difference in the freezing time was not significantly changed in PrP-KO and ThySynPrPOO mice 
(Figure 41). Altogether, the pathological effect of aSyn in ThySyn mice was rescued by PrPCknockout in ThySynPrPOO mice.

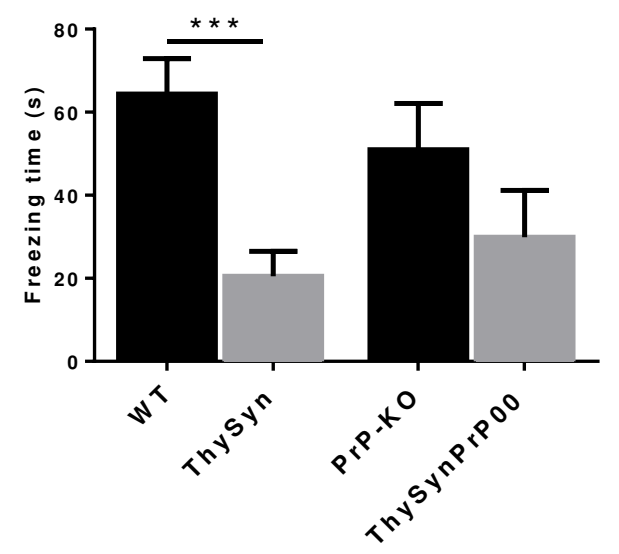

Figure 41: Analysis of tone fear conditioning

Associative learning was rated by the freezing time $(n \geq 8)$. WT mice achieved a significantly higher learning performance compared to ThySyn mice. PrP-KO mice presented a higher average freezing time than ThySynPrP00 mice but the difference was not significant. Data are presented as mean \pm SEM. Statistical analysis was performed by unpaired Student's t-test $\left({ }^{*} p<0,05 ;{ }^{* *} p<0,01 ;{ }^{* *} p<0,001\right)$.

\subsubsection{Alteration in fear behavior}

The naturally occurring anxiety behavior was evaluated with the Elevated-Plus-Maze (EPM). The duration time of ThySyn mice ( $29.3 \pm 4.4$ seconds) in the open arm was distinctively higher compared to WT mice $(7.3 \pm 2.1$ seconds), which showed a higher degree of anxiety (Figure 42). Considering the fear behavior of ThySynPrP00 mice ( $14.0 \pm 4.2$ seconds) the average time spent in the open arms of the EPM time was closely resembling the time of PrP-KO mice (Figure 47). The pathological influence of oligomeric aSyn on the altered anxiety behavior in ThySyn mice was markedly recovered after PrPC knockout in ThySynPrP00 mice. 


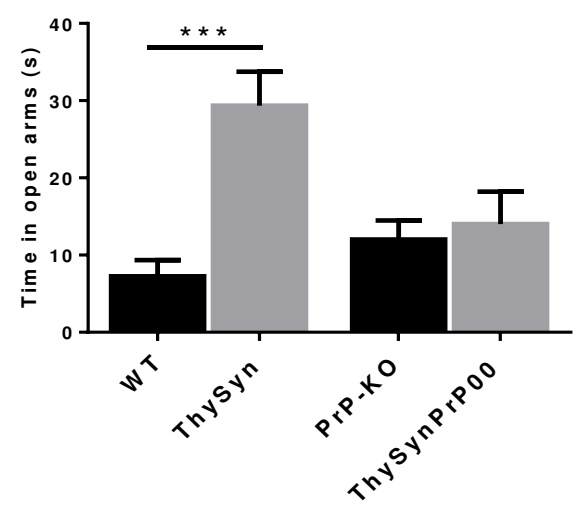

Figure 42: Analysis of anxiety behavior using the Elevated-Plus-Maze

Anxiety behavior was assessed by measuring the duration time in the open arms of Elevated-Plus-Maze ( $n \geq 8$ ). ThySyn mice remained significantly longer in the open arms of the Elevated-Plus-Maze compared to WT mice. This difference was not given in PrP-KO compared to ThSynPrP0O mice. Data are presented as mean \pm SEM. Statistical analysis was performed by unpaired Student's t-test $\left({ }^{*} p<0,05 ;{ }^{* *} p<0,01 ;{ }^{* *} p<0,001\right)$. 


\section{Discussion}

Synucleinopathies are characterized by a progressive aggregation of aSyn in several types of diseases. Amongst them, Parkinson's disease, MSA and LBD represent the most prevalent neurodegenerative diseases in this group. The toxic oligomerization and fibrillization of aSyn can be caused by locus multiplication, point mutations in the Park genes or yet unknown reasons for spontaneous aggregation (Cookson 2005). Indications are hinting to a possible spreading of misfolded aSyn from cell to cell, therefore promoting the disease progression (Recasens et al. 2014). Due to the ability to propagate misfolded protein to a recipient cell, a prion-like mechanism is postulated for aSyn (Angot et al. 2010; Bernis et al. 2015; Brundin et al. 2016). In this context, the mechanism for the release and uptake of aSyn is not yet completely understood. Yet, different possibilities for the aSyn propagation have been suggested like exosomal release, endocytosis of extracellular aSyn or tunneling nanotubes (Lee et al. 2008; Emmanouilidou et al. 2010; Ulusoy et al. 2015; Abounit et al. 2016).

In this study, the focus is on $\operatorname{PrPC}^{\mathrm{C}}$ as a potential receptor protein of aSyn, supporting the spreading and mediating the toxicity of misfolded aSyn. A similar receptor-function of $\operatorname{Pr} \mathrm{P}^{\mathrm{C}}$ was already shown for $A \beta$ in Alzheimer's disease (Salazar and Strittmatter 2017a).

\subsection{Uptake and localization of alpha-synuclein in cells}

In the process of fibrilization, highly toxic derivates of aSyn are generated, harming living cells and even causing cell death. Prior studies have proven the fatal impact of oligomerized aSyn in cell cultures (Chen et al. 2007; Danzer et al. 2007; Tetzlaff et al. 2008). To establish whether a potential binding to $\mathrm{PrP}^{\mathrm{C}}$ is a unique feature of oligomeric aSyn, monomeric aSyn was also included in the cell culture experiments. As a model, we used secondary cells (SH-SY5Y) exhibiting a permanent (approx. 5 fold) overexpression of $\operatorname{PrPC}$ (SH-PrP). To study the aSyn uptake, cells were subjected to monomeric as well as oligomeric aSyn overnight.

We found that the internalization of oligomeric aSyn was significantly higher in SH-PrP cells compared to SH WT cells, indicating an important role of $\operatorname{PrP}^{\mathrm{C}}$ in the cellular aSyn uptake. We confirmed these findings by inducing a sequential reduction of $\operatorname{PrP}^{C}$ via Glimepiride, which also reduced the amount of oligomeric aSyn uptake down to approx. one-tenth compared to untreated cells. 
Our findings were in line with others, who described the involvement of $\mathrm{PrP}^{\mathrm{C}}$ in N2a cells in the uptake of oligomeric aSyn. For comparison, $\operatorname{PrP}^{\mathrm{C}}$ deprived N2a cells, were also treated with oligomerized aSyn resulting in the decreased binding of aSyn (Aulić et al. 2017). Analogous to this experimental setup HEK293 cells were transfected with a plasmid containing murine $\operatorname{PrPC}$. The comparison of mock-transfected and PrP transfected HEK293 cells showed an enhanced amount of bound non-monomeric aSyn (Urrea et al. 2017).

To obtain information about the localization of the exogenous aSyn added to the SH cells, the phosphorylation status of the protein was also examined. The high expression of phosphorylated aSyn S129 is a hallmark for the pathological derivate of the protein called Lewy bodies (Okochi et al. 2000; Fujiwara et al. 2002; Anderson et al. 2006). SH PrP cells treated with oligomeric aSyn contained a higher amount of phosphorylated aSyn S129 compared to monomeric aSyn. For the phosphorylation of aSyn, a prior uptake of the protein is necessary, indicating the presence of exogenously added aSyn in the cell. This was supported by subcellular fractionation, in which aSyn was detected in SH WT cells and in higher amounts in SH PrP cells.

\subsection{Influence of PrPC on alpha-synuclein expression and iso- form composition}

The expression level of aSyn in ThySyn mice was shown to be increased with age, depending on the brain area (Rabl et al. 2017). Therefore, we were interested in the total amount and the isoform composition of aSyn. Considering the expression level of aSyn, neither TgmPrPOO nor ThySynPrP00 mice revealed significant differences in comparison to their control group. Although, $\operatorname{PrP}^{C}$ was found in the nucleus (Gu et al. 2003; Nikles et al. 2008) and able to bind DNA (Lima et al. 2006) and RNA (Bera and Biring 2018), PrPC is not well known for the suppression of other genes like aSyn.

Furthermore, the examination of phosphorylated aSyn is of high interest due to its close relation to neurotoxicity and aggregation (Oueslati 2016). Finding evidence for in vivo kinases have been unsuccessful so far yet. Some in vitro kinases have been shown like casein kinase I/II as well as the polo-like kinases 2/3 (Zhang et al. 2019). Moreover, these kinases have been known to be interacting with $\operatorname{PrP}^{C}$ (Chen et al. 2008; Wang et al. 2015; Zamponi et al. 2017) but no significant difference could be measured concerning the S129 phosphorylation in our aSyn transgenic mice compared to double transgenic PrP-KO mice. 
Additionally, we were investigating a possible effect of phosphorylated Y125 since it was shown to be important for the S129 phosphorylation (Kosten et al. 2014). Y125 can be phosphorylated by Fyn kinase, which also forms a complex with $\operatorname{PrPC}^{\mathrm{C}}$ and $\beta$-amyloid impairing neurons (Um et al. 2012), yet ThySyn mice did not exhibit a significant difference to ThySynPrP00 mice for the Y125 phosphorylation.

Furthermore, we analyzed the subcellular distribution of aSyn and found a higher amount of aSyn in the cytosol of ThySynPrP00 compared to ThySyn mice, indicating a decreased binding capacity of $\operatorname{PrP}^{C}$ deprived transgenic mice. If not for a direct binding, $\operatorname{PrP}^{C}$ might affect the aSyn concentration by regulating the synaptic vesicle recycling and exocytosis (Peggion et al. 2019). Due to the binding of aSyn to these particular synaptic vesicles, the distribution might be altered (Kahle et al. 2000).

\subsection{Interaction of alpha-synuclein and $\mathrm{PrP}^{\mathrm{C}}$}

The analysis of subcellular fractions of SH cells showed the co-localization of aSyn and $\operatorname{PrPC}$ in SH WT cells and the increased uptake of aSyn in SH PrP cells. Therefore, we were interested in the potential interaction of the protein.

To investigate a possible direct interaction we used recombinant human $\operatorname{PrP}^{\mathrm{C}}$ as well as recombinant human monomeric and oligomeric aSyn for surface plasmon resonance spectrometry. We were able to obtain equilibration constants for $\operatorname{PrP}^{\mathrm{C}}$ with monomeric aSyn $\left(\mathrm{K}_{\mathrm{D}}=3,70 \mathrm{E}-\right.$ 09) and oligomeric aSyn (K $\left.\mathrm{K}_{\mathrm{D}}=2,39 \mathrm{E}-09\right)$.

Other groups also presented similar attempts with SPR to show the interaction of the proteins but failed to detect the direct binding of aSyn and $\operatorname{PrP}^{\mathrm{C}}$. Possible reasons for different outcomes are:

1) Source of proteins: The group of La Vitola et al. immobilized the $\operatorname{PrP}^{\mathrm{C}}$ specific antibodies 3F4 and 94B4 on a GLC chip surface catching PrPC from brain lysates of transgenic PrPC overexpressing mice instead of using recombinantly produced $\operatorname{PrP}^{C}$. Subsequently, $\operatorname{PrP}^{C}$ ligand was exposed to oligomeric aSyn. The exposition of the GLC chip to whole-brain lysates containing a mixture of a huge diversity of different molecules can mask or significantly disturb the interaction of $\operatorname{PrP}^{\mathrm{C}}$ and aSyn.

2) Species barrier: La Vitola et al., used murine PrPC in combination with human aSyn instead of both proteins from the same species. Although aSyn is highly conserved among both 
species, it may have also influenced the outcome of the protein interaction analysis in SPR spectrometry (La Vitola et al. 2019).

3) Experimental protocol: Potential reasons for the discrepancies might be due to the special characteristic of $\operatorname{PrP}^{\mathrm{C}}$ having an isoelectric point ( $\mathrm{pl}$ ) in a wide range of approximately 5 to 8 due to the existence of different isoforms (Zanusso et al. 2004; Schmitz et al. 2014a). The $\mathrm{pl}$ is important for the immobilization of the protein to the chip surface. In general, the $\mathrm{pH}$ of the ligand solution should be below the $\mathrm{pl}$ of the protein so the protein is positively charged and binds to the negatively charged surface of the chip during ligand immobilization. Since the $\mathrm{pH}$ also affects the folding of the protein it must be chosen carefully to not affect the folding of $\operatorname{PrP} P^{C}$. Due to the variable $\mathrm{pl}$ of $\operatorname{PrP}^{\mathrm{C}}$ due to the existence of different isoforms, the aSyn-PrPC is only measurable at optimal folding properties, which may also depend on the $\mathrm{pH}$ of the ligand solution.

Besides SPR, co-immunoprecipitation was used to detect the aSyn-PrPC interaction (Ferreira et al. 2017) by precipitating aSyn and $\operatorname{PrP}^{\mathrm{C}}$ with specific antibodies. In addition, Ferreira and colleagues suggest the amino acid region 93-109 of $\mathrm{PrPC}^{\mathrm{C}}$ to be involved in aSyn uptake. Using Co-IP, we could also demonstrate an interaction of human aSyn with mouse $\operatorname{PrPC}^{\mathrm{C}}$ in our ThySyn mouse line. Yet, there are considerable disadvantages of Co-IP compared to SPR spectrometry such as the lack of binding-information about whether a direct or indirect interaction is given and about the binding affinity $\left(K_{D}\right)$. Additionally, unspecific protein bands can occur, which might be masking a potential protein-interaction.

\subsection{Knockout of $\operatorname{PrPC}^{\mathrm{C}}$ may rescue the pathological aSyn-in- duced phenotype in transgenic mice}

After our in vitro studies had shown that PrPC may act as a binding partner for beta-sheet-rich oligomeric and toxic aSyn mediating its internalization, we were interested in exploring the receptor-function hypothesis of $\mathrm{PrP}^{\mathrm{C}}$ in vivo. However, for studying aSyn based neurodegenerations in rodents, it needs to be considered that synucleinopathies are not occurring naturally in mice. Therefore, several artificial models have been generated to recreate the pathological effects of aSyn in mice. A major problem in the available mice models is that none of them is able to recreate all symptoms of synucleinopathies occurring in PD. Only parts of the 
diseases could be mimicked in transgenic mouse models so far, depending on two major differences, which need to be considered when comparing mice overexpressing aSyn. The promoter affects the expression pattern and the amount of the protein in the brain whereas the choice of WT or mutated aSyn influences pathological features linked to familial PD (Magen and Chesselet 2010). Therefore, we decided to use two different mouse models with different traits. One of these was the ThySyn model, which is characterized by the genetic insertion of WT aSyn on the $X$ chromosome regulated by the murine Thy1 promoter (Chesselet et al. 2012). Typically, male mice are used for experiments, therefore, rodents are heterozygous for transgenic aSyn which is already sufficient to induce the early onset of the disease's progression in ThySyn mice.

Additionally, we used Tgm83 mice as a second mouse model in which the mutated A53T aSyn is regulated by the murine $\operatorname{PrP}^{\mathrm{C}}$ promoter. Mice homozygous for aSyn were strongly affected showing early onset of the disease. Nesting and grooming were severely neglected as well as other motoric impairments (Giasson et al. 2002). Since ThySyn mice are already showing early onset progression, we decided to use hemizygous mice displaying also a distinct phenotype at older ages representing the later onset of familial PD (Graham and Sidhu 2010).

To investigate the role of $\mathrm{PrP}^{\mathrm{C}}$ in aSyn mediated pathology, we created two double transgenic mouse lines by crossing the ThySyn mouse line and TgM83, with the PrP-KO (Zurich1)mouse line (Büeler et al. 1992b).

Mouse models were tested for different aspects of their behavior to assess the pathological phenotype including cognitive-, anxiety-, locomotor-, associative learning- and motoric deficits.

1) The associative learning was tested by tone and contextual fear conditioning in which we were able to observe decreased freezing time in ThySyn mice compared to WT mice. In addition to this previously described behavior (Rabl et al. 2017), we also compared ThySynPrP00 with PrP-KO mice showing that the phenotype of transgenic aSyn mice was recovered with the additional $\operatorname{PrP}^{\mathrm{C}}$ depletion.

2) Assessing the Elevated-Plus maze, ThySyn exhibited significantly less anxiety compared to WT mice, supported by prior studies (Rieker et al. 2011). Regarding the ThySynPrP00 mouse line, the anxiety level was re-established in double transgenic mice. Moreover, Tgm83 mice also presented a decrease in anxiety at 9 and 18 months. This specific phenotype could be also rescued in TgmPrPOO mice with PrP-KO. 
3) Nesting behavior was also tested showing lower scoring of ThySyn and Tgm83 mice in comparison to WT mice as described in the literature (Paumier et al. 2013; Rabl et al. 2017). Yet our double transgenic mouse models did not show an improvement in the nest building. Considering the low scoring in the PrP-KO control group (Schmitz et al. 2014b), an improvement of the scoring in double transgenic mice was not measurable due to the effect of $\operatorname{PrPC}^{\mathrm{C}}$ on nest building.

4) Furthermore, memory performance was studied via the Novel-object-recognition index. WT mice reached a higher NOR index compared to ThySyn mice in accordance with prior studies (Magen et al. 2012) indicating an aSyn induced worsening. The testing of ThySynPrP00 mice in comparison to PrP-KO mice did not exhibit any differences in memory performance. The low scoring of PrP-KO mice was also observed in prior experiments (Schmitz et al. 2014c). Therefore, the effect of PrP-KO impeds the final conclusion whether the lack of PrPC could recover the deficits induced by misfolded aSyn. Thus, the validity of this behavior test is restricted.

5) Comparing the motoric phenotype, ThySyn mice did not present a significant difference neither in Rotarod nor in the Open Field test. This may arise due to the development of the extracellular dopamine level of ThySyn mice while aging. Until 6 months of age, an increased dopamine level was observed, normalizing around the age of 8-12 months and depleting with 14 months of age (Chesselet et al. 2012). Increasing levels of dopamine have been connected to hyperactivity in mice (Zhuang et al. 2001) which was also observed in ThySyn mice with higher activity in the Open Field test at the age of 7 months (Lam et al. 2011). Therefore, the specific age of our tested mice can be the reason for the lack of a significant motoric phenotype. Applying the challenging beam test to assess the fine motoric of younger mice (Cuvelier et al. 2018) or testing of various ages may result in significant differences.

In addition, Tgm83 mice also displayed a phase of hyperactivity (Unger et al. 2006) as well as motoric impairments in hemizygous Tgm83 mice (Graham and Sidhu 2010). Yet some reported no signs of neurological illness in heterozygous Tgm83 mice (Watts et al. 2013). The untypical development of increased hyperactivity in younger mice with later impairment at older ages was observed in different aSyn mouse models. In combination with the decreased expression rate of aSyn in heterogeneous Tgm83 mice, the assessment of the motoric phenotype would probably need several different ages of mice to be tested. Furthermore, fine motor skills might help to observe a significant deviation of the phenotype. 
Altogether, our behavior study indicated a rescue of the misfolded aSyn-induced pathological phenotype via $\operatorname{PrP}$ knockout which suggests an involvement of $\operatorname{PrP}^{C}$ in the pathogenesis of synucleinopathies.

\subsection{Involvement of clathrin-coated-vesicles in alpha-synu- clein internalization via PrPC}

In order to examine the possibility of a complex of aSyn and $\operatorname{PrP}^{C}$ with additional proteins we performed Co-IPs of aSyn and $\mathrm{PrPC}^{\mathrm{C}}$ and analyzed common proteins with qualitative mass spectrometry. Clathrin was present in both precipitates as a mutual interacting protein. Therefore we analyzed the clathrin expression in ThySyn and ThSynPrP00 mice. We observed a decreased expression of clathrin in transgenic aSyn mice with $\operatorname{PrP}^{C}$ depletion which was not given in WT mice compared to PrP-KO mice. Functionally, clathrin assembles into a lattice structure on the inner surface of the plasma membrane leading to the invagination, budding and subsequently fission of the vesicle (Schmid 1997). In this context, $\operatorname{PrPC}^{\mathrm{C}}$ is known to translocate out of lipid rafts (Taylor and Hooper 2006b) before the endocytic uptake of $\operatorname{PrP}^{\mathrm{C}}$ by clathrin-coated pits and vesicles proceeds (Shyng et al. 1994). Additionally, it was shown that the transmission of aSyn can be decreased by blocking the clathrin-mediated endocytosis of extracellular aSyn. This is achieved by modulating the interaction with $\mathrm{N}$-methyl-D-aspartate receptors, exhibiting a protective effect on dopaminergic and cortical neurons (Oh et al. 2016). Evaluating our effects of the PrPC depletion on aSyn and downregulation of clathrin in ThySynPrP00 in comparison to ThySyn mice, we suggest the binding of aSyn via $\mathrm{PrP}^{\mathrm{C}}$ followed by a clathrin depending endocytosis and the subsequent internalization of the binding complex into the cell (Figure 43). However, these results need further confirmation by additional studies. Analogous to the $\operatorname{PrPC}^{\mathrm{C}}$ depletion with Glimepiride in SHPrP cells, we are planning to analyze the uptake and phosphorylation of aSyn after chemical inhibition of clathrin-coated vesicles in these cells. 


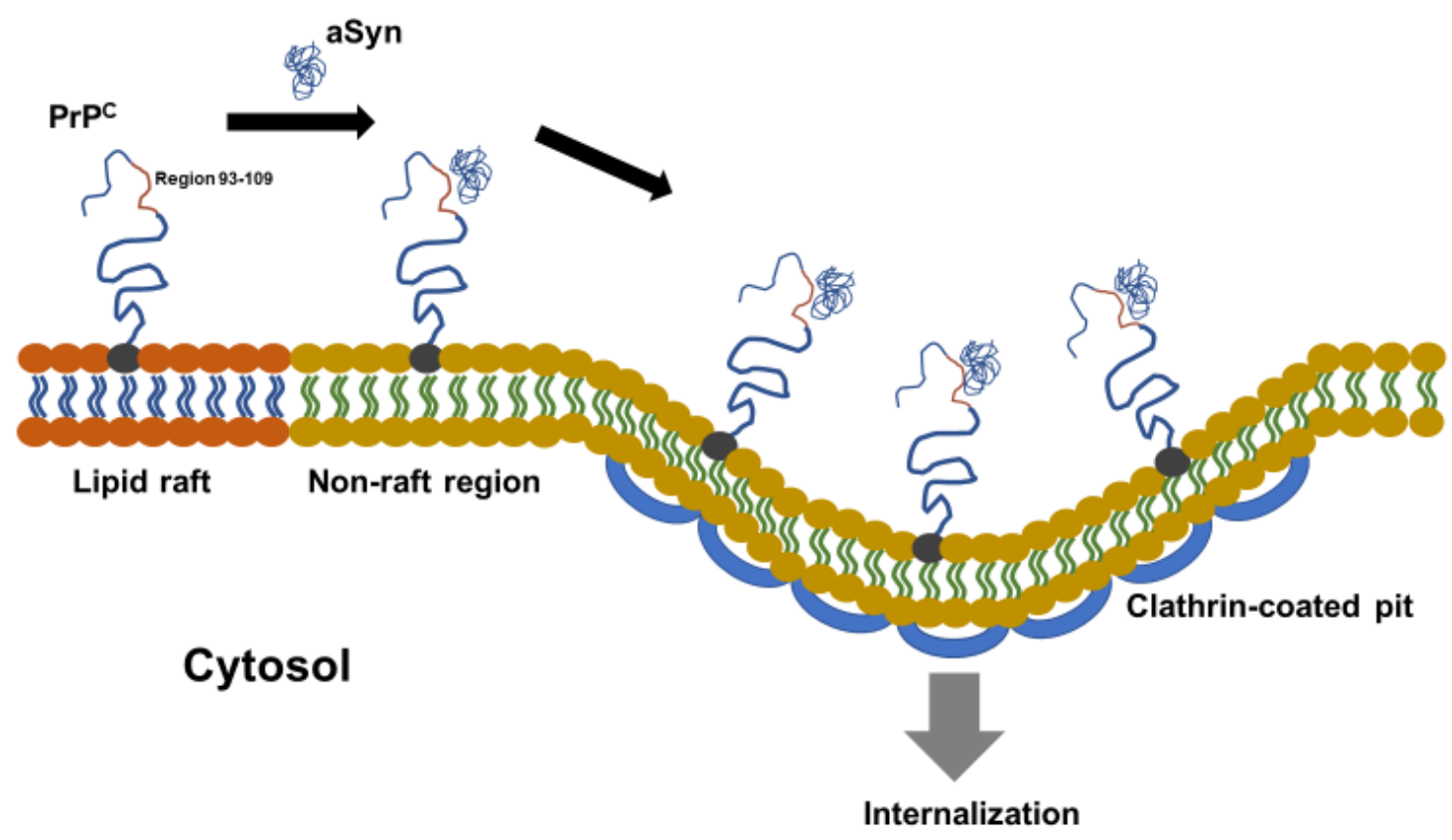

Figure 43: Possible mechanism of aSyn internalization via $\operatorname{PrP}^{\mathrm{C}}$ and clathrin

$\mathrm{PrP}^{\mathrm{C}}$ translocates from lipid rafts to non-lipid rafts. Extracellular monomeric and oligomeric aSyn can bind to the $\mathrm{PrP}^{\mathrm{C}}$ in the region 93 to 109. Clathrin coated vesicle depending endocytosis of $\operatorname{Pr}^{\mathrm{C}}$ promotes the internalization of aSyn. 


\section{Summary and conclusion}

The misfolding and oligomerization of aSyn is considered as the main pathological event in synucleinopathies resulting in the formation of insoluble aSyn deposits. In this context, an important issue is the cellular internalization of aSyn which may contribute to the proposed prion-like spreading within the brain tissue, influencing the pathological process. Previous studies on amyloid-beta indicated a relevant role of $\operatorname{PrP}^{C}$ as a putative receptor of misfolded proteins mediating their toxicity.

In this work, we examined if $\mathrm{PrP}^{\mathrm{C}}$ is involved in the aSyn uptake and potentially in the propagation of pathologic aSyn. For this purpose, we conducted in vitro experiments with WT SHSY5Y and PrPC overexpressing SH-SY5Y cells which were treated with monomeric and oligomeric aSyn. The combination of oligomeric aSyn and $\operatorname{PrP}^{C}$ overexpression resulted in a higher internalization of total and S129 phosphorylated aSyn in SH-SY5Y-PrP cells. Additionally, the uptake of aSyn and colocalization with $\mathrm{PrP}^{\mathrm{C}}$ could be confirmed in different subcellular fractions of these cells. Furthermore, the direct binding, as well as the binding characteristics of monomeric and oligomeric aSyn to $\operatorname{PrP}^{C}$, was shown with surface plasmon resonance spectrometry indicating lower $K_{D}$ values for oligomeric aSyn than for monomeric species.

For the in vivo analysis, two different pathological aSyn mouse models (Tgm83 and ThySyn) were crossed with a PrP-KO model (Zurich I) to examine $\operatorname{PrP}^{\mathrm{C}}$ depending changes in the pathology of the newly generated mouse lines (TgmPrP00 and ThySynPrP00). The depletion of the prion protein resulted in the rescue of the pathological phenotype in ThySynPrPOO compared to ThySyn mice, suggesting $\operatorname{PrPC}^{\mathrm{C}}$ as a mediator of the misfolded aSyn induced toxicity. Analysis of the subcellular fractions showed a deviating distribution of aSyn in ThySyn and ThySynPrP00 mice which is translocated from the plasma membrane to the cytosol. Additionally, we performed a common binding partner study of aSyn and PrPC, via co-IPs of ThySyn brain lysates. Here, we detected aSyn in $\operatorname{PrP}^{\mathrm{C}}$ precipitates and vice versa, supporting the results from our interaction study using the SPR. To evaluate possible proteins, which might be involved in the aSyn-PrPC interaction, proteins obtained from both Co-IPs were analyzed by mass spectrometry. In this examination, the coat protein of clathrin-coated pits, clathrin, involved in endocytosis, was detected in the aSyn and PrPC precipitate as a common interaction partner. Comparing the expression of clathrin in our mice line, we observed a significant downregulation in ThySynPrP00 mice compared to ThySyn mice indicating clathrin as a crucial key player in the $\operatorname{PrP}^{\mathrm{C}}$ mediated internalization of aSyn. 
In summary, our work supports the theory of $\mathrm{PrP}^{\mathrm{C}}$ as a receptor protein, promoting the internalization of pathological aSyn via clathrin-coated vesicles, influencing the disease's progression. We propose that this mechanism is associated with the prion-like spreading of misfolded aSyn. The outcome can help to identify $\operatorname{PrP}^{C}$ as a specific target for future therapeutical interventions. 


\section{Appendix}

Table 13: List of overlapping proteins from aSyn and $\operatorname{PrP}^{\mathrm{C}}$ Co-IP

\begin{tabular}{|c|c|c|}
\hline Accession number & Protein names & Localization \\
\hline Q68FD5 & Clathrin & Cyt \\
\hline Q6PIC6 & Sodium/potassium-transporting ATPase & Mem \\
\hline P17710 & Hexokinase-1 & Mit, Mem, Cyt \\
\hline 008599 & Syntaxin-binding protein 1 & Cyt, Mem \\
\hline P16330 & 2',3'-cyclic-nucleotide 3'-phosphodiesterase & Mem \\
\hline P46460 & Vesicle-fusing ATPase & Cyt \\
\hline P84091 & AP-2 complex & Mem \\
\hline P63017 & Heat shock cognate $71 \mathrm{kDa}$ protein & Cyt, Nuc, Mem \\
\hline Q9R0K7 & Plasma membrane calcium-transporting ATPase 2 & Mem \\
\hline P47857 & ATP-dependent 6-phosphofructokinase & Cyt \\
\hline P63101 & 14-3-3 protein zeta/delta & Cyt \\
\hline Q8C194 & Glycogen phosphorylase & - \\
\hline P11499 & Heat shock protein HSP 90-beta & Cyt, Nuc, Mem \\
\hline P46096 & Synaptotagmin-1 & Mem \\
\hline P04370 & Myelin basic protein & Mem \\
\hline P63011 & Ras-related protein Rab-3A & Cyt, Mem \\
\hline Q04447 & Creatine kinase B-type & Cyt \\
\hline Q62277 & Synaptophysin & Mem \\
\hline P43006 & Excitatory amino acid transporter 2 & Mem \\
\hline P50516 & V-type proton ATPase catalytic subunit A & Cyt \\
\hline P61982 & 14-3-3 protein gamma & Cyt \\
\hline P62814 & V-type proton ATPase & Mem \\
\hline P98086 & Complement C1q subcomponent subunit A & Ext \\
\hline P14094 & Sodium/potassium-transporting ATPase & Mem \\
\hline P07901 & Heat shock protein HSP 90-alpha & Nuc,Cyt,Mem \\
\hline P56564 & Excitatory amino acid transporter 1 & Mem \\
\hline P17182 & Alpha-enolase & Cyt, Mem \\
\hline P62259 & 14-3-3 protein epsilon (14-3-3E) & Nuc \\
\hline Q9DB77 & Cytochrome b-c1 complex & Mit \\
\hline Q9CQQ7 & ATP synthase & Mit \\
\hline P00405 & Cytochrome c oxidase & Mit \\
\hline 055131 & Septin-7 (CDC10 protein homolog) & Cyt \\
\hline P62880 & Guanine nucleotide-binding protein & Cyt \\
\hline Q8CAA7 & Glucose 1,6-bisphosphate synthase & - \\
\hline P97427 & Dihydropyrimidinase-related protein 1 & Cyt \\
\hline Q61548 & Clathrin coat assembly protein AP180 & Mem \\
\hline Q8R191 & Synaptogyrin-3 & Mem \\
\hline Q9WUB3 & Glycogen phosphorylase & - \\
\hline
\end{tabular}

Cyt=Cytosol; Mem=Membrane; Mit=Mitochondria; Nuc=Nucleus; Ext=Extracellular 


\section{References}

Abounit S, Bousset L, Loria F, Zhu S, Chaumont F, Pieri L, Olivo-Marin J, Melki R, Zurzolo C (2016): Tunneling nanotubes spread fibrillar $\alpha$-synuclein by intercellular trafficking of lysosomes. EMBO J

Acevedo-Morantes CY, Wille H (2014): The structure of human prions: From biology to structural models - considerations and pitfalls. Viruses $\underline{6}$, 3875-3892

Anderson JP, Walker DE, Goldstein JM, De Laat R, Banducci K, Caccavello RJ, Barbour R, Huang J, Kling K, Lee M, et al. (2006): Phosphorylation of Ser-129 is the dominant pathological modification of $\alpha$-synuclein in familial and sporadic lewy body disease. J Biol Chem

Angot E, Steiner JA, Hansen C, Li JY, Brundin P (2010): Are synucleinopathies prion-like disorders? Lancet Neurol

Armstrong RA, Nochlin D, Bird TD (2000): Neuropathological heterogeneity in Alzheimer's disease: a study of 80 cases using principal components analysis. Neuropathology $20,31-$ 37

Aulić S, Masperone L, Narkiewicz J, Isopi E, Bistaffa E, Ambrosetti E, Pastore B, De Cecco E, Scaini D, Zago P, et al. (2017): $\alpha$-Synuclein Amyloids Hijack Prion Protein to Gain Cell Entry, Facilitate Cell-to-Cell Spreading and Block Prion Replication. Sci Rep $\underline{7}, 10050$

Baker HF, Ridley RM, Duchen LW, Crow TJ, Bruton CJ (1993): Evidence for the experimental transmission of cerebral beta-amyloidosis to primates. Int J Exp Pathol $\underline{74}, 441-54$

Bartels T, Choi JG, Selkoe DJ (2011): Alpha-Synuclein occurs physiologically as a helically folded tetramer that resists aggregation. Nature $\underline{477}, 107-111$

Baskakov I V., Legname G, Baldwin MA, Prusiner SB, Cohen FE (2002): Pathway complexity of prion protein assembly into amyloid. J Biol Chem 277, 21140-21148

Basler K, Oesch B, Scott M, Westaway D, Wälchli M, Groth DF, McKinley MP, Prusiner SB, Weissmann C (1986): Scrapie and cellular PrP isoforms are encoded by the same chromosomal gene. Cell $\underline{46}, 417-28$

Bendor JT, Logan TP, Edwards RH (2013): The function of alpha-synuclein. Neuron $\underline{79}$, 10441066

Bera A, Biring S (2018): A quantitative characterization of interaction between prion protein with nucleic acids. Biochem Biophys Reports $\underline{14}$, 114-124

Bernis ME, Babila JT, Breid S, Wüsten KA, Wüllner U, Tamgüney G (2015): Prion-like propagation of human brain-derived alpha-synuclein in transgenic mice expressing 
human wild-type alpha-synuclein. Acta Neuropathol Commun

Biedler JL, Schachner M (1978): Multiple Neurotransmitter Synthesis by Human Neuroblastoma Cell Lines and Clones. Cancer Res

Borchelt DR, Scott M, Taraboulos A, Stahl N, Prusiner SB (1990): Crapie and cellular prion proteins differ in their kinetics of synthesis and topology in cultured cells. J Cell Biol $\underline{110}$, $743-752$

Breydo L, Wu JW, Uversky VN (2012): alpha-Synuclein misfolding and Parkinson's disease. Biochim Biophys Acta - Mol Basis Dis 1822, 261-285

Bridi JC, Hirth F (2018): Mechanisms of $\alpha$-Synuclein Induced Synaptopathy in Parkinson's Disease. Front Neurosci 12, 1-18

Brown DR, Nicholas RSJ, Canevari L (2002): Lack of prion protein expression results in a neuronal phenotype sensitive to stress. J Neurosci Res $\underline{67}, 211-224$

Brundin P, Ma J, Kordower JH (2016): How strong is the evidence that Parkinson's disease is a prion disorder? Curr Opin Neurol

Büeler H, Fischer M, Lang Y, Bluethmann H, Lipp H-P, DeArmond SJ, Prusiner SB, Aguet M, Weissmann C (1992a): Normal development and behaviour of mice lacking the neuronal cell-surface PrP protein. Nature $\underline{356}, 577-582$

Büeler H, Fischer M, Lang Y, Bluethmann H, Lipp HP, Dearmond SJ, Prusiner SB, Aguet $M$, Weissmann C (1992b): Normal development and behaviour of mice lacking the neuronal cell-surface PrP protein. Nature

Burré J, Sharma M, Tsetsenis T, Buchman V, Etherton MR, Südhof TC (2010): $\alpha$-Synuclein promotes SNARE-complex assembly in vivo and in vitro. Science (80- ) 329, 1663-1667

Carulla P, Llorens F, Matamoros-Angles A, Aguilar-Calvo P, Espinosa JC, Gavín R, Ferrer I, Legname G, Torres JM, Del Río JA (2015): Involvement of PrP C in kainate-induced excitotoxicity in several mouse strains (Glimepirid). Sci Rep $\underline{5}$, 1-15

Caughey BW, Dong A, Bhat KS, Ernst D, Hayes SF, Caughey WS (1991): Secondary structure analysis of the scrapie-associated protein PrP 27-30 in water by infrared spectroscopy [published erratum appears in Biochemistry 1991 Oct 29;30(43):10600]. Biochemistry $\underline{30}$, $7672-7680$

Chandra S, Fornai F, Kwon H-B, Yazdani U, Atasoy D, Liu X, Hammer RE, Battaglia G, German DC, Castillo PE, Südhof TC (2004): Double-knockout mice for alpha- and beta-synucleins: effect on synaptic functions. Proc Natl Acad Sci U S A $\underline{101}, 14966-71$ 
Chen J, Gao C, Shi Q, Wang G, Lei Y, Shan B, Zhang B, Dong C, Shi S, Wang X, et al. (2008): Casein kinase II interacts with prion protein in vitro and forms complex with native prion protein in vivo. Acta Biochim Biophys Sin (Shanghai)

Chen L, Jin J, Davis J, Zhou Y, Wang Y, Liu J, Lockhart PJ, Zhang J (2007): Oligomeric $\alpha$-synuclein inhibits tubulin polymerization. Biochem Biophys Res Commun

Chen L, Periquet M, Wang X, Negro A, McLean PJ, Hyman BT, Feany MB (2009): Tyrosine and serine phosphorylation of alpha-synuclein have opposing effects on neurotoxicity and soluble oligomer formation. J Clin Invest $\underline{119}$, 3257-3265

Chesselet MF, Richter F, Zhu C, Magen I, Watson MB, Subramaniam SR (2012): A Progressive Mouse Model of Parkinson's Disease: The Thy1-aSyn („Line 61“) Mice. Neurotherapeutics 9, 297-314

Chia R, Tattum MH, Jones S, Collinge J, Fisher EMC, Jackson GS (2010): Superoxide dismutase 1 and tgSOD1 mouse spinal cord seed fibrils, suggesting a propagative cell death mechanism in amyotrophic lateral sclerosis. PLoS One $\underline{5}$, e10627

Chui HC, Teng EL, Henderson VW, Moy AC (1985): Clinical subtypes of dementia of the Alzheimer type. Neurology $\underline{35}, 1544-1550$

Chung SJ, Armasu SM, Biernacka JM, Lesnick TG, Rider DN, Lincoln SJ, Ortolaza AI, Farrer MJ, Cunningham JM, Rocca WA, Maraganore DM (2011): Common variants in PARK loci and related genes and Parkinson's disease. Mov Disord 26, 280-288

Clavaguera F, Bolmont T, Crowther RA, Abramowski D, Frank S, Probst A, Fraser G, Stalder AK, Beibel M, Staufenbiel M, et al. (2009): Transmission and spreading of tauopathy in transgenic mouse brain. Nat Cell Biol

Colby DW, Prusiner SB (2011): Prions. Cold Spring Harb Perspect Biol $\underline{3}, 1-22$

Colling SB, Khana M, Collinge J, Jefferys JGR (1997): Mossy fibre reorganization in the hippocampus of prion protein null mice. Brain Res $\underline{755}$, 28-35

Conway KA, Lee SJ, Rochet JC, Ding TT, Williamson RE, Lansbury PT (2000): Acceleration of oligomerization, not fibrillization, is a shared property of both alpha-synuclein mutations linked to early-onset Parkinson's disease: implications for pathogenesis and therapy. Proc Natl Acad Sci U S A 97, 571-6

Cookson MR (2005): The biochemistry of Parkinson's disease. Rev Lit Arts Am 29-52

Criado JR, Sánchez-Alavez M, Conti B, Giacchino JL, Wills DN, Henriksen SJ, Race R, Manson JC, Chesebro B, Oldstone MBA (2005): Mice devoid of prion protein have cognitive deficits 
that are rescued by reconstitution of PrP in neurons. Neurobiol Dis $\underline{19}, 255-265$

Cuvelier E, Méquinion M, Leghay C, Sibran W, Stievenard A, Sarchione A, Bonte MA, Vanbesien-Mailliot C, Viltart O, Saitoski K, et al. (2018): Overexpression of Wild-Type Human Alpha-Synuclein Causes Metabolism Abnormalities in Thy1-aSYN Transgenic Mice. Front Mol Neurosci

Danzer KM, Haasen D, Karow AR, Moussaud S, Habeck M, Giese A, Kretzschmar H, Hengerer B, Kostka M (2007): Different species of $\alpha$-synuclein oligomers induce calcium influx and seeding. J Neurosci

Deacon RMJ (2006): Assessing nest building in mice. Nat Protoc $\underline{1}, 1117-1119$

Desplats P, Lee H-J, Bae E-J, Patrick C, Rockenstein E, Crews L, Spencer B, Masliah E, Lee S-J (2009): Inclusion formation and neuronal cell death through neuron-to-neuron transmission of -synuclein. Proc Natl Acad Sci

Emanuele M, Chieregatti E (2015): Mechanisms of alpha-synuclein action on neurotransmission: Cell-autonomous and non-cell autonomous role. Biomolecules $\underline{5}$, 865-892

Emmanouilidou E, Melachroinou K, Roumeliotis T, Garbis SD, Ntzouni M, Margaritis LH, Stefanis L, Vekrellis K (2010): Cell-produced $\alpha$-synuclein is secreted in a calciumdependent manner by exosomes and impacts neuronal survival. J Neurosci

Ennaceur A (2010): One-trial object recognition in rats and mice: Methodological and theoretical issues. Behav Brain Res

Eraña $H$ (2019): The Prion 2018 round tables (II): A $\beta$, tau, $\alpha$-synuclein... are they prions, prionlike proteins, or what? Prion $\underline{13}, 41-45$

Fauvet B, Mbefo MK, Fares MB, Desobry C, Michael S, Ardah MT, Tsika E, Coune P, Prudent M, Lion $N$, et al. (2012): $\alpha$-Synuclein in central nervous system and from erythrocytes, mammalian cells, and Escherichia coli exists predominantly as disordered monomer. J Biol Chem 287, 15345-15364

Ferreira DG, Temido-Ferreira M, Miranda HV, Batalha VL, Coelho JE, Szegö ÉM, MarquesMorgado I, Vaz SH, Rhee JS, Schmitz M, et al. (2017): $\alpha$-synuclein interacts with PrPC to induce cognitive impairment through mGluR5 and NMDAR2B. Nat Neurosci $\underline{20}$

Février B, Vilette D, Laude H, Raposo G (2005): Exosomes: A bubble ride for prions? Traffic $\underline{6}$, 10-17

Fluharty BR, Biasini E, Stravalaci M, Sclip A, Diomede L, Balducci C, La Vitola P, Messa M, 
Colombo L, Forloni G, et al. (2013): An N-terminal fragment of the prion protein binds to amyloid- $\beta$ oligomers and inhibits their neurotoxicity in vivo. J Biol Chem $\underline{288}, 7857-7866$ Freir DB, Nicoll AJ, Klyubin I, Panico S, Mc Donald JM, Risse E, Asante EA, Farrow MA, Sessions RB, Saibil HR, et al. (2011): Interaction between prion protein and toxic amyloid $\beta$ assemblies can be therapeutically targeted at multiple sites. Nat Commun $\underline{2}$

Fujiwara H, Hasegawa M, Dohmae N, Kawashima A, Masliah E, Goldberg MS, Shen J, Takio K, Iwatsubo T (2002): $\alpha$-Synuclein is phosphorylated in synucleinopathy lesions. Nat Cell Biol 4, 160-164

Gambetti P, Kong Q, Zou W, Parchi P, Chen SG (2003): Sporadic and familial CJD: Classification and characterisation. Br Med Bull 66, 213-239

Ganzinger KA, Narayan P, Qamar SS, Weimann L, Ranasinghe RT, Aguzzi A, Dobson CM, McColl J, St. George-Hyslop P, Klenerman D (2014): Single-MOLECULE IMAGING REVEALS THAT SMALL AMYLOID- $\beta 1-42$ oligomers interact with the cellular prion protein (PrPC). ChemBioChem 15, 2515-2521

Giasson BI, Duda JE, Murray IVJ, Chen Q, Souza JM, Hurtig HI, Ischiropoulos H, Trojanowski JQ, Lee VMY (2000): Oxidative damage linked to neurodegeneration by selective ??synuclein nitration in synucleinopathy lesions. Science (80- ) 290, 985-989

Giasson BI, Duda JE, Quinn SM, Zhang B, Trojanowski JQ, Lee VMY (2002): Neuronal alphasynucleinopathy with severe movement disorder in mice expressing A53T human $\alpha$ synuclein. Neuron $\underline{34}, 521-533$

Goedert M (2001): Alpha-synuclein and neurodegenerative diseases. Nat Rev Neurosci 2, 492501

Govaerts C, Wille H, Prusiner SB, Cohen FE (2004): Evidence for assembly of prions with lefthanded -helices into trimers. Proc Natl Acad Sci 101, 8342-8347

Graham DR, Sidhu A (2010): Mice expressing the A53T mutant form of human alpha-synuclein exhibit hyperactivity and reduced anxiety-like behavior. J Neurosci Res $\underline{88}, 1777-1783$

Gu Y, Hinnerwisch J, Fredricks R, Kalepu S, Mishra RS, Singh N (2003): Identification of cryptic nuclear localization signals in the prion protein. Neurobiol Dis

Haraguchi T, Fisher S, Olofsson S, Endo T, Groth D, Tarentino A, Borchelt DR, Teplow D, Hood L, Burlingame A, et al. (1989): Asparagine-linked glycosylation of the scrapie and cellular prion proteins. Arch Biochem Biophys 274, 1-13

Harrison PM, Khachane A, Kumar M (2010): Genomic assessment of the evolution of the prion 
protein gene family in vertebrates. Genomics $95,268-277$

Heilbronner G, Eisele YS, Langer F, Kaeser SA, Novotny R, Nagarathinam A, Åslund A, Hammarström P, Nilsson KPR, Jucker M (2013): Seeded strain-like transmission of $\beta$ amyloid morphotypes in APP transgenic mice. EMBO Rep

Ironside JW, Ritchie DL, Head MW (2005): Phenotypic variability in human prion diseases. Neuropathol Appl Neurobiol 31, 565-579

Jin S, Kedia N, Illes-Toth E, Haralampiev I, Prisner S, Herrmann A, Wanker EE, Bieschke J (2016): Amyloid- $\beta$ (1- 42) Aggregation Initiates Its Cellular Uptake and Cytotoxicity. J Biol Chem 291, 19590-19606

Kahle PJ, Neumann M, Ozmen L, Müller V, Jacobsen H, Schindzielorz A, Okochi M, Leimer U, Van Der Putten H, Probst A, et al. (2000): Subcellular localization of wild-type and Parkinson's disease-associated mutant $\alpha$-synuclein in human and transgenic mouse brain. J Neurosci

Kang Y-S, Zhao X, Lovaas J, Eisenberg E, Greene LE (2009): Clathrin-independent internalization of normal cellular prion protein in neuroblastoma cells is associated with the Arf6 pathway. J Cell Sci 122, 4062-9

Kasten M, Klein C (2013): The many faces of alpha-synuclein mutations. Mov Disord 28, 697701

Kirchhausen T, Owen D, Harrison SC (2014): Molecular Structure, Function, and Dynamics of Clathrin-Mediated Membrane Traffic.

Kontopoulos E, Parvin JD, Feany MB (2006): $\alpha$-synuclein acts in the nucleus to inhibit histone acetylation and promote neurotoxicity. Hum Mol Genet $\underline{15}$, 3012-3023

Kosten J, Binolfi A, Stuiver M, Verzini S, Theillet FX, Bekei B, Van Rossum M, Selenko P (2014): Efficient modification of alpha-synuclein serine 129 by protein kinase CK1 requires phosphorylation of tyrosine 125 as a priming event. ACS Chem Neurosci $\underline{5}, 1203-1208$

Kovalevich J, Langford D (2013): Considerations for the Use of SH-SY5Y Neuroblastoma Cells in Neurobiology. 1078, 9-21

Lam HA, Wu N, Cely I, Kelly RL, Hean S, Richter F, Magen I, Cepeda C, Ackerson LC, Walwyn W, et al. (2011): Elevated tonic extracellular dopamine concentration and altered dopamine modulation of synaptic activity precede dopamine loss in the striatum of mice overexpressing human $\alpha$-synuclein. J Neurosci Res

Lashuel HA, Overk CR, Oueslati A, Masliah E (2013): The many faces of $\alpha$-synuclein: from 
structure and toxicity to therapeutic target. Nat Rev Neurosci $\underline{14}, 38-48$

Laurén J, Gimbel DA, Nygaard HB, Gilbert JW, Strittmatter SM (2009): Cellular prion protein mediates impairment of synaptic plasticity by amyloid-B oligomers. Nature $\underline{457}, 1128-$ 1132

Lavedan C (1998): The synuclein family. Genome Res $\underline{8}$, 871-880

Leclerc E, Serban H, Prusiner SB, Burton DR, Williamson RA (2006): Copper induces conformational changes in the N-terminal part of cell-surface PrPC. Arch Virol 151, 21032109

Lee HJ, Khoshaghideh F, Lee S, Lee SJ (2006): Impairment of microtubule-dependent trafficking by overexpression of ??-synuclein. Eur J Neurosci 24, 3153-3162

Lee HJ, Suk JE, Bae EJ, Lee JH, Paik SR, Lee SJ (2008): Assembly-dependent endocytosis and clearance of extracellular $\alpha$-synuclein. Int J Biochem Cell Biol

Lee Y, Dawson VL, Dawson TM (2012): Animal models of Parkinson's disease: Vertebrate genetics. Cold Spring Harb Perspect Med 2, 1-13

Lima LMTR, Cordeiro Y, Tinoco LW, Marques AF, Oliveira CLP, Sampath S, Kodali R, Choi G, Foguel D, Torriani I, et al. (2006): Structural insights into the interaction between prion protein and nucleic acid. Biochemistry

Lorenzen N, Lemminger L, Pedersen JN, Nielsen SB, Otzen DE (2014): The N-terminus of $\alpha$ synuclein is essential for both monomeric and oligomeric interactions with membranes. FEBS Lett $\underline{588}, 497-502$

Luk KC, Kehm VM, Zhang B, O'Brien P, Trojanowski JQ, Lee VMY (2012): Intracerebral inoculation of pathological $\alpha$-synuclein initiates a rapidly progressive neurodegenerative $\alpha$-synucleinopathy in mice. J Exp Med 209, 975-986

Magen I, Chesselet MF: Genetic mouse models of Parkinson's disease. The state of the art. Band 184; Elsevier B.V. 2010

Magen I, Chesselet M-F (2011): Mouse models of cognitive deficits due to alpha-synuclein pathology. J Parkinsons Dis $\underline{1}, 217-27$

Magen I, Fleming SM, Zhu C, Garcia EC, Cardiff KM, Dinh D, De La Rosa K, Sanchez M, Torres ER, Masliah E, et al. (2012): Cognitive deficits in a mouse model of pre-manifest Parkinson's disease. Eur J Neurosci $\underline{35}$, 870-882

Mallucci G, Dickinson A, Linehan J, Klöhn PC, Brandner S, Collinge J (2003): Depleting Neuronal PrP in Prion Infection Prevents Disease and Reverses Spongiosis. Science (80- ) 302, 871- 
874

Manson JC, Clarke AR, Hooper ML, Aitchison L, McConnell I, Hope J (1994): 129/Ola mice carrying a null mutation in PrP that abolishes mRNA production are developmentally normal. Mol Neurobiol

Marciniuk K, Taschuk R, Napper S (2013): Evidence for prion-like mechanisms in several neurodegenerative diseases: Potential implications for immunotherapy. Clin Dev Immunol $\underline{2013}$

Maroteaux L, Campanelli JT, Scheller RH (1988): Synuclein: a neuron-specific protein localized to the nucleus and presynaptic nerve terminal. J Neurosci $\underline{8}, 2804-2815$

McLennan NF, Brennan PM, McNeill A, Davies I, Fotheringham A, Rennison KA, Ritchie D, Brannan F, Head MW, Ironside JW, et al. (2004): Prion protein accumulation and neuroprotection in hypoxic brain damage. Am J Pathol 165, 227-235

Mendez OE, Shang J, Jungreis CA, Kaufer DI (2003): Diffusion-weighted MRI in CreutzfeldtJakob disease: A better diagnostic marker than CSF protein 14-3-3? J Neuroimaging $\underline{13}$, $147-151$

Middleton ER, Rhoades E (2010): Effects of curvature and composition on $\alpha$-synuclein binding to lipid vesicles. Biophys J 99, 2279-2288

Nikles D, Vana K, Gauczynski S, Knetsch H, Ludewigs H, Weiss S (2008): Subcellular localization of prion proteins and the $37 \mathrm{kDa} / 67 \mathrm{kDa}$ laminin receptor fused to fluorescent proteins. Biochim Biophys Acta - Mol Basis Dis

Oh SH, Kim HN, Park HJ, Shin JY, Bae EJ, Sunwoo MK, Lee SJ, Lee PH (2016): Mesenchymal Stem Cells Inhibit Transmission of $\alpha$-Synuclein by Modulating Clathrin-Mediated Endocytosis in a Parkinsonian Model. Cell Rep 14, 835-849

Okochi M, Walter J, Koyama A, Nakajo S, Baba M, Iwatsubo T, Meijer L, Kahle PJ, Haass C (2000): Constitutive phosphorylation of the Parkinson's disease associated $\alpha$ - synuclein. J Biol Chem

Ostapchenko VG, Beraldo FH, Mohammad AH, Xie Y-F, Hirata PHF, Magalhaes AC, Lamour G, Li H, Maciejewski A, Belrose JC, et al. (2013): The Prion Protein Ligand, Stress-Inducible Phosphoprotein 1, Regulates Amyloid- Oligomer Toxicity. J Neurosci 33, 16552-16564

Oueslati A (2016): Implication of Alpha-Synuclein Phosphorylation at S129 in Synucleinopathies: What Have We Learned in the Last Decade? J Parkinsons Dis $\underline{6}$, 39-51 Paleologou KE, Oueslati A, Shakked G, Rospigliosi CC, Kim H-Y, Lamberto GR, Fernandez CO, 
Schmid A, Chegini F, Gai WP, et al. (2010): Phosphorylation at S87 Is Enhanced in Synucleinopathies, Inhibits -Synuclein Oligomerization, and Influences SynucleinMembrane Interactions. J Neurosci 30, 3184-3198

Pan K-M, Stahl N, Prusiner SB (1992): Purification and properties of the cellular prion protein from Syrian hamster brain. Protein Sci $\underline{1}, 1343-1352$

Pan KM, Baldwin M, Nguyen J, Gasset M, Serban A, Groth D, Mehlhorn I, Huang Z, Fletterick RJ, Cohen FE (1993): Conversion of alpha-helices into beta-sheets features in the formation of the scrapie prion proteins. Proc Natl Acad Sci $\underline{\text { 90, }}$ 10962-10966

Paumier KL, Sukoff Rizzo SJ, Berger Z, Chen Y, Gonzales C, Kaftan E, Li L, Lotarski S, Monaghan M, Shen W, et al. (2013): Behavioral Characterization of A53T Mice Reveals Early and Late Stage Deficits Related to Parkinson's Disease. PLoS One $\underline{8}$

Peelaerts W, Baekelandt V (2016): a-Synuclein strains and the variable pathologies of synucleinopathies. J Neurochem $\underline{139}, 256-274$

Peelaerts W, Bousset L, Van der Perren A, Moskalyuk A, Pulizzi R, Giugliano M, Van den Haute C, Melki R, Baekelandt V (2015): $\alpha$-Synuclein strains cause distinct synucleinopathies after local and systemic administration. Nature $\underline{522}, 340-344$

Peggion C, Stella R, Chemello F, Massimino ML, Arrigoni G, Cagnin S, Biancotto G, Franchin C, Sorgato MC, Bertoli A (2019): The Prion Protein Regulates Synaptic Transmission by Controlling the Expression of Proteins Key to Synaptic Vesicle Recycling and Exocytosis. Mol Neurobiol

Pozo Devoto VM, Falzone TL (2017): Mitochondrial dynamics in Parkinson's disease: a role for $\alpha$-synuclein? Dis Model Mech

Prusiner SB (1982): Novel proteinaceous infectious particles cause scrapie. Science $\underline{216}, 136-$ 44

Prusiner SB, DeArmond SJ (1994): Prion Diseases and Neurodegeneration. Annu Rev Neurosci 17, 311-339

Puckett C, Concannon P, Casey C, Hood L (1991): Genomic structure of the human prion protein gene. Am J Hum Genet $\underline{49}, 320-329$

Puig S, Thiele DJ (2002): Molecular mechanisms of copper uptake and distribution. Curr Opin Chem Biol $\underline{6}, 171-180$

Rabl R, Breitschaedel C, Flunkert S, Duller S, AmschI D, Neddens J, Niederkofler V, Rockenstein E, Masliah E, Roemer H, Hutter-Paier B (2017): Early start of progressive motor deficits in 
Line $61 \alpha$-synuclein transgenic mice. BMC Neurosci 18, 22

Recasens A, Dehay B, Bové J, Carballo-Carbajal I, Dovero S, Pérez-Villalba A, Fernagut PO, Blesa

J, Parent A, Perier C, et al. (2014): Lewy body extracts from Parkinson disease brains trigger $\alpha$-synuclein pathology and neurodegeneration in mice and monkeys. Ann Neurol

Riek R, Hornemann S, Wider G, Billeter M, Glockshuber R, Wuthrich K (1996): NMR structure of the mouse prion protein domain $\operatorname{PrP}(121-231)$. Nature $\underline{382}, 180-182$

Rieker C, Dev KK, Lehnhoff K, Barbieri S, Ksiazek I, Kauffmann S, Danner S, Schell H, Boden C, Ruegg MA, et al. (2011): Neuropathology in mice expressing mouse alpha-synuclein. PLoS One $\underline{6}$

del Río JA, Ferrer I, Gavín R (2018): Role of cellular prion protein in interneuronal amyloid transmission. Prog Neurobiol 0-1

Rivera-Milla E, Oidtmann B, Panagiotidis CH, Baier M, Sklaviadis T, Hoffmann R, Zhou Y, Solis GP, Stuermer CAO, Málaga-Trillo E (2005): Disparate evolution of prion protein domains and the distinct origin of Doppel- and prion-related loci revealed by fish-to-mammal comparisons. FASEB J $\underline{20}$, 317-9

Roberts HL, Brown DR (2015): Seeking a Mechanism for the Toxicity of Oligomeric l-Synuclein. 282-305

Rockenstein E, Mallory M, Hashimoto M, Song D, Shults CW, Lang I, Masliah E (2002): Differential neuropathological alterations in transgenic mice expressing alpha-synuclein from the platelet-derived growth factor and Thy-1 promoters. J Neurosci Res $\underline{68}, 568-$ 578

Saborio GP, Permanne B, Soto C (2001): Sensitive detection of pathological prion protein by cyclic amplification of protein misfolding. Nature $\underline{411}, 810-813$

Salazar S V., Strittmatter SM (2017a): Cellular prion protein as a receptor for amyloid-?? oligomers in Alzheimer's disease. Biochem Biophys Res Commun 483, 1143-1147

Salazar S V., Strittmatter SM (2017b): Cellular prion protein as a receptor for amyloid- $\beta$ oligomers in Alzheimer's disease. Biochem Biophys Res Commun 483, 1143-1147

Santuccione A, Sytnyk V, Leshchyns'ka I, Schachner M (2005): Prion protein recruits its neuronal receptor NCAM to lipid rafts to activate p59fyn and to enhance neurite outgrowth. J Cell Biol $\underline{169}, 341-354$

Satake W, Nakabayashi Y, Mizuta I, Hirota Y, Ito C, Kubo M, Kawaguchi T, Tsunoda T, Watanabe M, Takeda A, et al. (2009): Genome-wide association study identifies common variants 
at four loci as genetic risk factors for Parkinson's disease. Nat Genet $\underline{41}, 1303-1307$

Savitt JM, Dawson VL, Dawson TM (2006): Diagnosis and treatment of Parkinson disease:

Molecules to medicine. J Clin Invest

Schätzl HM, Da Costa M, Taylor L, Cohen FE, Prusiner SB (1995): Prion protein gene variation among primates. J Mol Biol $\underline{245}, 362-74$

Schmid SL (1997): CLATHRIN-COATED VESICLE FORMATION AND PROTEIN SORTING:An Integrated Process. Annu Rev Biochem

Schmitt-Ulms G, Legname G, Baldwin MA, Ball HL, Bradon N, Bosque PJ, Crossin KL, Edelman GM, DeArmond SJ, Cohen FE, Prusiner SB (2001): Binding of neural cell adhesion molecules (N-CAMs) to the cellular prion protein. J Mol Biol 314, 1209-1225

Schmitz M, Lüllmann K, Zafar S, Ebert E, Wohlhage M, Oikonomou P, Schlomm M, Mitrova E, Beekes M, Zerr I (2014a): Association of prion protein genotype and scrapie prion protein type with cellular prion protein charge isoform profiles in cerebrospinal fluid of humans with sporadic or familial prion diseases. Neurobiol Aging $\underline{35}, 1177-1188$

Schmitz M, Zafar S, Silva CJ, Zerr I (2014b): Behavioral abnormalities in prion protein knockout mice and the potential relevance of PrPC for the cytoskeleton. Prion

Schmitz M, Greis C, Ottis P, Silva CJ, Schulz-Schaeffer WJ, Wrede A, Koppe K, Onisko B, Requena JR, Govindarajan N, et al. (2014c): Loss of Prion Protein Leads to Age-Dependent Behavioral Abnormalities and Changes in Cytoskeletal Protein Expression. Mol Neurobiol 50, 923-936

Schoch S, Deák F, Königstorfer A, Mozhayeva M, Sara Y, Südhof TC, Kavalali ET (2001): SNARE Function Analyzed in Synaptobrevin/VAMP Knockout Mice. Science (80- ) 294, 11171122

Shyng SL, Heuser JE, Harris DA (1994): A glycolipid-anchored prion protein is endocytosed via clathrin-coated pits. J Cell Biol $\underline{125}, 1239-1250$

Shyng SL, Moulder KL, Lesko A, Harris DA (1995): The N-terminal domain of a glycolipidanchored prion protein is essential for its endocytosis via clathrin-coated pits. J Biol Chem $\underline{270}, 14793-14800$

Siddiqui A, Chinta SJ, Mallajosyula JK, Rajagopolan S, Hanson I, Rane A, Melov S, Andersen JK (2012): Selective binding of nuclear alpha-synuclein to the PGC1alpha promoter under conditions of oxidative stress may contribute to losses in mitochondrial function: Implications for Parkinson's disease. Free Radic Biol Med 53, 993-1003 
Silva BA, Breydo L, Uversky VN (2013): Targeting the Chameleon: a Focused Look at $\alpha$ Synuclein and Its Roles in Neurodegeneration. Mol Neurobiol 47, 446-459

Silveira JR, Raymond GJ, Hughson AG, Race RE, Sim VL, Hayes SF, Caughey B (2005): The most infectious prion protein particles. Nature $\underline{437}, 257-261$

Simón-Sánchez J, Schulte C, Bras JM, Sharma M, Gibbs JR, Berg D, Paisan-Ruiz C, Lichtner P, Scholz SW, Hernandez DG, et al. (2009): Genome-wide association study reveals genetic risk underlying Parkinson's disease. Nat Genet $\underline{41}$, 1308-1312

Spudich A, Frigg R, Kilic E, Kilic Ü, Oesch B, Raeber A, Bassetti CL, Hermann DM (2005): Aggravation of ischemic brain injury by prion protein deficiency: Role of ERK-1/-2 and STAT-1. Neurobiol Dis $\underline{20}, 442-449$

Sriram SR, Dawson VL, Dawson TM (2005): Genetics of parkinson's disease. Neurogenetics Sci Clin Adv 621-641

Stahl N, Borchelt DR, Hsiao K, Prusiner SB (1987): Scrapie prion protein contains a phosphatidylinositol glycolipid. Cell

Stahl N, Baldwin M a., Hecker R, Pan KM, Burlingame a. L, Prusiner SB (1992): Glycosylinositol phospholipid anchors of the scrapie and cellular prion proteins contain sialic acid. Biochemistry 31, 5043-5053

Steele AD, Lindquist S, Aguzzi A (2014): The Prion Protein Knockout Mouse. Prion 1, 83-93

Surewicz WK, Apostol MI (2011): Prion Protein and its conformational conversion: A structural perspective. Top Curr Chem 305, 135-168

Taylor DR, Hooper NM (2006a): The prion protein and lipid rafts. Mol Membr Biol 23, 89-99

Taylor DR, Hooper NM (2006b): The prion protein and lipid rafts (Review). Mol Membr Biol 23, 89-99

Tetzlaff JE, Putcha P, Outeiro TF, Ivanov A, Berezovska O, Hyman BT, McLean PJ (2008): CHIP targets toxic $\alpha$-synuclein oligomers for degradation. J Biol Chem

Tobler I, Gaus SE, Deboer T, Achermann P, Fischer M, Rülicke T, Moser M, Oesch B, McBride PA, Manson JC (1996): Altered circadian activity rhythms and sleep in mice devoid of prion protein. Nature $\underline{380}, 639-642$

Tofaris GK, Razzaq A, Ghetti B, Lilley KS, Spillantini MG (2003): Ubiquitination of ??-Synuclein in Lewy Bodies Is a Pathological Event Not Associated with Impairment of Proteasome Function. J Biol Chem 278, 44405-44411

Tsui-Pierchala BA, Encinas M, Milbrandt J, Johnson EM (2002): Lipid rafts in neuronal signaling 
and function. Trends Neurosci $\underline{25}, 412-417$

Ulusoy A, Musgrove RE, Rusconi R, Klinkenberg M, Helwig M, Schneider A, Di Monte DA (2015):

Neuron-to-neuron $\alpha$-synuclein propagation in vivo is independent of neuronal injury. Acta Neuropathol Commun

Um JW, Nygaard HB, Heiss JK, Kostylev MA, Stagi M, Vortmeyer A, Wisniewski T, Gunther EC, Strittmatter SM (2012): Alzheimer amyloid-beta oligomer bound to postsynaptic prion protein activates Fyn to impair neurons. Nat Neurosci $\underline{15}$, 1227-1235

Um JW, Kaufman AC, Kostylev M, Heiss JK, Stagi M, Takahashi H, Kerrisk ME, Vortmeyer A, Wisniewski T, Koleske AJ, et al. (2013): Metabotropic Glutamate Receptor 5 Is a Coreceptor for Alzheimer $A \beta$ Oligomer Bound to Cellular Prion Protein. Neuron $\underline{79}$, 887902

Unger EL, Eve DJ, Perez XA, Reichenbach DK, Xu Y, Lee MK, Andrews AM (2006): Locomotor hyperactivity and alterations in dopamine neurotransmission are associated with overexpression of A53T mutant human $\alpha$-synuclein in mice. Neurobiol Dis $\underline{21}, 431-443$

Urrea L, Segura-Feliu M, Masuda-Suzukake M, Hervera A, Pedraz L, Aznar JMG, Vila M, Samitier J, Torrents E, Ferrer I, et al. (2017): Involvement of Cellular Prion Protein in $\alpha$ Synuclein Transport in Neurons. Mol Neurobiol 1-14

Uversky VN (2003): A protein-chameleon: conformational plasticity of alpha-synuclein, a disordered protein involved in neurodegenerative disorders. J Biomol Struct Dyn 21, 211234

Uversky VN, Li J, Fink AL (2001): Evidence for a partially folded intermediate in alpha-synuclein fibril formation. J Biol Chem 276, 10737-44

Vargas KJ, Makani S, Davis T, Westphal CH, Castillo PE, Chandra SS (2014): Synucleins Regulate the Kinetics of Synaptic Vesicle Endocytosis. J Neurosci 34, 9364-9376

Vella LJ, Sharples RA, Lawson VA, Masters CL, Cappai R, Hill AF (2007): Packaging of prions into exosomes is associated with a novel pathway of PrP processing. J Pathol $\underline{211}, 582-590$

Visanji NP, Wislet-Gendebien S, Oschipok LW, Zhang G, Aubert I, Fraser PE, Tandon A (2011): Effect of Ser-129 phosphorylation on interaction of $\alpha$-synuclein with synaptic and cellular membranes. J Biol Chem 286, 35863-35873

La Vitola P, Beeg M, Balducci C, Santamaria G, Restelli E, Colombo L, Caldinelli L, Pollegioni L, Gobbi M, Chiesa R, Forloni G (2019): Cellular prion protein neither binds to alphasynuclein oligomers nor mediates their detrimental effects. Brain 1-6 
Wadsworth JDF, Collinge J (2007): Update on human prion disease. Biochim Biophys Acta $\underline{1772}, 598-609$

Waggoner DJ, Bartnikas TB, Gitlin JD (1999): The Role of Copper in Neurodegenerative Disease. Neurobiol Dis $\underline{6}, 221-230$

Walter ED, Chattopadhyay M, Millhauser GL (2006): The affinity of copper binding to the prion protein octarepeat domain: evidence for negative cooperativity. Biochemistry $\underline{45}$, 13083-92

Wang H, Tian C, Fan XY, Chen LN, Lv Y, Sun J, Zhao YJ, Zhang L Bin, Wang J, Shi Q, et al. (2015): Polo-like kinase 3 (PLK3) mediates the clearance of the accumulated PrP mutants transiently expressed in cultured cells and pathogenic PrPSc in prion infected cell line via protein interaction. Int J Biochem Cell Biol

Waterston RH, Lindblad-Toh K, Birney E, Rogers J, Abril JF, Agarwal P, Agarwala R, Ainscough R, Alexandersson M, An P, et al. (2002): Initial sequencing and comparative analysis of the mouse genome. Nature

Watts JC, Giles K, Oehler A, Middleton L, Dexter DT, Gentleman SM, DeArmond SJ, Prusiner SB (2013): Transmission of multiple system atrophy prions to transgenic mice. Proc Natl Acad Sci U S A

Waxman EA, Giasson BI (2008): Specificity and regulation of casein kinase-mediated phosphorylation of ??-synuclein. J Neuropathol Exp Neurol 67, 402-416

Weiss E, Ramljak S, Asif AR, Ciesielczyk B, Schmitz M, Gawinecka J, Schulz-Schaeffer W, Behrens C, Zerr I (2010): Cellular prion protein overexpression disturbs cellular homeostasis in SH-SY5Y neuroblastoma cells but does not alter p53 expression: A proteomic study. Neuroscience $\underline{169}, 1640-1650$

Westergard L, Christensen HM, Harris DA (2007): The cellular prion protein $(\operatorname{PrP}(C))$ : its physiological function and role in disease. Biochim Biophys Acta 1772, 629-44

Winner B, Jappelli R (2011): In vivo demonstration that $\alpha$-synuclein oligomers are toxic. Proc Natl Acad Sci 108, 4194-4199

Withers GS, George JM, Banker GA, Clayton DF (1997): Delayed localization of synelfin (synuclein, NACP) to presynaptic terminals in cultured rat hippocampal neurons. Dev Brain Res 99 , 87-94

Xicoy H, Wieringa B, Martens GJM (2017): The SH-SY5Y cell line in Parkinson's disease research: a systematic review. Mol Neurodegener $\underline{12}, 1-11$ 
Yamin G, Uversky VN, Fink AL (2003): Nitration inhibits fibrillation of human $\alpha$-synuclein in vitro by formation of soluble oligomers. FEBS Lett $\underline{542}$, 147-152

Zamponi E, Buratti F, Cataldi G, Caicedo HH, Song Y, Jungbauer LM, LaDu MJ, Bisbal M, Lorenzo A, Ma J, et al. (2017): Prion protein inhibits fast axonal transport through a mechanism involving casein kinase 2 . PLoS One

Zanusso G, Farinazzo A, Prelli F, Fiorini M, Gelati M, Ferrari S, Righetti PG, Rizzuto N, Frangiones B, Monaco S (2004): Identification of distinct N-terminal truncated forms of prion protein in different Creutzfeldt-Jakob disease subtypes. J Biol Chem

Zhang J, Li X, Li J Da (2019): The Roles of Post-translational Modifications on $\alpha$-Synuclein in the Pathogenesis of Parkinson's Diseases. Front Neurosci 13, 1-11

Zhang L, Zhang C, Zhu Y, Cai Q, Chan P, Uéda K, Yu S, Yang H (2008): Semi-quantitative analysis of $\alpha$-synuclein in subcellular pools of rat brain neurons: An immunogold electron microscopic study using a C-terminal specific monoclonal antibody. Brain Res $\underline{1244}, 40$ 52

Zhuang X, Oosting RS, Jones SR, Gainetdinov RR, Miller GW, Caron MG, Hen R (2001): Hyperactivity and impaired response habituation in hyperdopaminergic mice. Proc Natl Acad Sci U S A

Zou WQ, Xiao X, Yuan J, Puoti G, Fujioka H, Wang X, Richardson S, Zhou X, Zou R, Li S, et al. (2011): Amyloid- $\beta 42$ interacts mainly with insoluble prion protein in the Alzheimer brain. J Biol Chem 286, 15095-15105 